\title{
Review \\ Agricultural Potentials of Molecular Spectroscopy and Advances for Food Authentication: An Overview
}

\author{
John-Lewis Zinia Zaukuu ${ }^{1}\left(\mathbb{D}\right.$, Eszter Benes ${ }^{2} \mathbb{D}$, György Bázár ${ }^{3} \mathbb{D}$, Zoltán Kovács ${ }^{4} \mathbb{D}$ and Marietta Fodor ${ }^{2, *} \mathbb{D}$ \\ 1 Department of Food Science and Technology, Kwame Nkrumah University of Science and \\ Technology (KNUST), Kumasi 00233, Ghana; zaukuu.jz@knust.edu.gh \\ 2 Department of Food and Analytical Chemistry, Institute of Food Science and Technology, \\ Hungarian University of Agriculture and Life Sciences, Villányi út 29-43, 1118 Budapest, Hungary; \\ Benes.Eszter.Luca@uni-mate.hu \\ 3 ADEXGO Ltd., Lapostelki u. 13, 8230 Balatonfüred, Hungary; george.bazar@adexgo.hu \\ 4 Department of Measurements and Process Control, Institute of Food Science and Technology, \\ Hungarian University of Agriculture and Life Sciences, Somlói út 14-16, 1118 Budapest, Hungary; \\ kovacs.zoltan.food@uni-mate.hu \\ * Correspondence: Fodor.Marietta@uni-mate.hu
}

Citation: Zaukuu, J.-L.Z.; Benes, E.; Bázár, G.; Kovács, Z.; Fodor, M. Agricultural Potentials of Molecular Spectroscopy and Advances for Food Authentication: An Overview.

Processes 2022, 10, 214.

https://doi.org/

$10.3390 /$ pr10020214

Academic Editor: Chi-Fai Chau

Received: 16 December 2021

Accepted: 17 January 2022

Published: 24 January 2022

Publisher's Note: MDPI stays neutral with regard to jurisdictional claims in published maps and institutional affiliations.

Copyright: (C) 2022 by the authors. Licensee MDPI, Basel, Switzerland. This article is an open access article distributed under the terms and conditions of the Creative Commons Attribution (CC BY) license (https:// creativecommons.org/licenses/by/ $4.0 /)$.

\begin{abstract}
Meat, fish, coffee, tea, mushroom, and spices are foods that have been acknowledged for their nutritional benefits but are also reportedly targets of fraud and tampering due to their economic value. Conventional methods often take precedence for monitoring these foods, but rapid advanced instruments employing molecular spectroscopic techniques are gradually claiming dominance due to their numerous advantages such as low cost, little to no sample preparation, and, above all, their ability to fingerprint and detect a deviation from quality. This review aims to provide a detailed overview of common molecular spectroscopic techniques and their use for agricultural and food quality management. Using multiple databases including ScienceDirect, Scopus, Web of Science, and Google Scholar, 171 research publications including research articles, review papers, and book chapters were thoroughly reviewed and discussed to highlight new trends, accomplishments, challenges, and benefits of using molecular spectroscopic methods for studying food matrices. It was observed that Near infrared spectroscopy (NIRS), Infrared spectroscopy (IR), Hyperspectral imaging (his), and Nuclear magnetic resonance spectroscopy (NMR) stand out in particular for the identification of geographical origin, compositional analysis, authentication, and the detection of adulteration of meat, fish, coffee, tea, mushroom, and spices; however, the potential of UV/Vis, ${ }^{1} \mathrm{H}-\mathrm{NMR}$, and Raman spectroscopy (RS) for similar purposes is not negligible. The methods rely heavily on preprocessing and chemometric methods, but their reliance on conventional reference data which can sometimes be unreliable, for quantitative analysis, is perhaps one of their dominant challenges. Nonetheless, the emergence of handheld versions of these techniques is an area that is continuously being explored for digitalized remote analysis.
\end{abstract}

Keywords: authentication; adulteration; NIRS; IR; HSI; Raman spectroscopy; NMR

\section{Introduction}

Food authentication is a subject of much repute that is continuing to gain attention due to consumer curiosity and interventions for food safety by regulatory authorities such as the World Health Organization (WHO), Food and Agriculture Organization (FAO), Food and Drugs Authority (FDA), and Codex Alimentarius (CODEX). Food authentication encompasses all elements of food security, which is defined by the FAO as a state which exists "when all people, at all times, have physical and economic access to sufficient, safe, and nutritious food that meets their dietary needs and food preferences for an active and healthy life" [1]. It is a complex process of evaluating specific constituents or all the components of food and is a necessary measure that can be implemented across all points of the food chain 
from farm to fork. Basically, there are two different approaches to food authenticity, which often overlap in connection with the production of the food (e.g., geographical origin, bio vs. non-bio), as well as in relation to composition (e.g., issues of adulteration). For these, scientific analytical methods and instrumental analysis are the bedrocks of authenticity and have been widely studied over the last century. They range from conventional methods such as the Soxhlet extraction, Dumas method, titration, electrophoresis, etc. to more refined ones such as chromatography, spectrometry, spectroscopy, radiation technology, etc. Food authentication has been interchangeably used in the recent decade to relate to terminologies such as food fraud, food adulteration, and food control, which are all focused on the deviation of food from its intrinsic (nutritional and compositional parameters) and extrinsic (size, shape, color, gloss, consistency, texture, etc.) qualities. Publications focusing on food authentication have steadily increased in the past decade (Figure 1). In these reports, common methods for food authentication were high-performance liquid chromatography (HPLC), liquid chromatography (LC), proton transfer reaction mass spectrometry (PTR-MS), matrix-assisted laser desorption/ionization time-of-flight mass spectrometry (MALDI-TOF-MS), and ambient mass spectrometry techniques such as direct analysis in real time (DART-MS) [2].

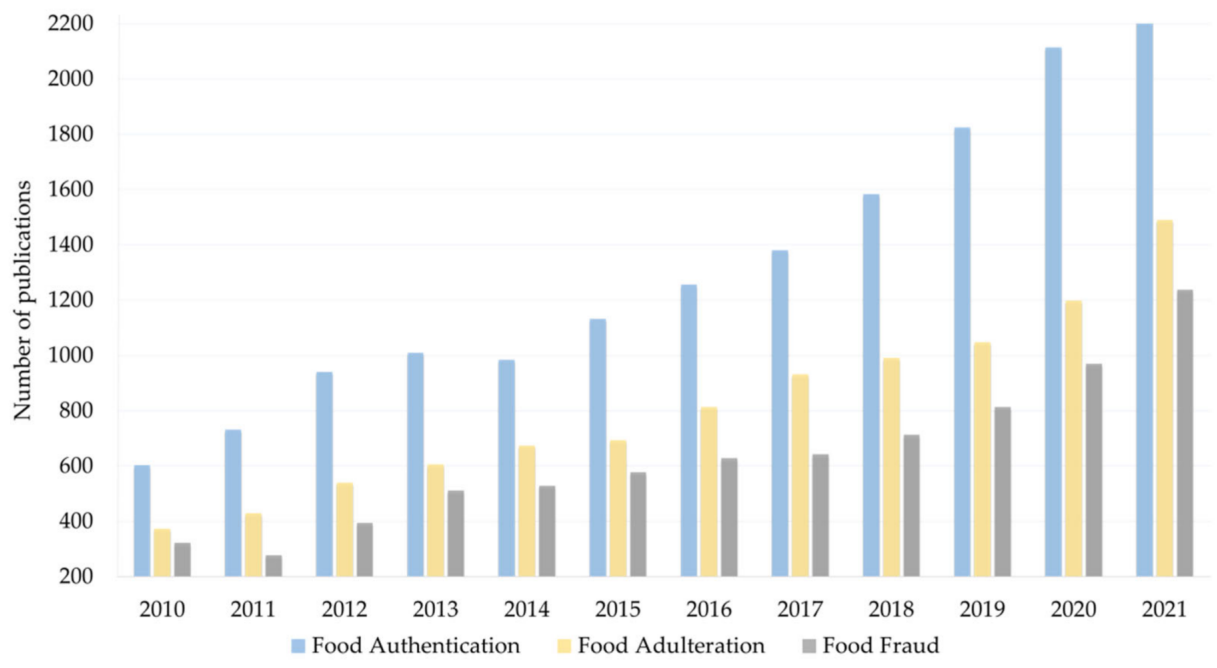

Figure 1. Number of publications in the last decade from Science Direct using search keywords "food authentication", "food adulteration", and "food fraud". Accessed on 16 November 2021.

Although these methods have been very effective in food authentication, they also require high technical expertise and can sometimes be expensive, in addition to the use of reagents and budgets for waste management. Due to these and other issues such as their bulky nature, lengthy analytical time, and technical design of the instruments, some researchers have focused on rather rapid noninvasive techniques such as spectroscopy. When matter is exposed to electromagnetic radiation, the radiation can be absorbed, transmitted, reflected, scattered, or undergo photoluminescence. These interactions can be studied by molecular spectroscopy. Among the most often used molecular spectroscopic methods are near-infrared spectroscopy (NIR), ultraviolet-visible spectroscopy (UV/Vis), Raman spectroscopy (RS), nuclear magnetic resonance (NMR) spectroscopy, and hyperspectral imaging (HSI).

Generally, molecular spectroscopic methods have been acknowledged for both smallscale and industry applications in the construction cosmetics, pharmaceutical, medical, veterinarian agricultural, and food industries but this review mainly focuses on their applications in the agricultural and food industries. 


\section{Principle and Mode of Operation of Molecular Spectroscopy}

Molecular spectroscopic techniques operate on the principle that every molecule is composed of multiple atoms with related characteristic bonds between them. Using a particular type of electromagnetic radiation, the molecule can be excited (undergoes short-term vibrations in terms of reflection, transmission, and absorption) on the basis of its elemental composition and bond strength and can sometimes be referred to as photoluminescence [3]. Photoluminescence is a term used to describe a number of effects, such as fluorescence, phosphorescence, and Raman scattering. Molecular spectroscopy employs the interaction of electromagnetic radiation with materials to produce an absorption spectrum that holds structural and compositional information on the given material. Electromagnetic radiation is conventionally divided into the following regions [4]: radiofrequency (ca. 105-109 Hz), microwave (ca. 109 to $3 \times 1010 \mathrm{~Hz}$ ), infrared (ca. $3 \times 1010$ to $3 \times 1014 \mathrm{~Hz}$ ), visible and ultraviolet (ca. $3 \times 1014$ to $3 \times 1016 \mathrm{~Hz}$ ), X-rays (ca. $3 \times 1016$ to $3 \times 1018 \mathrm{~Hz}$ ), and gamma $(\gamma)$-rays $(\mathrm{ca} .3 \times 1018$ to $1021 \mathrm{~Hz})$. Each region covers a range of energies that correspond to a different type of molecular process. Every region has different features and stands for a specific kind of molecular or atomic transition that corresponds to specific spectroscopic techniques. Among these, ultraviolet-visible (UV/Vis) and infrared (IR) regions have received much attention as most spectroscopic instruments used in nonlaboratory conditions utilize these energy ranges and can result in electron transitions or molecular vibrations. However, infrared is still a very broad range, covering the far-, mid-, and nearinfrared (FIR, MIR, NIR) regions used in analytical laboratory measurements according to the International Commission on Illumination (CIE) and the International Organization for Standardization [5] (Table 1). The behavior of the infrared light is unique for each organic molecule and acts as a characteristic spectral fingerprint in the infrared region. Infrared light separates the visible and microwave regions of the electromagnetic spectrum and ranges from $700 \mathrm{~nm}$ to $1 \mathrm{~mm}$.

Table 1. Types of infrared light according to the International Commission on Illumination (CIE) and the International Organization for Standardization (ISO).

\begin{tabular}{cccc}
\hline Region & Near-Infrared & Mid-Infrared & Far-Infrared \\
\hline Photon energies & $215-430 \mathrm{eV}$ & $100-215 \mathrm{eV}$ & $3-100 \mathrm{eV}$ \\
Wavelength (CIE) & $700-1400 \mathrm{~nm}$ & $1400-3000 \mathrm{~nm}$ & $3000-1.4 \times 10^{4} \mathrm{~nm}$ \\
Wavelength (ISO 20473) & $780-3000 \mathrm{~nm}$ & $3000-5 \times 10^{5} \mathrm{~nm}$ & $5 \times 10^{5}-10^{6} \mathrm{~nm}$ \\
\hline
\end{tabular}

The most common infrared spectroscopic technology of this current century is the NIRS, which covers the range of $800-2500 \mathrm{~nm}$. The electromagnetic radiation at this energy range excites molecular vibrations (stretching, bending) mostly related to hydrogen, since $\mathrm{C}$ $\mathrm{H}, \mathrm{O}-\mathrm{H}, \mathrm{N}-\mathrm{H}$, and $\mathrm{S}-\mathrm{H}$ bonds are frequent in organic substances. The range and intensity of the electromagnetic radiation has led to the development diverse instruments that correspond to the different molecular spectroscopic techniques. The potential applications, advantages, and disadvantages of some common molecular spectroscopy methods have been summarized in Table 2 but the factors leading to the choice of an ideal analytical instrument are continuously being challenged by the ever-evolving complexities of the food chain. Some of these complexities have been reported to have numerous limitations for certain analysis due to issues such as instrumental design, sample size requirement, cost and maintenance, and spectra reliability [6]. Furthermore, consumer intolerance for low-quality food and a competitive market have resulted in continuous improvement of these factors of method selection.

The choice of a method or instrument is largely dependent on certain parameters such as the intrinsic and extrinsic property of the food to be analysis, the sensitivity of the method/instrument, the cost, ease of application, speed of analysis, and sample preparation requirements (Figure 2). 


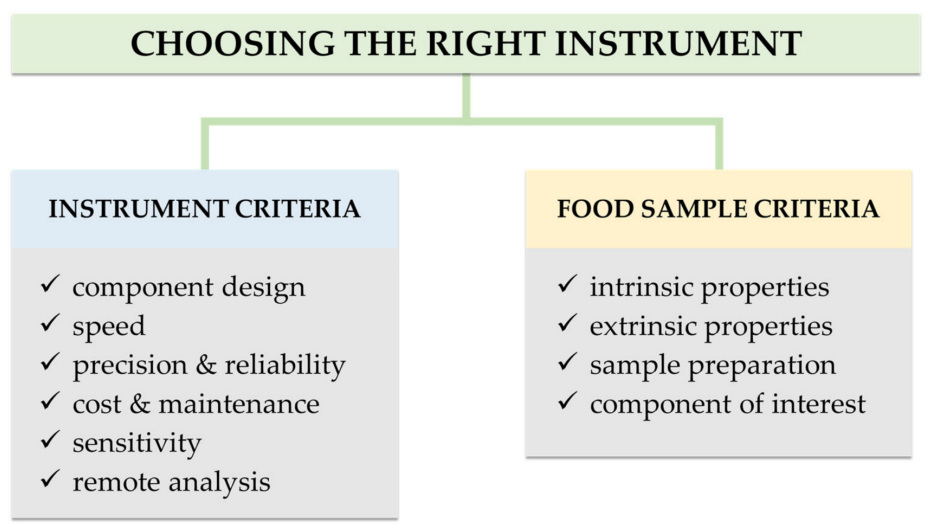

Figure 2. Factors influencing the choice of ideal analytical methods.

NIRS became a widely used technology in agricultural applications where costeffective and relatively fast testing is needed. Originally, some decades ago, when it was still used in laboratories only, its major benefit was the low cost, little or no need for sample preparation, and the easy-to-use nature. Recently, when NIRS applications have been broadly appearing out of the laboratories, even the compactness of technology, and the very rapid feedback capabilities give the greatest benefits such as light weight and requiring no physical contact between the sample and the instrument; moreover, the researcher has the option to position the sample either directly on the sample or some distance away, results can be qualitative or quantitative, it requires no reagents, instruments are often portable, and some can facilitate remote use. Many NIRS instruments ranging from benchtop to handheld versions have been developed to keep pace with the complexities of the food chain.

In the case of $\mathrm{UV} / \mathrm{Vis}$ spectroscopy, the absorption is primarily due to electronic transitions. Most UV/Vis absorptions by organic molecules are attributed to transitions involving nonbonding (n) electrons or electrons in molecular orbitals found in unsaturated molecules [7]. The basic wavelength range may be converted to 340-950 nm using an accessory phototube and filters. The technique has been employed for analytical purposes because it is easy-to-use and has handheld or portable instruments available.

Raman spectroscopy (RS), like IR spectroscopy, belongs to the group of vibrational (and rotational) spectroscopic methods. The vibrational spectrum is used to obtain information about the type, position, and orientation of functional groups in molecules. IR and RS differ in the way they produce the analytical signal. IR spectra are mainly recorded in absorption mode, while RS is based on the principle of light scattering [8]. Until recently, Raman spectroscopy (RS) was a very difficult technique to use even within a laboratory environment, especially in the case of biological samples such as food or food ingredients. Significant improvements in instrument design, detector sensitivity, laser construction, and the availability of fiber-optic sampling probes have led to an expansion of applications in this and many other fields and even into process environments [9].

Nuclear magnetic resonance (NMR) is not one of the optical molecular spectroscopy methods, but its role in authentication and detection of adulteration makes it worth mentioning. It is a method of chemical structure analysis, which works by applying radiofrequency electromagnetic pulses to nuclei of atoms with magnetic moment placed in a constant magnetic field by selective excitation with an electromagnetic pulse. The most commonly studied isotopes are ${ }^{1} \mathrm{H}$ and ${ }^{13} \mathrm{C}$ (Figure 3) [10]. Some NMR methodologies, for instance, low-field NMR relaxometry and magnetic resonance imaging (MRI), are completely noninvasive and produce substantial information regarding the texture of the sample, water distribution, and molecular dynamics, all of which can be important in determining product authenticity. High-resolution NMR simultaneously brings "highthroughput" spectroscopic/structural information" on a wide range of metabolites with high analytical precision, giving a foodstuff a metabolic fingerprint, which is important to assure its quality, genuineness, geographical origin, etc. [11]. 


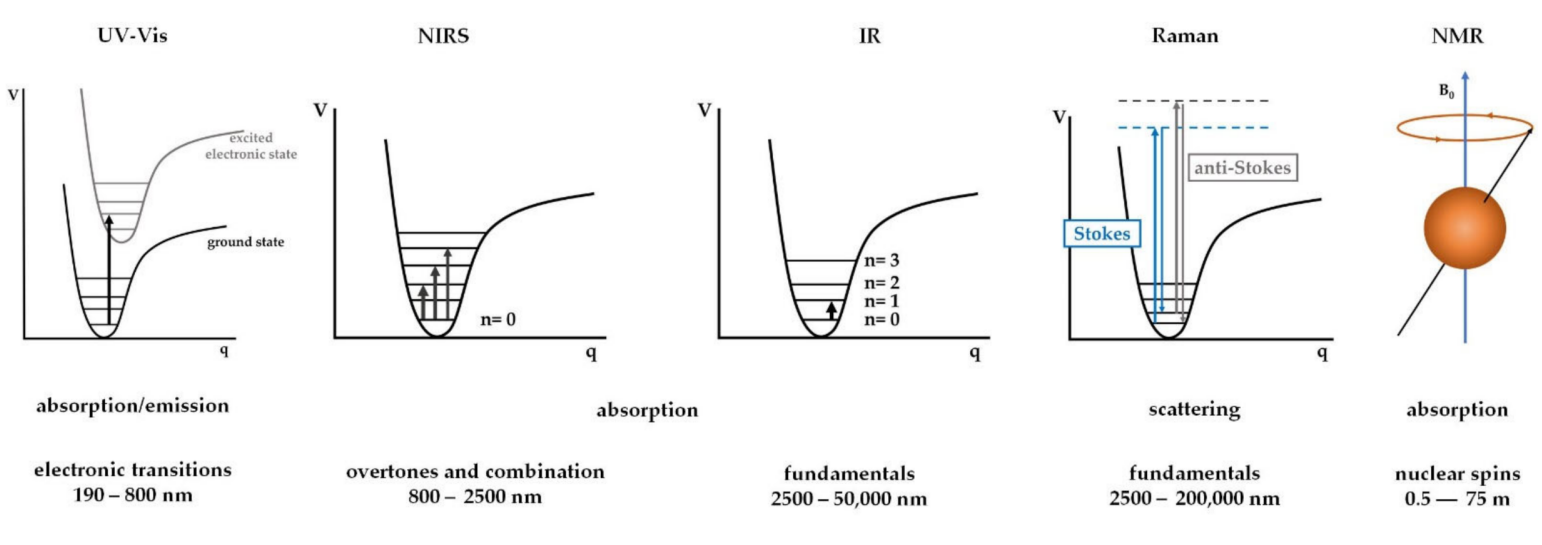

Figure 3. Characteristics of molecular spectroscopy methods (based on Burns et al. [12]).

HSI was originally developed for remote sensing applications and has since been applied in many fields. It analyzes the spatial distribution of the sample parameters by using imaging technology [13].

\section{Instrumentation}

Mostly, spectrophotometers are the instruments used for spectroscopic measurements. They are primarily composed of a light source, light adjusting elements (e.g., monochromators, interferometers, microelectromechanical systems, linear variable filters), a sample chamber, and a detector [14].

The light source is mainly responsible for providing the photonic energy (light) that will be absorbed or reflected by the sample. It can be a Tungsten halogen lamp, pc-NIR LED, laser diode, or a Nichrome heater. In pre- or post-dispersion spectrophotometers, the polychromatic light is decomposed be-fore or after interacting with the sample, respectively, resulting in the monochromatic light beams reaching the detectors. In spectrophotometers with diffraction grating monochromators, the monochromator selects a narrow band of light from a wider range of wavelengths (emitted light) [15]. The gratings are made of metal or glass engraved surfaces with many fine parallel lines. When the light beam strikes the surface, it is divided into various wavelengths by diffraction [16], and a small portion shines through the slits and order sorting filters.

Many modern instruments have an interferometer that decomposes broadband IR radiation into discrete wavenumber values with a given spectral resolution. The most common one is the Michelson interferometer, but there are other constructions such as Rocksolid. In this system, the light beam is split into two beams with a beam splitter. The two separated beams strike the fixed and moving mirrors, and they are reflected back to beam splitter. They are then recombined and exit the interferometer in the direction of sample. From the resulting interferogram, the spectrum of the sample is obtained by Fourier transform (FT) that is commonly used in Raman, NIR, IR, and NMR spectrophotometers. A major advantage is that the signal-to-noise ratio of spectrum is significantly higher than some generation IR spectrophotometers [17].

Small-sized spectrophotometers contain miniaturized microelectromechanical systems (MEMS) such as digital micro mirrors to produce the monochromatic light or contain no moving elements and use static systems such as linear variable filters (LVF) as band pass filters for each pixel of a detector array. A dispersive Raman spectrophotometer uses a prism or a grating, while a nondispersive Raman spectrophotometer uses an interferometer, such as a Michelson interferometer in a Fourier-transform Raman spectrophotometer. Modern Raman spectrophotometers use a laser light source. These laser sources provide a stable and intense beam. A wide range of lasers, such as the argon ion laser (488 and $514.5 \mathrm{~nm})$, krypton ion laser (530.9 and $647.1 \mathrm{~nm})$, helium-neon $(\mathrm{He}-\mathrm{Ne})$ laser $(632.8 \mathrm{~nm})$, near-infrared (IR) diode lasers (785 and $830 \mathrm{~nm}$ ), neodymium-yttrium-aluminum-garnet (Nd:YAG) and neodymium-yttrium-orthrium-vanadate $\left(\mathrm{Nd}: \mathrm{YVO}_{4}\right)$ lasers $(1064 \mathrm{~nm})$, and 
frequency-division $\mathrm{Nd}: \mathrm{YAG}$ and $\mathrm{Nd}: \mathrm{YVO}_{4}$ diode lasers $(532 \mathrm{~nm}$ ) can be used as light sources in Raman spectrophotometers. However, long wavelength sources such as diode or Nd:YAG lasers can be operated at much higher power without causing photocomposition of the sample and, in most cases, can eliminate or reduce fluorescence. Band pass filters are used to isolate a single laser beam. In dispersive instruments, a combination of a notch filter and a high-quality grating monochromator is most commonly used. Double or even triple grating monochromators, super notch filters, rejection filters, holographic notch or edge filters, and holographic filters are used to separate relatively weak Raman lines from intense Rayleigh scattering radiation.

In modern instruments, detectors have been replaced by more sensitive charge transfer devices (CTDs) such as charge-coupled devices (CCDs) and charge injection devices (CIDs). In CTD arrays, the photosite converts the incoming optical signal into a charge, which is integrated and transmitted to the readout devices. Multichannel CCD detectors are used for laser wavelengths of less than $1 \mu \mathrm{m}$, while single-element, low-bandgap semiconductors such as germanium (Ge) or indium-gallium-arsenic (InGaAs) detectors are used for laser wavelengths greater than $1 \mu \mathrm{m}$. The low sensitivity due to weak Raman scattering can be increased by resonance Raman spectroscopy (RRS) and surface-enhanced Raman spectroscopy (SERS). In RRS, the frequency of the incident radiation matches the electronic transition of the molecule, resulting in a much more intense Raman spectrum. SERS is a modified technique in which the sample is adsorbed onto a colloidal metallic surface (silver, gold, or copper) to improve the intensity of the Raman signal and suppress fluorescence caused by cutting agents, diluents, and matrices. The combination of RRS and SERS techniques (i.e., surface resonance-enhanced Raman spectroscopy (SERRS) can increase sensitivity by up to 10 orders of magnitude compared to RS [18].

Detectors in such instruments (e.g., NIR spectrometers) are mostly made of $\mathrm{Si}, \mathrm{PbS}$, and InGaAs depending on many factors such as the required wavelength range and photosensitivity, the given light intensity, and temperature stability, but they are all responsible for detecting the amount of light dispersion (transmittance/reflectance/transflectance) from the sample [15].

Typically, most benchtop spectrophotometers, grating monochromators, or Michelson/Rocksolid interferometers are used to decompose light when measuring the full spectrum. Instruments may be used in transmittance or reflectance mode [15]. Depending on the energy source and the detectors used [19], instruments measuring the MIR or FIR regions of the electromagnetic spectrum are mostly used in analytical chemistry where fundamental vibrations of molecules are measured. The MIR spectrum results from the absorption of specific frequencies of MIR radiation as a function of the chemical structure of the sample. The peaks and troughs in a MIR spectrum are very specific to the sample measured. These techniques require sample preparation for solid samples, usually by some form of solvation or extraction. Liquid samples can also be analyzed directly. Contrarily, NIRS measures the overtone and combination bands of the fundamental vibrations, with the help of highly versatile instrumentation.

HSI systems have evolved from whiskbrooms to push-brooms, wavelength scanning, and snapshot instrument architectures. At the simplest level, the whiskbroom instrument architectures have a single image channel (scalar) and a 1D data field sensor (vector). This instrument architecture can be implemented with an imaging fiber-optic cable connected to a diffraction grating and a linear optical sensor (corresponding to one spectral dimension). At the next level of complexity, push-broom instrument architectures consist of a onedimensional image channel array (vector) connected to a two-dimensional data array sensor (matrix). This instrument architecture is implemented by linear imaging coupled to a diffraction grating and a 2D optical sensor (one spatial and one spectral dimension). For mapping in the next spatial dimension and to form the two-dimensional image (matrix), the push-broom instrument architecture scans time line by line, forming a three-dimensional data cube (tensor). These techniques generally require a large format image sensor to 
provide adequate spatial separation of the three measured dimensions (two spatial and one wavelength) [20].

Depending on the type of experiments needed in a particular research area, NMR spectrometers offer different options for 1D and 2D experiments, as well as different types of nuclei such as ${ }^{1} \mathrm{H},{ }^{2} \mathrm{H},{ }^{7} \mathrm{Li},{ }^{11} \mathrm{~B},{ }^{13} \mathrm{C},{ }^{15} \mathrm{~N},{ }^{19} \mathrm{~F}$, and ${ }^{31} \mathrm{P}$. The current trend in instrument development follows that of conventional high-field NMR instruments, aiming at increasing sensitivity by improving field strength and field homogeneity, providing access to a wider range of nuclei, and extending the range of NMR experiments that can be performed.

Today's NMR spectrophotometers use permanent magnets with similar field strengths between 1 and $2 \mathrm{~T}$ and are inherently less sensitive than high-field-strength spectrometers. In addition, permanent magnets are sensitive to temperature. Long-term stability of the magnet is also critical for long-term signal transfer, 2D spectroscopy, and reaction monitoring. A drifting field spoils the coherent combination of signals and leads to drifting lines in NMR spectra recorded at different times.

\section{Data Processing}

Overlapping bands in the electromagnetic spectrum of light sometimes result in a complex spectrum that makes it difficult to read the sorted compositional information directly. These differences can be due to several conditions such as nonhomogeneous distribution of the particles, changes in refractive index, particle size distribution, sample packing/density variability, and sample morphology (surface roughness/shape) [21]. For this reason, many researchers have studied multiple preprocessing or pretreatment techniques, which are often mainly mathematical correction techniques.

Wavelength selection is often the first approach in such situations because it is regarded as the simplest, but most effective pretreatment procedure in spectroscopy if prior knowledge is available about the regions of interest. More advanced techniques are required for more complex spectra that could be as a result of the following:

1. Reflected baseline offset or simple baseline shift (additive effect);

2. Multiplicative effect (pure) that scales the entire spectrum by a given factor, for example, due to path length differences;

3. Wavelength-dependent baseline variation, where the degree of baseline shift varies with wavelength. In addition to wavelength selection, many types of pretreatment methods have also been reported.

For some of the challenges, prominent methods such as derivatives [22] detrending (baseline correction) [23], auto-scaling [24], standard normal variate (SNV) [25], standardization [26], normalization [27], multiplicative scatter correction (MSC), and extended multiplicative scattering correction (EMSC) [28] have proven vital in extracting important and relevant information from consolidated spectra. These pretreatments can very effectively remove or reduce the additive and multiplicative spectral distortions, but caution must be exercised when applying them as the mathematical changes in the measured data may lead to even more destruction; unwise application of derivatives can enhance noise of the spectral data, the noisy regions of a spectrum can damage the whole spectrum when pretreated with SNV, and an outlier spectrum can falsify all the other spectra when MSC is applied [29]. However, variable physical and other properties of the sample or instrument may cause interference in the spectral data. It is, therefore, important to apply selection and pretreatment to identify and eliminate extreme outliers that may sometimes materially decrease the model performance. This is because the chemical information of the constituent under investigation can be obscured by changes in the spectra due to some intrinsic properties of the constituent of interest or environmental conditions during the experiment.

In addition to preprocessing, the recorded spectra may sometimes have to be combined with reference information, and the combination of the two knowledge may finally result in a calibration model where the relation of spectral and reference data is described. To achieve the calibration models, various types of multivariate data analysis approaches are 
used, which, when displayed in ways that allow chemical interpretation of the relation, are called chemometrics. One of multivariate modeling's major strengths is the possibility to measure several constituents concurrently. One of the limitations is the dependence on some less precise reference methods in food analysis.

Chemometrics or multivariate data analyses are generally computation numerical analyses that serve as a bedrock for the new age of machine learning. Broadly, they can be categorized into quantitative and qualitative methods. Quantitative calibration modeling, as mentioned above, requires reference data to be described by the spectral variables. The qualitative methods used for pattern recognition and classification can generally be grouped into supervised and non-supervised methods (Figure 4). Non-supervised modeling, like principal component analysis (PCA), describes the major variance of the recorded spectral data without influencing the data reduction with any background information about the samples or sample groups. Contrary to this descriptive mode, the supervised classification methods, such as linear discriminant analysis (LDA), find the linear or nonlinear combinations of the spectral variables that optimally describe the differences of the predefined groups and minimize in-group variations [30-32]. Since multivariate data are often very complicated, simple non-supervised models are rarely able to explain the desired group identities. Supervised classification models, on the other hand, serve as highly effective pattern recognition tools, while they can be easily overfitted, as with the quantitative calibration models. To minimize overfitting, careful cross-validations and independent tests have to be applied during the model optimization [29]. Due to the development of the computational capacity, nonlinear modeling is more often used for both qualitative and quantitative purposes [30-32]. Although these methods can provide very good results also for extremely complex cases, it has to be considered that they require a very large amount of sample, and, from a chemometrician point of view, they are black boxes, since little or no information can be achieved about the relation of the multivariate spectral data and the qualitative or quantitative reference variables.

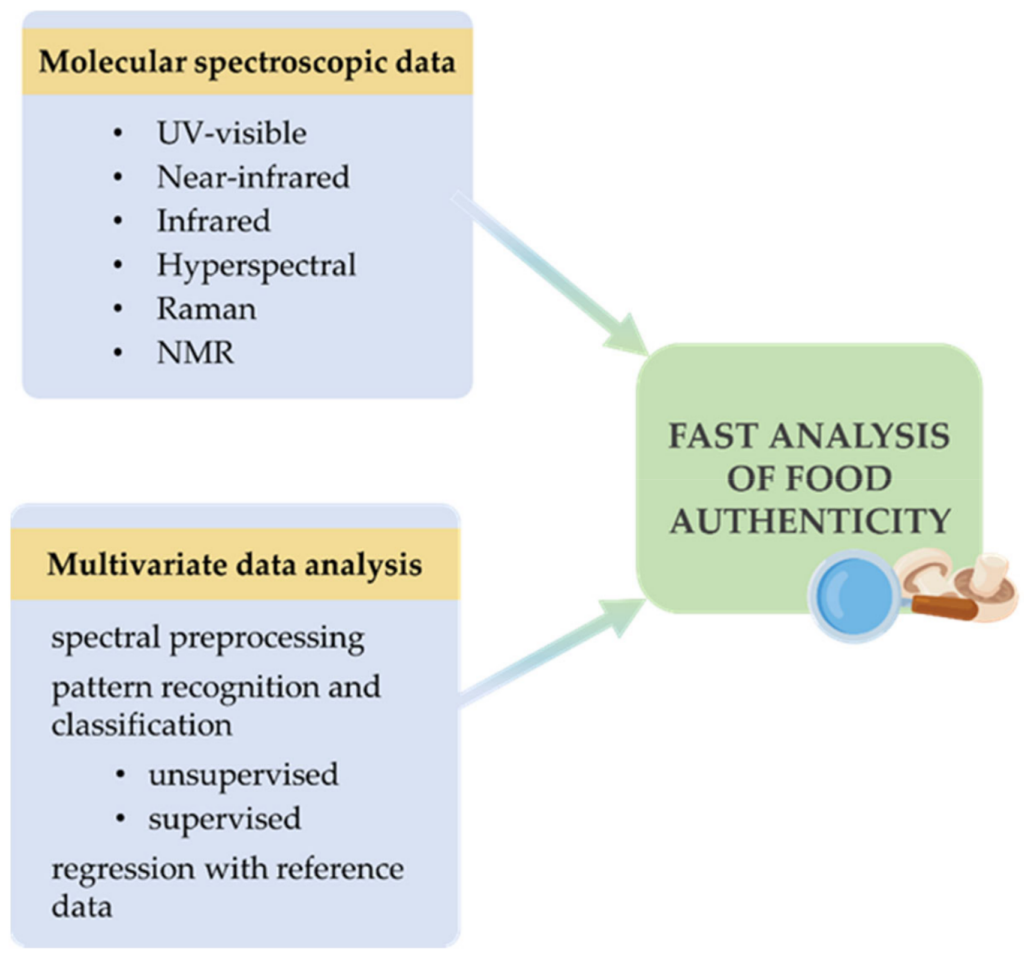

Figure 4. Molecular spectroscopy methods and chemometric data evaluation in food authenticity.

\section{Applications of Molecular Spectroscopy for Food Authentication}

Molecular spectroscopic methods, in general, are routinely employed to give a compositional, functional, and sensory analysis overview of food raw materials, process in- 
termediates, and final products [33]. Therefore, it is nearly impossible to cover all the diverse foods of application in this review; as such, only some of those with protein-rich content (meat and fish), medicinal properties (spices, mushroom), and beverages rich in phytochemicals (coffee and tea) are in focus. In addition, these foods were chosen because their ubiquitous nature, economic potential, and nutritional value risks of adulteration across the production chain are some of the reasons why they have been previously targeted for fraudulent purposes.

\subsection{Meat and Fish}

Meat is composed of water, proteins, amino acids, fatty acids, cholesterol, phospholipids, minerals, and vitamins, which can all be related to its nutritional quality [34]. A similar biochemical composition also exists in fish, and these elements are often determinants of wholesomeness or perishability. The vulnerability and perishability of fish and meat products are premises that make it essential to develop effective and rapid techniques for monitoring their quality changes and determining authenticity. In the last decade alone, several methods have been developed and tested to overcome the reported limitations of conventional methods. In this regard, spectroscopic methods, including MIR, NIR, laser breakdown (LBD), and RS, have proven to be very successful alternatives to traditional techniques as different kinds of meat or their products will give varying absorption patterns in the electromagnetic spectrum. This is the basis for applying different spectroscopic techniques to determine multiple quality parameters of meat and seafood products.

Table 3 shows the current trends of different molecular spectroscopic techniques for quality assessment in meat and seafood products. UV/Vis spectroscopy has been applied for both the accurate determination of the $\mathrm{K}$ value of fish flesh [35], predicting fatty acids in fresh and freeze-dried beef [36], and detection of minced beef adulteration with turkey meat [37].

Using the backpropagation neural network (BP-NN) model, the protein content of various processed pork meats could be determined with a coefficient of cross-validation $\left(\mathrm{R}^{2} \mathrm{CV}\right)=0.8318$ and root-mean-square error of cross-validation $(\mathrm{RMSECV})=8.38 \mathrm{mg} / \mathrm{g}$ when HSI was used [38]. For the prediction of monounsaturated and polyunsaturated fatty acids of various processed pork meats, the improved hyperspectral imaging technique proved that the performance of least squares support vector machines (LS-SVM) models was better than that of partial least squares regression (PLSR) models; the $\mathrm{R}^{2}$ of the LS-SVM based on optimal wavelengths was more than 0.81 [39].

In the monitoring of accumulated toxicity, RS proved vital in the detection of prohibited drugs including enrofloxacin, furazolidone, and malachite green in tilapia using principal component analysis (PCA). The $\mathrm{R}^{2}$ of actual values versus values predicted with PLS models for furazolidone and MG was 0.970 and 0.915 [40]. In the meat industry, the technique was used to predict drip loss and measure $\mathrm{pH}$ of fresh pork, with a secondary aim to measure intramuscular fat [41].

${ }^{1} \mathrm{H}-\mathrm{NMR}$ has not been widely applied for meat quality evaluations, but it has proven useful in fish monitoring. It was used to prove that the metabolome content of the common carp oocyte changed with time post ovulation. The metabolite changes were mainly related to energy-linked metabolites, amino acids, methylated metabolites, citric acid cycle intermediates, and apoptotic-related metabolites [42]. In the molecular study of anesthesia in fish, the method showed that plasma levels of valine, isoleucine, creatine, $\mathrm{N}, \mathrm{N}$ dimethylglycine, and glucose significantly increased in the anesthetized group compared to the control group according to metabolite profiling results. In contrast, the plasma levels of $\mathrm{N}$-acetylglucosamine and succinate significantly decreased in the anesthetized fish compared to the control group [43].

Structural and metabolic changes in the liver samples of wild and aqua cultured gilthead sea bream (S. aurata) were also studied with FTIR, whereby spectral peaks revealed important information about the different liver structures [44]. In the meat industry, FTIR has also been applied for the species discrimination of meat and bone meals based on 
lipid characteristics [45], the assessment of red meat quality [46] and the detection of beef, mutton, camel, and lamb meat adulterated with pork [47].

As shown in Table 4, NIRS has been applied in the rapid discrimination of minced port quality [48], classification of chicken breast fillet [49], prediction of fatty acids in fresh and frozen pork [50], quality control of frying fat samples [51], and identification of meat species [52]. The NIRS has proven to be effective in the determination of intramuscular fat of pork [53] and rabbit hind leg [54]. High correlations between moisture and fat of beef have been established using NIRS [55]. The study of major chemical compositions in fresh meat, such as fat, moisture, or protein, is necessary not only for labeling and consumer-acceptance purposes, but also for establishing the right balance in the quality of the fresh or processed products. Table 4 shows a summary of some studies that assessed these parameters in different meat products using the NIRS. For quality assurance purposes, NIRS has been used to discriminate turkey meat as an adulterant in beef [56] and to assess plant and animal proteins as potential adulterants in minced beef and pork [57].

It can also be observed in Table 3 that different mathematical correctional approaches yielded good $R^{2}$. This emphasizes that a key aspect of multi-sensor analysis is signal processing. In this regard, Riovanto et al. [58] revealed that, although the raw spectrum may appear not to be much informative in assessment of the fatty-acid composition of ground chicken breast, applying a first- and second-derivative mathematical treatment will improve the models. This was supported by Marchi et al. [59] who used different combinations of scatter correction and derivative mathematical treatments to achieve the best model for predicting saltiness in chicken. Meat tenderness is regarded as one of the most important sensorial qualities for consumers. It is in this sense that NIRS has been used to predict tenderness in chicken with $\mathrm{R}^{2}=0.70$ [60] and 0.81 [61], as well as in cattle with $R^{2}=0.45$ [62]. Since PLSR can be used as a full-spectrum multivariate analysis to eliminate collinearity, PLS-based calibrations may be further improved by proper selection of wavelengths $[63,64]$.

It can be observed in Tables 3 and 4 that various preprocessing techniques have been explored to enhance spectral information. It can also be concluded that, although spectral examination methods such as spectral peak analysis and band assignments have proven useful in using these techniques, several chemometric methods have also been tested and proven very relevant and important for advanced data analysis and modeling multiple parameters in meat and fish, ranging from contamination to storage, geographical identification, adulteration, and even monitoring processed products. Data fusion, a complex but statically acclaimed method for mathematical evaluation of data from different instruments, also proved vital for quantitative and qualitative analysis, as well as in the determination of biochemical changes in meat and fish.

Selecting essential wavelengths with respect to the response information can marginally reduce the amount of data to be analyzed and, therefore, is a supplementary step for developing multispectral systems although it is often subjective. In pork analysis, it has been reported that both the $\mathrm{pH}$ and the iodine number $45 \mathrm{~min}$ postmortem cannot be predicted from NIR spectra [65]. In quantitative treatment of data and often with a large number of calibration sets, it is worth mentioning artificial neural networks (ANNs) as an emerging alternative for NIRS calibration. This technique may present some advantages when nonlinearity (not easily accommodated by principal component regression (PCR) and PLSR) between the spectral data and the quantitative information of interest exists. Considering the synergism between NIRS technology and chemometrics, it is probable that new data treatment alternatives, which can help make good use of the NIR spectroscopic information, will be provided in the near future, but application of mathematical corrective measures and the ability to select good spectra vary per user and greatly influence the predictive model.

Clearly, from this review, the different spectroscopic techniques have proven to be pivotal in quality determination and could be an efficient and promising tool to control meat and fish quality and authenticity [34]. This is particularly important because the 
high price and scarcity of meat are the major factors that reduce meat consumption and consequently lead to adulteration/substitution or mislabeling of meat and meat products. Moreover, many preservation techniques have been applied to retard deterioration and extend the shelf-life of fish and meat products, but rapid affordable methods have remained a challenge. From Tables 3 and 4, it can be concluded that these spectroscopic techniques could bridge this challenge as the method has also been used to monitor and track biochemical changes in different meat products. Until recently, identification of meat and fish species in processed products was generally much more difficult than in raw meat, but spectroscopic technologies have proven that it is now possible.

\subsection{Mushroom}

The chemical composition of mushrooms is highly dependent on the geographical region, and different parts of the same mushroom have different chemical compositions. For this reason, identification and authentication are also important for mushrooms. Of the nearly 2000 edible mushroom species found in nature, only 35 are cultivated commercially. In this section, we summarize the molecular spectroscopic methods in the case of the most common cultivated and wild mushroom species (Table 5) [66]. Furthermore, there have been many studies on Ganoderma lucidum. As this mushroom is mainly used for medicinal purposes and not as a food, its analytical analysis is not discussed here.

For mushrooms, adulteration is less of a problem but geographical origin, shelf-life quality, and avoiding any possible toxicity remain a clarion call. The differentiation of mushroom samples at a species level (strain classification, taxon delimitation), the differentiation of new candidate varieties with improved nutritional properties, the differentiation of wild and cultivated or of fresh and old and damaged mushroom samples, and the identification of mushroom samples from a specific growing area are essential for quality control of raw materials.

Quality classification was performed on the basis of water content, water-soluble solids, and freshness for the cultivated mushroom species Agaricus bisporus using Vis/NIR spectroscopy. Separate analysis of the mushroom cap and stalk was performed, but unfortunately no data on the reliability of the classification were reported. The statistical properties of the models were rather poor $\left(\mathrm{R}^{2}=0.78\right)$ [67].

New cultivar candidates of Pleurotus ostreatus were screened using FT-NIRS techniques to quickly and nondestructively select a new candidate with the most favorable traits. On the basis of the free amino-acid content, total polyphenol content, and ferric ion reducing antioxidant power (FRAP) values, chemometric analysis of the spectra successfully classified the most favorable candidates [68].

In another study, PCA of the FTIR spectrum of Agaricus bisporus showed that physical damage to the mushrooms had a significant effect on tissue structure and the aging process. Random forest (RF) modeling of FTIR data predicted mushroom damage with error rates of $5.9 \%$ and $9.8 \%$, and it successfully distinguished fresh and refrigerated mushrooms [69]. Zervakis et al. [70] used diffuse reflectance Fourier-transform infrared spectroscopy (DRIFT) to classify the genus Pleurotus and to delimit taxa. A total of 73 strains of 16 taxa of Pleurotus were examined. A binary matrix based on the presence/absence of FTIR-specific peaks combined with cluster analysis showed that the IR region is clearly distinct among Pleurotus species, making this method perfectly suited for species classification. FTIR in conjunction with appropriate chemometrics was explored for the identification and discrimination of Boletus edulis and Boletus tomentipes collected from different geographical regions. The unsupervised PCA and hierarchical cluster analysis (HCA) techniques were reported to classify and identify both mushroom samples as a function of the differences in their metabolic fingerprint characteristics. The supervised partial least squares discriminant analysis (PLS-DA) technique successfully differentiated between both mushroom samples on the basis of their geographical locations [71].

The geographical tracking of the wild Boletus mushroom was investigated using FTIR. Samples were collected from 10 different geographical areas in China. Different 
pattern recognition techniques (PCA, support vector machine (SVM), RF) were applied to discriminate samples from different geographical areas [72].

Further studies confirmed that the combined data fusion of FTIR and UV spectra of Boletus mushrooms with SVM could be used for efficient geographic classification of samples. The classification accuracy was 99\% [73,74].

Boletus edulis (and related species, BEAS), also known as "porcini mushrooms", represent almost the entire range of wild mushrooms available on the Italian market, both fresh and dried. A significant proportion of these dried mushrooms are imported from China. The presence of Tylopilus spp. and other foreign species (i.e., edible but not BEAS species) in dried samples, particularly those imported from China and sold in Italy, may pose a commercially valuable problem. Partial least squares density modeling (PLS-DM) of NIR spectra and the application of the modeling version of quadratic discriminant analysis (UNEQ) and soft independent modeling of class analogy (SIMCA) class assessment techniques resulted in a clear discrimination among dried samples of BEAS, Tylopilus spp., and Boletus violaceofuscus [75]. The molecular spectroscopic procedures for the authentication and adulteration of mushroom species and varieties are summarized in Table 5.

In keeping track with the numerous existing species of mushrooms, NIRS, NMR, $\mathrm{UV} / \mathrm{Vis}$, and RS proved to be reliable alternatives for the differentiation of mushroom samples at species level (strain classification, taxon delimitation). This is particularly important because the differentiation of new candidate varieties with improved nutritional properties, the differentiation of wild and cultivated or fresh and old and damaged mushroom samples, and the identification of mushroom samples from a specific growing area are essential for quality control of raw materials. The above-introduced examples clearly present that, despite the rather complex chemical composition and high inhomogeneity of mushrooms, the various molecular spectroscopic techniques have proven very useful in characterization, identification, and authentication of various mushrooms. The use of chemometric methods such as PCA, SVM, PLS-DM, and SIMCA increased the model performance of the different spectroscopic techniques for monitoring mushroom quality.

\subsection{Spices}

Different molecular spectroscopic methods combined with chemometric techniques have proven to be a useful tool for authentication of spices and for the identification of adulteration and adulterants [76].

Spices are the ingredients of our everyday meals. Their quality is closely linked to the area where they are grown. For this reason, it is very important to verify their geographical origin and to detect adulteration. The most commonly adulterated spices include paprika (Capsicum annuum), black pepper (Piper nigrum), cinnamon (Cinnamon verum), turmeric (Curcumina longa), oregano (Origanum vulgare L.), and saffron (Crocus sativus L.) (Table 6).

NIRS was applied for the first time to saffron spice to determine the chemical composition and geographical origin of samples from the three main producing countries: Iran, Greece, and Spain. Discriminant analysis (DA) of the three geographical origins showed that the Iranian samples were completely distinct from the others, while the Greek and Spanish samples showed greater similarity to each other [77].

Turmeric powders of Egyptian and Algerian origin were also classified according to their geographical origin. The analyses were performed using UV/Vis, FTIR, and ${ }^{1} \mathrm{H}-\mathrm{NMR}$ techniques. PCA and HCA methods were used for chemometric evaluation. The UV/Vis and FTIR methods were also unable to distinguish between the same species on the basis of their quality, as all species contained the same phytochemical constituents but in different concentrations. In the PCA model based on the full spectral range of ${ }^{1} \mathrm{H}-\mathrm{NMR}$, the two geographical origins could not be distinguished. However, when using only the region of essential oils/fatty acids ( $0.4-3 \mathrm{ppm})$ for the evaluation, complete separation of Algerian and Egyptian samples was observed [78,79].

The ${ }^{1} \mathrm{H}-\mathrm{NMR}$ analytical protocol was proposed to characterize saffron samples from different geographical origins (Greece, Spain, Hungary, Turkey, and Italy). A 
microwave-assisted extraction procedure was used. Comparing the metabolite profiles of the saffron extracts, significant differences in the content of each metabolite were identified. According to the metabolite profiles, the geological identification of saffron samples was successful [80]. A quantitative NMR metabolomics approach was developed to distinguish between two cinnamon species (Cinnamomum verum Ceylon and Cinnamomum cassia China). Nine key organoleptic metabolites were detected, among which $(E)$-cinnamaldehyde was the major form. Multivariate data analyses revealed the leading presence of eugenol in C. verum and its enrichment in fatty acids in C. cassia. Compounds related to the aroma and flavor of $C$. verum were identified and quantified, which can be used as markers to authenticate this spice [81].

Fraud in the global food supply chain is becoming increasingly common due to the huge profits that are made from this type of crime. Food commodities and ingredients that are part of expensive and complex supply chains are particularly vulnerable.

In the past, various compounds - often harmful to health-were used, e.g., in the case of cayenne pepper and chili, red lead $\left(\mathrm{Pb}_{3} \mathrm{O}_{4}\right)$, vermillion $(\mathrm{HgS})$, and venetian red $\left(\mathrm{Fe}_{2} \mathrm{O}_{3}\right)$ were added as color fillers [82]. Today, the adulteration process does not mainly involve the addition of chemicals, but of ground rice husks, rice flour, mustard seed husks, sawdust, salt or brick dust, or Sudan I to the spices. In the case of ground cinnamon, as with all other finely ground products, common adulterants include flour and other bulking agents (possibly coffee husks). The use of cinnamon as a spice and flavoring is widespread throughout the world, often adulterated with inferior cinnamon. Due to the high cost of true cinnamon, which is only produced in Sri Lanka, it is adulterated with Cinnamon cassia due to its low commercial value. On the other hand, Cinnamon cassia contains a high content of coumarin (1\%) which is a family of compounds containing 1,2-benzopyrone structures that are present only in minimal amounts in the barks of Cinnamon verum $(0.04 \%)$. Due to its hepatotoxic effects, the Food Safety Regulatory Agencies have imposed restrictions on the use of coumarin in their countries. NIRS and chemometric analysis have been successfully used to detect adulterations of genuine cinnamon [83,84].

The performance of three NIR spectroscopic (desktop, handheld, and portable) instruments was compared by investigating the authenticity of the coriander seed. A total of 200 authentic coriander core samples and 90 adulterated samples were analyzed with each instrument. All instruments correctly predicted $100 \%$ of the adulterated samples [85]. The NIR spectroscopic method was used to classify black pepper samples adulterated with papaya seeds, to distinguish between pure and adulterated samples. However, the authors only showed that NIRS can distinguish between pure and adulterated samples [86]. The spice turmeric is often adulterated with metanil yellow (1-25\%). This has been successfully detected using the NIRS method combined with chemometric evaluation. The structure of metanil yellow resembles that of a secondary amine; thus, high precision $\left(Q^{2}=0.99\right)$ can be achieved in the quantification of metanil yellow in turmeric samples [87]. The NIR and FTIR spectra coupled with chemometrics can be used to detect black pepper adulterated with papaya seeds, chili, and nonfunctional black pepper substances such as black pepper flakes, pinheads, and degreased used substances. A good separation performance was demonstrated between black pepper and adulterated samples. After running the binary classification model with an external test set, the area under the receiver operator characteristic curve was 0.98 for both the NIRS and the FTIR models [88].

Chili powder is a globally traded commodity, often adulterated with Sudan I dye. The tests were carried out using NIRS and RS. Chemometric methods were applied to the spectral data. The detection limit of adulterant dye was $0.25 \%$ for the NIRS technique and $0.88 \%$ for the Raman technique [88]. Other authors used FTIR to predict the concentration of Sudan dye in pepper samples $[89,90]$. Saffron is one of the most important and expensive spices in the world. It is, therefore, highly vulnerable to fraudulent practices, including the use of adulterants of plant origin. DRIFTS and chemometric techniques have been used to investigate saffron adulteration. Six typical commonly used adulterants of plant origin were investigated: Crocus sativus stamens, marigold, safflower, turmeric, buddleia, and 
gardenia. The investigations were successful in identifying the presence of adulteration, as well as the quality and quantity of adulterants [90,91].

The main producers of oregano reside in the United States of America, Mexico, Greece, and Turkey. Compared to most herbs, oregano has a complicated history as its true identity is very difficult to define. This is partly due to the large heterogeneity of the Origanum genus, as well as the grouping of different botanical genera: Origanum (lamiaceae) from the Mediterranean and Lippia (verbenaceae) from Mexico. Although Mexican and Mediterranean oregano are clearly distinguishable, only Origanum vulgare L. ssp. hirtum and Origanum onites L. are allowed by the European Pharmacopoeia (PhEur) and the European Spice Federation to be marketed as true oregano. Oregano is most commonly adulterated with olive leaf, myrtle leaf, sumac leaf, cistus leaf, or hazelnut leaf. The attenuated total reflection Fourier-transform infrared (ATR-FTIR) procedure successfully identified the presence of adulteration $\left(Q^{2}=0.96\right)[90,92]$.

Various forms of adulteration have been found in paprika, including substitution with waste or inferior products, misrepresentation of origin, and adulteration using illegal colorants such as the commonly found Sudan I. Examples of adulteration by substitution with waste products include adulteration by weight gain with white pepper, turmeric, brick powder, and barium sulfate. Sudan I is the most commonly used dye in adulteration. RS with a $785 \mathrm{~nm}$ laser excitation can be applied directly to paprika powder for the determination of Sudan I content. Mathematical pretreatment of the Raman spectra was done by fitting a polynomial to each spectrum and then subtracting it to remove the fluorescence background signal, and this was key for proper interpretation and modeling of the spectra. The percentage of correctly classified samples was 89\% [93] Another approach developed for detection and measurement is a sensor combining SERS, molecularly imprinted polymers, and thin-layer chromatography to identify samples of paprika adulterated with Sudan I and quantify the adulterant in low proportions (5 to $100 \mathrm{ppm})$ [94].

The developed Raman HSI system was employed for the simultaneous detection of Sudan dye and Congo red dye adulteration in paprika powder, as well as benzoyl peroxide and alloxan monohydrate adulteration in wheat flour at different concentrations $(w / w)$ from 0.05 to $1 \%$. The results obtained based on the Raman chemical images of adulterants showed a strong correlation $\left(R^{2}>0.98\right)$ between added and pixel-based calculated concentration of adulterant materials [95].

Others utilized FT-Raman and FTIR spectroscopy as separate but complementary methods for detecting metanil yellow adulteration of turmeric powder. Sample mixtures of turmeric powder and metanil yellow were prepared at concentrations of $30 \%, 25 \%, 20 \%$, $15 \%, 10 \%, 5 \%, 1 \%$, and $0.01 \%(w / w)$. Spectral analysis showed that the FTIR method in this study could detect metanil yellow at the 5\% concentration, while the FT-Raman method appeared to be more sensitive and could detect metanil yellow at the $1 \%$ concentration. Relationships between metanil yellow spectral peak intensities and metanil yellow concentration were established using representative peaks at FT-Raman $7110 \mathrm{~nm}$ and FTIR $8770 \mathrm{~nm}$ with correlation coefficients of 0.93 and 0.95 , respectively [96]. The same research group developed a new $1064 \mathrm{~nm}$ dispersive point Raman model for the detection of metanil yellow and Sudan I impurities in curry powder. The results showed that the number of detected adulterant pixels correlated linearly with the sample concentration $\left(R^{2}=0.99\right)$. They further used self-modeling mixture analysis (SMA) to extract the spectra of the pure components, and then identified from the spectral information divergence (SID) values that they were identical to the spectra of Sudan I and metanil yellow [97].

Raman imaging and FTIR spectroscopy were used to detect Sudan red and white turmeric adulteration in turmeric powder. While Sudan red Raman spectral peaks were identifiable in turmeric/Sudan red samples, Sudan red false-positive detection was observed in binary Raman images, limiting effective quantitative detection. In addition, white turmeric Raman spectral peaks were unidentifiable in turmeric/white turmeric mix- 
tures. However, IR spectra of turmeric/Sudan red and turmeric/white turmeric samples provided discrete identifier peaks for both adulterants [98].

For the detection of safflower (Carthamus tinctorius L.) and tartrazine adulterants in saffron, Dowlatabadi et al. [99] used ${ }^{1} \mathrm{H}-\mathrm{NMR}$ spectroscopy combined with chemometric multivariate data analysis methods. The molecular spectroscopic procedures for the authentication and adulteration of spices are summarized in Table 6.

The above-listed publications clearly present the wide range of available spices, which are not only numerous by their varieties and available quality, but also often targeted for food adulteration; molecular spectroscopic methods combined with chemometric techniques have been proven still very useful for their authentication. Among others, the different spectroscopic methods were shown useful in the identification of geographical or botanical origin of spices and in the quantification of different ingredients or fraudulent materials. Spice producers, processes, and quality control personnel can adapt the techniques for increased quality assurance and nutritional composition fingerprinting.

\subsection{Coffee}

Coffee and its beverages are becoming increasingly popular because of their pleasant aroma and high caffeine content. According to internationally accepted definitions, commercially available coffee products must not contain any substance other than green coffee beans. Due to the continuous increase in the price of the raw material, industrial coffee producers often either use low-quality beans (not from the declared geographical origin or defective beans) [100-102] or roast them with various adulterants (coffee husks, coffee grounds, cereals like wheat, maize, barley, or rye, soya beans, etc.). These processes result in misleading consumers and have a negative impact on the aroma and taste of the coffee drink. There are two main commercial coffee species: Coffea arabica (Arabica coffee) and Coffea canephora (Robusta coffee) [103]. They are commercially available in a proportion of approximately 2:1. Arabica coffee is a raw material of high quality and aroma. Although the caffeine content is lower than that of Robusta coffee, the taste is silkier and softer, making it more popular. For this reason, its price is higher than that of Robusta coffee. Many varieties of Arabica are known, such as Bourbon and Typica, as well as varieties or cultivars that are specific to the area of production. These include the Caturra (Guatemala, Costa Rica, Honduras, and Panama), Mundo Novo (Brazil, Peru), Blue Mountain (Jamaica), Villa Sarchi (originally from Ethiopia, Yemen, but currently more from the Caribbean), Limani and Fronton (Puerto Rico), Jackson (Rwanda, Burundi), Harrar Rwanda (Rwanda), and Catimor (Malawi, Zambia, Zimbabwe). The climatic conditions of coffee cultivation give special attributes to the beverage and could increase its value.

The quality of green coffee is influenced by a number of factors, such as genotype, growing conditions, and the processing of the coffee beans, which can be closely linked to the place of origin. There are a number of analytical methods available to qualify and authenticate coffee samples. These methods (gas chromatography-mass spectrometry (GCMS), gas chromatography with flame ionization detection (GC-FID), gas chromatographytime-of-flight mass spectrometry (GC-TOF-MS), high-performance liquid chromatographymass spectrometry (HPLC-MS), high-performance liquid chromatography with UV detection (HPLC-UV), high-performance liquid chromatography with diode-array detection (HPLC-DAD), etc.) are chemical and labor-intensive processes. Lengthy analytical procedures can be replaced by nondestructive molecular spectroscopic methods as a result of advances in instrumentation and statistical evaluation software [104].

To identify the geographical origin, genetic variety, and farming system of coffee, NIRS and HSI, together with chemometrics, offer a nondestructive, noninvasive, and accurate technical option. Both techniques have been shown to be effective, accurate, and sufficiently selective for the detection of adulteration and for the identification of geographical origin, genetic variety, and farming system [105]. 
For the identification of Arabica coffee by geographical origin and genotype, NIR spectroscopic data and PLS-DA evaluation gave similarly successful results (sensitivity and specificity $=1.0$ ) [106]. The analysis of Robusta coffee beans using FT-NIRS coupled with a self-organizing map (SOM) method allowed the identification and classification of the genotypic origin of Robusta coffee (with 100\% accuracy) [107].

Arabica and Arabica/Robusta blends produced under different farming systems (conventional and organic) from five geographically distinct production areas in Brazil were analyzed using PTR-MS and NIRS to determine whether the samples could be distinguished from each other by the producing areas and farming method. In the case of geographical origin, both methods gave almost the same accuracy (PTR-MS $=69 \%$, NIR $=61 \%$ ), whereas, for the farming systems aspect, the NIRS method combined with PLS-DA gave a better accuracy (PTR-MS $=39 \%$, NIR $=69 \%$ ) $[108,109]$.

Giraudo et al. [110] analyzed Arabica and Robusta samples from nine countries (from Central-South America and Asia), using FT-NIRS combined with PLS-DA chemometric data processing. The discrimination according to the variety was $100 \%$. They achieved $>93 \%$ accuracy for both continent- and country-based classification. Their results were confirmed by two independent laboratories.

Jesztl et al. [111] analyzed beans and ground Arabica samples using FT-NIRS. The geographical origin of the samples (Colombia, Guatemala, Brazil, and India) was certified. Samples subjected to different roasting procedures (Viennese, Italian, and French) were ground under identical conditions and parameters. It was found that the spectra of both beans and ground coffee were perfectly distinguishable between samples from different production areas using linear discriminant analysis (LDA). The accuracy of the classification was verified by random grouping.

Using the FT-NIRS technique, Bertone et al. [112] investigated the Arabica/Robusta ratio in roasted ground coffee blends. The determination coefficient $\left(R^{2}\right)$ of the validated PLSR model was 0.97 for the Arabica content. Mees et al. [113] examined coffee leaves for identification and obtained a $100 \%$ classification rate.

NIRS combined with a one-class classification method has been used to monitor Brazilian specialty coffee. The spectral data were obtained with a portable NIRS instrument, and a Savitzky-Golay filter was applied to correct the baseline variation (a second-order derivative based on a quadratic polynomial and an 11-point window). Unsupervised pattern recognition techniques (PCA and HCA) were used, and the classification was built using the data-driven soft independent modeling of class analogy (DD -SIMCA) algorithm. The classification model achieved the highest correct classification rate (CCR) of $100 \%$ and $87 \%$ in the validation and test groups, respectively. The results showed that the applied procedure can be used to verify the authenticity of samples produced by specialty agroforestry [109].

According to the results of analysis of variance (ANOVA)/simultaneous component analysis (ASCA), PLS-DA and SIMCA were used to generate classification models to validate the varietal origin of coffee beans by NIR spectroscopy. PLS-DA resulted in a CCR of about $98 \%$ on the test set (100\% for Arabica and 95\% for Robusta), while SIMCA almost always achieved sensitivity and specificity values above $90 \%$ (93\% and 96\% for Arabica and $77 \%$ and $96 \%$ for Robusta) [114].

The use of portable micro-spectrometers such as a micro near-infrared region (microNIR) spectrometer is a promising technique for solving analytical problems in several areas of science. Accordingly, microNIRS was successfully used to determine the quality of Arabica coffee by identification and quantification of adulterations such as Robusta coffee (in different roasting levels), as well as corn, peels, and sticks. The NIR data were combined with chemometric evaluation using PCA and PLSR. The developed models were also applied to monitor the quality of 16 commercial coffee samples. The results obtained using microNIRS proved the ability of the method to be efficient and capable in the prediction of adulterations with minimum quantification levels (LOQs of 5-8 wt.\%) [115]. 
IR and SVM were used to geographically classify different genotypes of Arabica coffee. The spectra were recorded in the NIR and MIR regions. For data analysis, an SVM was built using radial basis as kernel function and a one-versus-all multiclass approach. Using the NIRS-SVM method, all test samples were correctly classified with $100 \%$ sensitivity and specificity, while FTIR-SVM showed slightly lower performance [116]. In terms of Arabian coffee, for geographic and genotypic ancestry classification, FTIR spectra were analyzed using a type of ANN (artificial neural network), the radial basis function network (RBF). The optimized RBFs were able to classify Arabica coffee samples both geographically (100\% correct classification) and genotypically $(94.44 \%)$ [117,118]. Moreira and Scarminio [119] examined four different Coffea arabica cultivars using FTIR spectroscopy and HPLC with diode array detector (DAD). Different extraction mixtures were studied, and the IR spectra were collected in the 2500-25,000 nm region. PCA was successfully used for pattern recognition purposes. The chromatographic elution was monitored at 210, 240, and $254 \mathrm{~nm}$ to gain deeper insight into the composition of the samples.

The HSI technique can also be successfully used in combination with different discriminant models to identify coffee beans. Bao et al. [120] applied NIR-HSI technology to identify different coffee beans of Chinese origin. Different discriminant methods were used to evaluate the data: PLS-DA, RF, K-nearest neighbor algorithm (k-NN), SVM, and extreme learning machine (ELM). Prior to the evaluation, a successive projection algorithm (SPA) was used to select the sensitive wavelengths from the whole spectrum. For each coffee bean variety, the sensitivity, accuracy, and specificity of the ELM models based on the full spectrum and the sensitive wavelengths were above $93.5 \%$ in both the calibration and the prediction sets. SVM models applied optimal wavelengths selected using second-derivative spectra gave even better results (prediction accuracy 98\%) [117].

Hawaiian Kona coffee is a highly prized and sought-after variety. Because of its value, it is often blended with less valuable varieties. ATR-FTIR spectroscopy has been used to test these blends. Using second derivative and mean-centered data preprocessing and PLS regression, a prediction model was developed in the 5260-12,500 nm range with $\mathrm{R}^{2}=0.999$ and a mean error of prediction SEP $=0.7 \%$ [100]. Mixing good-quality coffee beans with defective beans (black, unripe, and acidic) is considered adulteration in the same way as adulteration with any other substance. Ripe, unripe, defective, and non-defective green coffee beans from Brazil were analyzed by FTIR spectroscopy using transmission and reflectance measurements. In the latter, ATR and diffuse reflectance (DR) enhancements were used. PCA and HCA were performed to distinguish between defective and nondefective coffee samples [102]. Barbin [121] and Ebrahimi [122] applied NIRS to different blends using Arabica and Robusta coffees and four types of barley at different roasting degrees. PLSR was used to predict the amount of barley $(\% w / w)$ in the mixtures. The best results were obtained after applying genetic algorithm (GA) variable selection method.

DRIFT has been successfully applied to the detection of adulterated roasted coffee. The most common adulterants are coffee husks and corn. Using chemometric data processing (PCA and LDA) of DRIFT spectra, a 100\% detection and prediction model was developed to discriminate among roasted coffee, pure adulterants (corn and coffee husks), and adulterated coffee samples [123]. The FTIR method has been used to detect the most commonly used substances for roasted coffee adulteration (coffee grounds, roasted coffee husks, roasted maize, and roasted barley) using two different acquisition techniques (ATR and DR).

Hierarchical models were constructed using two-level PLS-DA models. The first level included a model that discriminates between unadulterated and adulterated coffee samples. The second tier included four models that could identify the presence of each of the adulterants tested, in pure or blended form. The models were constructed using DR, ATR, and combined DR/ATR data (data fusion). At the first level, each model was constructed using 310 samples (30 samples of coffee grounds, 45-45 samples of pure coffee, pure roasted barley, pure roasted maize, and roasted coffee beans, and 100 samples containing a mixture of the four adulterants and coffee). Each of the four models in the 
second tier was constructed from 265 samples (the same 310 samples as in the first-tier model-except for 45 pure coffee samples). The percentage of misclassified samples in the second level models went as low as $0 \%[90,124]$.

Sibutramine, a neurotransmitter reuptake inhibitor used to treat obesity, has effects on the human body such as heart attack and stroke. For this reason, it has been banned since 2010. Because it has overweight-reducing effects, it is artificially added to green coffee samples, which are then marketed as "100\% natural overweight-reducing effect products". A method for detecting this banned adulterant has been developed using a combination of ATR-FTIR spectroscopy and chemometrics. HCA and PCA were applied to the 3640-3770 $\mathrm{nm}$ region for classification and discrimination using Euclidean distance and Ward's algorithm. It was found that the method could be successfully applied to the detection of the banned substance in the concentration range of $0.375-12 \mathrm{mg}$ sibutramine [125].

Given the price and quality differences, it is essential to have effective tools to distinguish between green Arabica and Robusta coffee. To this end, the use of multispectral imaging systems can provide reliable and accurate real-time monitoring at relatively low cost. Hyperspectral data of green coffee samples were evaluated using PLS-DA to perform classification and sparse PLS-DA (sPLS-DA) for variable selection. According to the results, four band pass filters showed the best match with the selected region. From 33 coffee bean samples (18 Robusta and 15 Arabica), three batches per sample were selected to be representative of the sample. Two images were taken of each selected unit, repeated on two different days. Finally, 12 hyperspectral images were included for each lot, resulting in a dataset of 396 hyperspectral images. Proper strategies for the definition of the training set and the selection of the most effective combinations of spectral channels led to satisfactory classification performances $(100 \%$ classification efficiency in prediction of the test set) [126].

A special application of Fourier-transform Raman spectroscopy (FT-RS) was used for the differentiation of botanical species of green and roasted coffee. Samples with 25 different geographic origins were examined. The analyzed Kenyan and Jamaican coffees were grown at high altitudes (Arabica), while the Australian coffees were grown at low altitudes (Robusta). It was recognized that the lipid fractions of the coffee species studied showed differences. In particular, they differed in their kahweol content (diterpene), which is present in Arabica beans at $0.1-0.3 \%$ dry matter, whereas, in Robusta, it is only present in trace amounts $(<0.01 \%)$. Visual inspection of the Raman spectra of the lipid fraction extracted from Arabica, Robusta, and Liberica samples showed variations in the mid-infrared region. The spectrum of Arabica contained two characteristic scattering bands at 6380 and $6770 \mathrm{~nm}$, which were found to be similar to the spectrum of pure kahweol. The spectra were evaluated using PCA. The first principal component (PC1) explained $93 \%$ of the spectral variations. It was observed that the loading plot of PC1 corresponded to the spectrum of kahweol. As a result of the PCA, the two groups of coffees analyzed could be clearly distinguished: one group with high kahweol content (Kenyan and Jamaican samples) and the other group with low kahweol content (Australian samples) [127].

Most NMR technique-based research is carried out on liquid samples primarily to determine coffee quality; it is most often used to identify the geographical origin of roasted coffee and to investigate Arabica-Robusta blend ratios. The first studies on the geographical origin of roasted coffee were carried out with African, Asian, and American Coffea arabica samples. The NMR results, evaluated by multivariate statistical analysis, perfectly distinguished the profile of metabolic aqueous extracts [128]. NMR has proven to be a versatile and robust tool for the identification of adulterants in foods. ${ }^{1} \mathrm{H}-\mathrm{NMR}$ combined with chemometric tools is a successful technique for the quantification of coffee adulteration. ${ }^{1} \mathrm{H}-\mathrm{NMR}$ analysis of aqueous extracts of roasted and ground coffee blends of Coffea arabica and Coffea canephora var. robusta was combined with multivariate statistical analysis to obtain an orthogonal projection to latent structures (OPLS) model with high predictive power. This approach allowed the evaluation of the composition of 
coffee blends with unknown Arabica and Robusta content based on several chemical components. Differences in the geographical origin of the samples analyzed did not affect the determination of the composition of the coffee blends. This approach is a valid tool for the authentication of roasted and ground Arabica and Robusta coffee blends $[129,130]$. In a study, OPLS model was used to correlate sensory parameters with NMR spectra of roasted Arabica and Robusta coffees from Brazil, Colombia, and Indonesia. Sourness, saltiness, and astringency were correlated with Arabica coffee (due to chlorogenic acid, citric acid, malate, formic acid, acetate, trigonelline, arabinose, and galactose contents), while sweetness, body, and bitterness were correlated with Robusta coffee (due to lipid, quinine, quinic acid, and mannose contents). Using this model, the taste of four commercial coffees was correctly estimated, confirming the correct choice of NMR-based metabolomics to predict the sensory characteristics of roasted coffee beans [131]. NMR was applied to the geographical identification of 192 roasted coffee samples of different species. The samples came from Asia, Africa, and the USA. The ${ }^{1} \mathrm{H}-\mathrm{NMR}$ spectra were acquired in a fully automated procedure (tuning, shimming, pulse calibration, and spectral processing) using a $400 \mathrm{MHz}$ spectrometer. Particular attention was paid to Colombian coffee, which showed good separation from non-Colombian coffee; PLS-DA models highlighted fatty acids, acetate, and caffeine as metabolites characteristic of Colombian samples [132].

Kwon et al. [133] used an NMR-based metabolomics approach to investigate the quality class of Arabica green coffee beans. High-quality green coffee beans were characterized by high sucrose content and lower $\gamma$-aminobutyric acid (GABA), quinic acid, choline, acetate, and fatty acid content, while lower-quality green coffee beans reported lower GABA, quinic acid, choline, acetate, and fatty acid content compared to commercially available coffees.

The ${ }^{1} \mathrm{H}-\mathrm{NMR}$ method was also applied to investigation of samples from different Brazilian states (São Paulo, Minas Gerais, Espírito Santo, Santa Catarina, Bahia, Paraná, Maranhão, and Paraíba) and four other countries (Spain, Italy, Argentina, and Colombia). Two different roasting methods were used (medium and dark). The adulterants used were coffee husks, soya beans, maize, barley, rice, and wheat. The spectrum used for the authentication of coffee samples was the pre-saturated ${ }^{1} \mathrm{H}$ spectrum. When comparing the spectra of pure $100 \%$ Arabica samples with the spectra of coffee samples adulterated at a 1:1 weight ratio, it was found that a chemical shift signal was observed in the spectra of samples containing maize, rice, barley and wheat. This shift occurred in areas which, as further experiments confirmed, were clearly associated with the starch in maize, rice, barley, and wheat used as adulterants. The same phenomenon was not observed in coffee husks, soya beans, and pure coffee, as no starch is present in the composition of soya beans and coffee husks. In these adulterants, signal shifts were observed at sites that could be linked to sugars in the endocarp of the grain (in the case of coffee husks) or to hydrogen atoms in the carbon atoms of the stachyose or sucrose anomer (in the case of soybeans) [134,135].

${ }^{1} \mathrm{H}-\mathrm{NMR}$ was used to investigate the metabolic fingerprinting of Brazilian and Colombian coffee varieties of different qualities. As a result of the evaluation of the data by PCA, they were able to successfully distinguish among the conventional, superior, and gourmet groups, as well as between samples with different caffeoylquinic acid, trigonelline, and quinine levels related to quality [136]. The molecular spectroscopic procedures for the authentication and adulteration of coffee species and varieties are summarized in Table 7.

The diversity of coffee in both price and quality, as well as in its popularity, results in an immense need for its rapid quality determination. The above-reviewed publications clearly present the unique potential of the different molecular spectroscopic methods combined with chemometric techniques in the quality characterization of coffee from many various aspects. These include but are not limited to the fast and nondestructive botanical or geographical origin identification, quality grade determination, or quantification of composition or intentional compositional manipulations. Coffee beans and tea leaves 
of different origins could be distinguished using the molecular spectroscopic methods, and their quality parameters could also be predicted. This is essential for the beverage industry as these are all economic drivers for the preparation of beverages and products from raw materials. Furthermore, consumer preferences for specific coffee and tea varieties or blends are an ever-increasing challenge that can be bridged with these methods when rapid assessment is used in the right way.

\subsection{Tea}

Tea is the oldest and most consumed beverage in the world [137]. The classic tea is an article of enjoyment produced from the leaves or buds of the Camellia sinensis plant by various processes. Green, yellow, and white tea products undergo minimal processing, whereas oolong and black tea products are oxidized, and Pu-erh tea is fermented [138]. Tea is chemically a very complex system as it contains caffeine, polyphenols, polysaccharides, and other nutrients such as proteins, amino acids, lipids, and vitamins [139]. The character and quality of tea products are determined by the quantity and quality of free amino acids, total tea polyphenols, soluble sugars, and caffeine [140], which typically depend on the processing technology of the tea leaves and buds. In the case of tea made from Camellia sinensis leaves, classification according to oxidation and/or fermentation conditions is an important criterion, in addition to geographical classification.

Green teas have been discriminated using UV/Vis spectroscopy [141] and FTIR spectroscopy in combination with chemometric methods. The results obtained from the unsupervised pattern recognition techniques (HCA and PCA) clarified the differentiation of the samples into discriminate clusters in accordance with their geographical origin, which reflect the notable variation among the green tea samples. SIMCA and PLS-DA as supervised pattern recognition techniques were adopted to further ascertain the results obtained from the unsupervised techniques composition [142].

NIR spectra were used to identify green, black, and oolong teas from different geographical areas in China. PCA and SVM methods were used for pattern recognition and classification. The identification rate ranged from $90-100 \%$ depending on the type of tea $[143,144]$.

HSI coupled with four kinds of classification methods were applied to detect the variety and grade of five green teas (Biluochun, Jingshan, Longjing, Queshe, and Sanbeixiang). Robust models were built for green tea classification using the SVM method on separating three grades of each green tea with the classification accuracy higher than 93\% [145]. Using visible and near-infrared hyperspectral imaging (Vis/NIR-HSI), five tea categories (green, yellow, white, black, and oolong tea) were identified on the basis of classification pattern recognition. The CCR achieved $98.39 \%$ [146]. An adaptive improved possibility c-means (AIPCM) clustering with fuzzy Mahalanobis distance has been proposed for fast, efficient, and nondestructive identification of different tea varieties of geographical origin for FTIR spectral classification of tea samples. After MSC data preprocessing, PCA and LDA analysis were applied and the data were clustered using several fuzzy clustering algorithms. The maximum accuracy was $98.5 \%$ [147].

NIR-HSI has been successfully used to classify, authenticate, and detect adulteration of tea products produced by different technologies. HSI data were processed by comparing linear data visualization methods. The oolong, green, yellow, white, black, and Pu-erh teas studied could be classified into three groups with $97 \%$ classification accuracy using a newly developed classification model (multiclass error-correcting output code model containing support vector machine (SVM-ECOC)): minimally processed, oxidized, and fermented products [148]. A simple method based on surface-enhanced Raman spectroscopy (SERS) has been developed to extract the full spectrum of tea varieties to detect the purity of samples based on processing and cultivation type. For this purpose, fingerprints of tea samples from seven different tea species (herbal tea, rosehip, chamomile, lime, green, and sage, black tea, and Earl Grey green tea) were analyzed using SERS. PCA was used to separate the individual teal samples [149]. 
Visible spectroscopy combined with chemometric data analysis has been successfully used to identify matcha tea powder adulterants. Matcha is rich in nutrients and is more expensive than green tea. It is often adulterated using steamed green tea powder. The presence of steamed tea leaves can be detected by classification methods (PCA-LDA, SIMCA), and the amount of adulterant in matcha tea can be estimated by PLS regression [150].

Darjeeling black tea is a tea variety known worldwide and is currently listed in both the Register of Protected Designations of Origin (PDO) and the Register of Protected Geographical Indications (PGI). As it is a valuable tea, adulteration is often a problem. To clarify this issue, the NIRS technique using PLS-DA and SIMCA classifications is satisfactory to distinguish PGI samples from other teas and adulterated Darjeeling. In the adulteration process, genuine Indian Darjeeling tea is most often blended with various Ceylon teas [151]. Roasted green tea is adulterated with sugar and glucose syrup, which, in addition to the adulteration, is also extremely dangerous because it increases the risk of moisture sensitivity and microbiological hazards in tea products. The detection of sugar and glucose syrup is generally carried out by HPLC, which has a sufficiently high specificity and sensitivity, but is a time-consuming and expensive method. This has been replaced by FT-NIR spectroscopy. A prediction model was constructed by PLS regression and optimized by leave-one-out cross-validation. The identification accuracy of adulterants in roasted green tea was $96 \%$ (sugar) and 100\% (glucose syrup) [152]. As in the case of coffee, green tea leaves have been blended with sibutramine and marketed as a "100\% natural" weight loss product. The ATR-FTIR method combined with chemometric methods also resulted in perfect pattern recognition in this case [125].

FTIR combined with chemometrics has been successfully used to detect talcum illegally added to tea. Smoothing, normalization, and SNV were used to preprocess the FTIR raw spectra. Before data evaluation, variable selection was performed to improve the model [153]. The molecular spectroscopic procedures for the authentication and adulteration of Camellia sinensis are summarized in Table 8.

Similarly to coffee, tea is also a broadly consumed drink, raising the need for analytical techniques providing rapid and nondestructive quality analysis. A wide arsenal of molecular spectroscopic methods combined with chemometric techniques have been found to be indispensable in this concept, as explored in the above research studies. The advantages of these rapid analytical techniques have been clearly proven in the classification of teas with different botanical and geographical origin or on the basis of their different preparation technologies, as well as further applications.

\section{Future Prospects of Sensor-Based Equipment: Mobile and Online Diagnostics}

There has been a steady rise in demand for mobile devices with online technologybased functions. Such devices have been widely applied for purposes of monitoring and evaluation in the agro industry [154] as they provide rapid and on-site analysis for preliminary and meaningful information extraction. The goal is to avoid the use of expensive and bulky instrumentations that are routinely used by trained personnel but with the motive of saving cost and time. For these devices, essential prerequisites are to be compact enough, robust, high temperature-resistant, waterproof, and easy to clean [155]. Materials having direct contact must also be food-safe. Recently, new innovative handheld devices based on micro-electro-mechanical systems (MEMS) have been developed and incorporated into the NIRS fields of application [50] and can be easily applied with internet access (Figure 5).

Bázár et al. [157] reported the use of an advanced handheld NIRS scanner (Tellspec), with a spectral interval of 950-1630 nm, to successfully analyze beef sirloin and tenderloin samples that were stored at $4{ }^{\circ} \mathrm{C}$ in plastic bags for a 10 day period with a 93.55\% accuracy of LDA classification by days of storage. A handheld fiber-optic NIRS spectrometer with a spectral range of 700 to $1050 \mathrm{~nm}$ was used by [158] for the assessment of fatty acids in 12 market beef samples. These results proved that the optical data could be applied for breeding, as well as improving beef quality and feedback data 
on beef production. A similar brand of handheld spectrophotometer $\left(\mathrm{SCiO}^{\mathrm{TM}}\right)$, with a spectral range of $740 \mathrm{~nm}$ to $1070 \mathrm{~nm}$, was reportedly used [155] for egg evaluation. It was observed that the reflectance spectral data of the egg contained important information about its shelf-life (storage time), an essential quality of freshness. There were also noticeable differences in the processed spectral values of the eggs as a function of storage time.

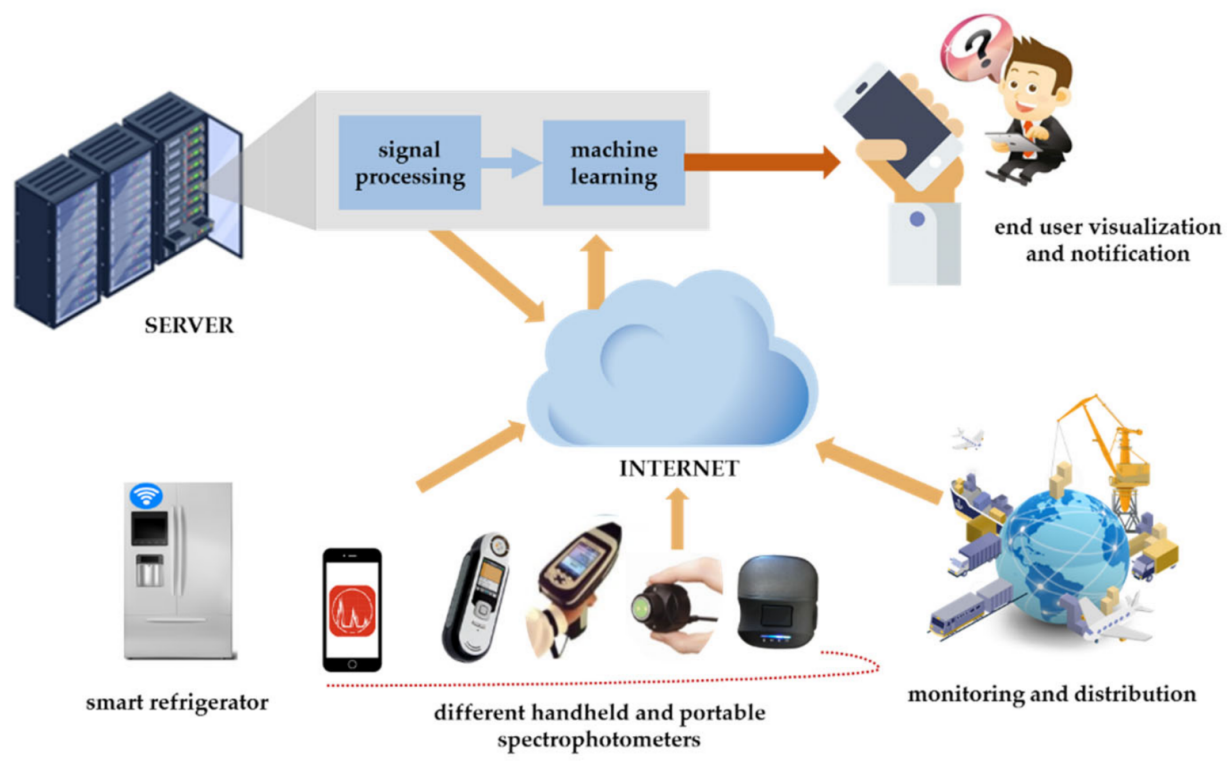

Figure 5. Flow diagram for the implementation of mobile diagnostics (based on Wijaya et al. [156]).

Tellspec and Texas Instrument's NIRScan nano scanners possess a wider spectral range $(950-1630 \mathrm{~nm})$ than both the fiber-optic NIRS (700 to $1050 \mathrm{~nm}$ ) and SCiO ${ }^{\mathrm{TM}}$ (740 to 1070 $\mathrm{nm}$ ), but a narrower range than the indico-pro NIRS (350 to $1800 \mathrm{~nm}$ ). Tellspec, however, possesses the advantage of being the post portable in terms of size. Nonetheless, all the three devices are effective and have a great potential of application in the meat industry. Both SCiOTM and Tellspec provide an advantage of real-time data transfer onto servers that can be remotely assessed by the users. The devices can be used for preliminary evaluation of carcass before they are transferred to the lab for major quality assurance tests.

Miniaturization can be seen in all the analytical technologies, as well as in the molecular spectroscopic devices. Not only NIRS [159], but also Raman spectrometers can reach the portable size and may be a highly practical tool in advanced field testing for contaminants in food industry [160]. Some decades ago, it was the big achievement of NIR spectroscopy to allow nontechnical personnel to perform routine quality measurements, but still in lab conditions. Currently, as process analytical technologies are becoming more required by intelligent industrial systems, tools such as NIRS and other molecular spectroscopic applications provide great opportunities out of laboratories [161]. Unquestionably, there is a potential of these technologies to reach the end-users as hidden tools, for example, as part of a smart refrigerator or as an NIR camera of a smartphone. Novel miniaturization technologies allow all these developments. However, the biggest challenge remains to prepare predefined calibration models that work in everyday conditions provided by nonprofessional end-users. This is an even harsher challenge than required by the industrial applications where, although spectrometers may have to withstand vibration and humid conditions, the spectral acquisition is nevertheless performed in standardizable way. It also becomes obvious that, in addition to data scientists and mathematicians preparing sophisticated calibration models for large spectral databases, classical and practical spectroscopic experiences remain crucial while planning future applications. 
Table 2. Advantages and disadvantages of different molecular spectroscopy methods.

\begin{tabular}{|c|c|c|}
\hline Important Parameters & Advantages & Disadvantages \\
\hline \multicolumn{3}{|c|}{ UV/Vis $[162,163]$} \\
\hline $\begin{array}{l}200 \mathrm{~nm} \leq \lambda \leq 800 \mathrm{~nm} \\
\text { absorption } \\
\text { excitation of valence } \\
\text { (bonding) electrons }\end{array}$ & $\begin{array}{l}\text { 1. Cheap } \\
\text { 2. Relatively simple method } \\
\text { 3. Linear relationship between absorbance and } \\
\text { concentration (Lambert-Beer law) } \\
\text { 4. Both organic and inorganic molecules } \\
\text { 5. San be measured }\end{array}$ & $\begin{array}{l}\text { 6. The sample quantity is medium/high } \\
\text { 7. Requires chemical } \\
\text { 8. Onple preparation } \\
\text { 9. Only possible for the analytes which } \\
\text { have a chromophore } \\
\text { 10. Strongly affected by } \mathrm{pH} \text {, temperature, } \\
\text { contaminants, and impurities. }\end{array}$ \\
\hline
\end{tabular}

\section{NIRS [164,165]}

$780 \mathrm{~nm} \leq \lambda \leq 2500 \mathrm{~nm}$

diffuse reflection/

transmission/transflection

vibrational energies (bond length/angle of bond)

infra-active molecule $\Rightarrow$ dipole moment change
1. Fast

2. Small sample requirements

3. No or minimal (physical) sample preparation

4. No chemicals required

5. Sample not damaged during measurement

6. Nondestructive

7. Measurement can be performed off-line, at-line, in-line, and on-line

8. Solid and liquid samples

9. Physical, chemical property process analysis analytical technology (pat) can be measured equally

10. Qualitative and quantitative measurement

11. Stable instrument

12. Reproducible measurement

13. Spectrum complex information carrier (multiple parameters from one measurement simultaneously)

14. Immediate result

15. Concentration of organic macromolecules
1. Not an absolute technique: depends on accuracy of reference data measurements

2. Calibration: multivariate linear/nonlinear regression method

3. Calibration function requires many (minimum 50-100) reference data

4. Only suitable for organic molecules (except water)

5. High moisture content may cause problems

6. Temperature dependence (especially for liquids)

7. Spectrum complex information carrier (spectrum overlay)

8. Evaluation requires appropriate mathematical background and chemometric knowledge

$$
\text { IR [166] }
$$

$2500 \mathrm{~nm} \leq \lambda<25,000 \mathrm{~nm}$ infra-active molecule $\Rightarrow$ dipole moment change range of chemical vibrations $2500 \mathrm{~nm}<\lambda<6670$ fingerprint range $6670 \mathrm{~nm} \leq$ $\lambda \leq 25,000 \mathrm{~nm}$
1. Advantages specific to the NIRS technique

2. Solid/liquid/gas samples

3. Studies of organic and certain inorganic molecules

4. Range of chemical vibrations: characteristic of compound groups

5. Fingerprint range: unique signal specific to a given compound
6. Chemical structure, chemical bonds, composition, sample stability/degradation, contamination, identification of additives

7. In situ monitoring of reactions

8. Disadvantages specific to the NIRS technique

9. Complicated technique

10. Data interpretation complicated

11. Expensive procedure

\section{HSI [167]}

1. Combining the advantages of spectroscopy and traditional image processing

2. Infer the spatial distribution of content properties of materials with inhomogeneous structures

Measuring range: Vis (400-1000 nm) or NIR/Vis (900-1700 nm)
3. Hyperspectral images have good spectral resolution, and sensitivity is good

4. No sample preparation

5. Nondestructive
6. Solid/gel samples

7. Mainly surface measurements

8. Mainly surface measurements

9. Special sensors

10. Advanced IT requirements

11. Narrow measurement range

12. Small sensitivity 
Table 2. Cont.

\section{RS [168,169]}

1. Homonuclear diatomic molecules can also be measured such as $\mathrm{H}_{2}, \mathrm{~N}_{2}$, and $\mathrm{O}_{2}$

2. Fast

3. No sample preparation

4. Nondestructive

5. Solid, liquid (colloids) and gas phase samples

6. Sample size is not limited

$800 \mathrm{~nm}<\lambda<2500 \mathrm{~nm}$ based on light scattering

Raman-active $\Rightarrow$ change in polarizability
7. Lateral resolution good

8. Less sensitive to water

9. Works at high pressure and temperature

10. Measurement of packaged samples (packaging material is minimally Raman active)

11. Calibration using univariate models

12. Mainly for monitoring reactions and changes (e.g., deterioration)

13. Weak signal strength

14. The intensity is less than the IR

15. Fluorescence is often a disturbing effect

16. Less effective in pattern recognition
17. Raman spectrum quality strongly dependent on the wavelength of the irradiating laser (signal to noise ratio)

18. Compared to other spectroscopic measurements, the equipment is more expensive

19. Sensitive to even small amounts of fluorescent contamination

20. Excessive intensity of the laser may increase the temperature of the sample

21. Unstructured images (backgrounds, matrices) $\Rightarrow$ identification is rather complex and cumbersome

22. Artificial lighting may be required depending on lighting conditions

23. Disadvantage of light sources $\Rightarrow$ they can have significant heat dissipation

24. The detection limit is strongly influenced by the particle size, the chemical and spatial heterogeneity of the sample, and the spatial resolution of the image

\section{NMR [170]}

1. Nondestructive

2. Chemical reaction testing

3. Structural analysis

4. Isomerism study: enantiomers

5. Organic chemistry: qualitative analysis

nucleus spin energies nonoptical method

6. Physicochemical tests, reaction kinetics
7. Solid and liquid samples

8. Lower maintenance cost

9. Lower analysis time

10. Easy sample preparation

11. Require very small sample volumes

12. High reproducibility
13. Can be used online

14. Sensitive to the homogeneity of the sample

15. Data processing, data evaluation complex

16. Expensive instrument

17. Sample requirements are significant

18. Molecular size limitations

19. Real-time data collection results in broader signals and less clean spectrum

20. Chemical shielding

21. Signal strength is lower compared to techniques such as optical spectroscopy

Table 3. Overview of molecular spectroscopic techniques for quality determination in meat and fish.

\begin{tabular}{|c|c|c|c|c|c|}
\hline Spectroscopic Technique & Investigated Parameter & $\begin{array}{c}\text { Spectral } \\
\text { Region }(\mathrm{nm})\end{array}$ & $\begin{array}{l}\text { Preprocessing } \\
\text { Method }\end{array}$ & Chemometrics & Reference \\
\hline \multirow{3}{*}{$\begin{array}{l}\text { Ultraviolet/visible/near- } \\
\text { infrared spectroscopy } \\
\text { (UV-Vis-NIR) }\end{array}$} & $\begin{array}{l}\text { Predicting fatty acids in fresh and } \\
\text { freeze-dried beef }\end{array}$ & $400-2400$ & Not reported & ANOVA, PLSR & [36] \\
\hline & $\begin{array}{l}\text { Accurate determination of the } \mathrm{K} \text { value of } \\
\text { fish flesh }\end{array}$ & $250-600$ & $\mathrm{SG}+\mathrm{MSC}$ & iPLS & [35] \\
\hline & $\begin{array}{l}\text { Detecting bovine meat adulteration with } \\
\text { turkey meat }\end{array}$ & $220-700$ & SNV & PCA, LDA & [37] \\
\hline $\begin{array}{l}\text { Fourier-transform near } \\
\text { infrared spectroscopy } \\
\text { (FT-NIRS) }\end{array}$ & $\begin{array}{l}\text { Detection of beef, mutton, camel, and lamb } \\
\text { meat adulterated with pork }\end{array}$ & $1000-2500$ & $\begin{array}{l}\text { SNV+ auto } \\
\text { scaling }\end{array}$ & PCA, PLS-DA, PLSR & [47] \\
\hline $\begin{array}{l}\text { Fourier-transform } \\
\text { infrared spectroscopy } \\
\text { (FTIR) }\end{array}$ & $\begin{array}{l}\text { Structural and metabolic } \\
\text { changes in the liver samples of wild and } \\
\text { aqua cultured gilthead sea bream (S. aurata) }\end{array}$ & $2702-10,638$ & SG-19 points & $\begin{array}{l}\text { Spectral peak } \\
\text { analysis and } \\
\text { band assignments }\end{array}$ & [44] \\
\hline \multirow{2}{*}{$\begin{array}{l}\text { Hyperspectral imaging } \\
\text { spectroscopy } \\
\text { (HSI) }\end{array}$} & $\begin{array}{l}\text { Prediction of monounsaturated and } \\
\text { polyunsaturated fatty acids of various } \\
\text { processed pork meats }\end{array}$ & 1000-2000 & Not reported & SVM & [38] \\
\hline & $\begin{array}{l}\text { Protein content evaluation of processed } \\
\text { pork meats }\end{array}$ & $465-630$ & Not reported & BP-NN, PLSR & [39] \\
\hline
\end{tabular}


Table 3. Cont.

\begin{tabular}{|c|c|c|c|c|c|}
\hline $\begin{array}{l}\text { Spectroscopic } \\
\text { Technique }\end{array}$ & Investigated Parameter & $\begin{array}{c}\text { Spectral } \\
\text { Region (nm) }\end{array}$ & $\begin{array}{l}\text { Preprocessing } \\
\text { Method }\end{array}$ & Chemometrics & Reference \\
\hline & Determination of $\mathrm{pH}$ in pork & $400-750$ & Not reported & SVR & [171] \\
\hline & $\begin{array}{l}\text { Muscle type, rigor process, and aging } \\
\text { assessment of lamb }\end{array}$ & $550-1700$ & MSC, SNV & SVM, PLSR & {$[39]$} \\
\hline \multirow[t]{2}{*}{$\begin{array}{l}\text { Raman spectroscopy } \\
\text { (RS) }\end{array}$} & $\begin{array}{l}\text { Analyses of prohibited } \\
\text { drugs including enrofloxacin, furazolidone, } \\
\text { and green malachite in tilapia }\end{array}$ & $5000-25,000$ & Not reported & PCA, PLSR & {$[40]$} \\
\hline & $\begin{array}{l}\text { Testosterone propionate and } \\
\text { nandrolone residues in duck meat }\end{array}$ & $5555-25,000$ & Normalization + D1 & SVM & {$[172]$} \\
\hline \multirow{2}{*}{$\begin{array}{l}\text { Raman, near-infrared, } \\
\text { and fluorescence } \\
\text { spectroscopy } \\
\text { (RS + NIR + FS) }\end{array}$} & $\begin{array}{l}\text { Predict drip loss and } \\
\text { measure } \mathrm{pH} \text { of fresh pork, with a secondary } \\
\text { aim to measure intramuscular fat }\end{array}$ & $\begin{array}{c}5291-6666 \\
400-2500 \\
300-500\end{array}$ & $\mathrm{SG}+\mathrm{EMSC}+\mathrm{SNV}$ & ANOVA, PLSR & {$[173]$} \\
\hline & $\begin{array}{l}\text { Predict drip loss and } \\
\text { measure pH of fresh pork, with a secondary } \\
\text { aim to measure intramuscular fat }\end{array}$ & $\begin{array}{c}5291-6666 \\
400-2500 \\
300-500\end{array}$ & $\mathrm{SG}+\mathrm{EMSC}+\mathrm{SNV}$ & ANOVA, PLSR & {$[173]$} \\
\hline \multirow{2}{*}{$\begin{array}{l}\text { Fourier-transform } \\
\text { infrared spectroscopy } \\
\text { and Raman } \\
\text { spectroscopy } \\
\text { (FTIR + RS) }\end{array}$} & $\begin{array}{l}\text { Species discrimination of meat and bone } \\
\text { meals based on lipid characteristics }\end{array}$ & $5555-18,181$ & SNV+ auto scaling & PCA, PLS-DA & {$[45]$} \\
\hline & $\begin{array}{l}\text { Low-, mid-, and high-level fusion strategies } \\
\text { for combining Raman } \\
\text { and infrared spectroscopy for quality } \\
\text { assessment of red meat }\end{array}$ & $\begin{array}{c}3306-3623 \\
5618-5847 \\
6734-9479 \\
5814-13,333\end{array}$ & $\mathrm{LBC}+\mathrm{SNV}+\mathrm{SG}-7$ & $\begin{array}{l}\text { Spectral peak } \\
\text { analysis and } \\
\text { band } \\
\text { assignments, } \\
\text { PLSR }\end{array}$ & {$[46]$} \\
\hline \multirow{2}{*}{$\begin{array}{l}\text { Proton nuclear } \\
\text { magnetic resonance } \\
(\mathrm{NMR})\end{array}$} & $\begin{array}{l}\text { Metabolite profiling of the post-ovulatory } \\
\text { oocytes of the common carp, Cyprinus carpio }\end{array}$ & Not reported & \multirow{2}{*}{$\begin{array}{l}\text { Normalization }+ \\
\text { auto scaling } \\
\text { Normalization }+ \\
\text { auto scaling }\end{array}$} & \multirow{2}{*}{$\begin{array}{l}\text { ANOVA, PCA, } \\
\text { PLS-DA } \\
\text { ANOVA, PCA, } \\
\text { PLS-DA }\end{array}$} & {$[42]$} \\
\hline & Molecular study of anesthesia in fish & $400 \mathrm{MHz}$ & & & {$[43]$} \\
\hline $\begin{array}{l}\text { Laser-induced } \\
\text { breakdown } \\
\text { spectroscopy }\end{array}$ & $\begin{array}{l}\text { Authentication of salami and } \\
\text { processed sausages }\end{array}$ & $186-900$ & Not reported & $\begin{array}{l}\text { PCA, PLSR, LOD, } \\
\text { LOQ }\end{array}$ & {$[174]$} \\
\hline $\begin{array}{l}\text { Laser-induced } \\
\text { breakdown } \\
\text { spectroscopy }\end{array}$ & $\begin{array}{l}\text { Discrimination of beef, chicken, and pork } \\
\text { from five different farms }\end{array}$ & $186-900$ & 1st der. & $\begin{array}{l}\text { PCA, PLSR, LOD, } \\
\text { LOQ }\end{array}$ & {$[52]$} \\
\hline $\begin{array}{l}\text { Laser micro-Raman } \\
\text { spectroscopy and } \\
\text { Fourier-transform } \\
\text { spectroscopy }\end{array}$ & $\begin{array}{l}\text { Effect of } \mathrm{NaNO}_{2} \text { on protein structure } \\
\text { changes during oxidation of myoglobin }\end{array}$ & $\begin{array}{l}6060-7410 \\
5882-6250\end{array}$ & Not reported & $\begin{array}{l}\text { Spectral peak } \\
\text { analysis and } \\
\text { band } \\
\text { assignments, } \\
\text { ANOVA }\end{array}$ & [175] \\
\hline
\end{tabular}

1st der. = first derivative; ANOVA: analysis of variance; EMSC: extended multiplicative scattering correction iPLS: interval partial least squares; LBC: linear baseline correction; LOD: limit of detection; LOQ: limit of quantification; MSC: multiplicative scatter correction; PCA: principal component analysis; PLS-DA: partial least squares discriminant analysis; PLSR: partial least squares regression; SG: Savitzky-Golay smoothing; SNV: standard normal variate; SVM: support vector machine.

Table 4. PLSR prediction of different quality parameters in meat and fish using near infrared spectroscopy.

\begin{tabular}{|c|c|c|c|c|c|c|c|}
\hline $\begin{array}{l}\text { Objective of } \\
\text { Study }\end{array}$ & $\begin{array}{l}\text { Spectral } \\
\text { Region } \\
(\mathrm{nm})\end{array}$ & $\begin{array}{l}\text { Predicted } \\
\text { Parameter }\end{array}$ & $\begin{array}{l}\text { Spectral } \\
\text { Pre- } \\
\text { Treatments }\end{array}$ & $\mathbf{R}^{2} \mathrm{~V}$ & RMSECV & Reference & Findings/Implications \\
\hline $\begin{array}{l}\text { Potential of NIR } \\
\text { to predict drip } \\
\text { loss and } \\
\text { intramuscular } \\
\text { (IMF) fat of pork }\end{array}$ & $780-1850$ & $\begin{array}{l}\text { Drip loss } \\
\text { Vacuum drip loss } \\
\text { Intramuscular fat }\end{array}$ & SNV & $\begin{array}{l}0.06 \\
0.12 \\
0.57\end{array}$ & $\begin{array}{l}1.69 \mathrm{~g} / 100 \mathrm{~g} \\
1.00 \mathrm{~g} / 100 \mathrm{~g} \\
0.11 \mathrm{~g} / 100 \mathrm{~g}\end{array}$ & [173] & $\begin{array}{l}\text { Regression coefficients from NIR } \\
\text { spectroscopy was only meaningful } \\
\text { for IMF models. This was attributed } \\
\text { to noisy spectra from regions } \\
\text { suspected to be drip loss regions }\end{array}$ \\
\hline $\begin{array}{l}\text { Potential of NIR } \\
\text { in predicting pork } \\
\text { belly softness }\end{array}$ & 780-1900 & $\begin{array}{l}\text { Lean } \\
\text { Intramuscular fat } \\
\text { Subcutaneous fat } \\
\text { lean } \\
\text { Subcutaneous fat }\end{array}$ & $\begin{array}{c}\mathrm{SNV}+\mathrm{DT} \\
\mathrm{SG} \\
\mathrm{SNV}+\mathrm{DT} \\
\mathrm{SNV}+\mathrm{DT}\end{array}$ & $\begin{array}{l}0.44 \\
0.72 \\
0.65 \\
0.66\end{array}$ & $\begin{array}{l}0.67 \mathrm{~g} / 100 \mathrm{~g} \\
0.44 \mathrm{~g} / 100 \mathrm{~g} \\
0.51 \mathrm{~g} / 100 \mathrm{~g} \\
0.49 \mathrm{~g} / 100 \mathrm{~g}\end{array}$ & {$[33]$} & $\begin{array}{l}\text { NIR offers the option of a } \\
\text { noninvasive pork belly softness } \\
\text { classification. This can be used for } \\
\text { export and merchandise in the } \\
\text { pork industry }\end{array}$ \\
\hline
\end{tabular}


Table 4. Cont.

\begin{tabular}{|c|c|c|c|c|c|c|c|}
\hline $\begin{array}{l}\text { Objective of } \\
\text { Study }\end{array}$ & $\begin{array}{c}\text { Spectral } \\
\text { Region } \\
(\mathrm{nm})\end{array}$ & $\begin{array}{l}\text { Predicted } \\
\text { Parameter }\end{array}$ & $\begin{array}{c}\text { Spectral } \\
\text { Pre- } \\
\text { Treatments }\end{array}$ & $\mathbf{R}^{2} \mathbf{v}$ & RMSECV & Reference & Findings/Implications \\
\hline $\begin{array}{l}\text { Determine the salt } \\
\text { content in fish } \\
\text { water phase in } \\
\text { marinated } \\
\text { herring fillets }\end{array}$ & $1000-2500$ & Salt & SNV & 0.91 & $0.27 \mathrm{~g} / 100 \mathrm{~g}$ & {$[176]$} & $\begin{array}{l}\text { NIR wavelength in the range of } \\
1170-1290 \text { nm holds information } \\
\text { related to the changes in salt, but } \\
\text { spectral ranges of } 1180-1290 \mathrm{~nm} \\
\text { contained information associated } \\
\text { with the change in salt of herring } \\
\text { marinade. These can be used } \\
\text { markers of quality in similar } \\
\text { fish species }\end{array}$ \\
\hline $\begin{array}{l}\text { Determination of } \\
\text { fat content in } \\
\text { commercial } \\
\text { chicken } \\
\text { hamburgers }\end{array}$ & $1000-2500$ & Fat & $\begin{array}{c}\text { iPLS } \\
\text { (MSC) } \\
\text { iSPA-PLS } \\
\text { (MSC) }\end{array}$ & $\begin{array}{l}0.76 \\
0.94\end{array}$ & $\begin{array}{l}3.59 \mathrm{~g} / 100 \mathrm{~g} \\
1.59 \mathrm{~g} / 100 \mathrm{~g}\end{array}$ & {$[177]$} & $\begin{array}{l}\text { Successive projections algorithm for } \\
\text { interval selection in partial least } \\
\text { squares regression (iSPA-PLS) } \\
\text { showed superior predictive } \\
\text { performance and can be used in } \\
\text { tandem with NIR for quality control } \\
\text { purposes in chicken hamburger }\end{array}$ \\
\hline
\end{tabular}

\section{Classification of}

intact chicken

breast fillets

(pectoralis major)

with PC scores

extracted from 5

quality traits: color,

$\mathrm{pH}$, drip loss (DL),

expressible fluid

(EF), and

salt-induced water

(SIW) as quality

parameters

Evaluate NIR

reflectance

spectroscopy as a

tool for detecting

lipid peroxidation

of light lamb meat

400-2500 $\begin{gathered}\text { Lipid } \\ \text { peroxidation }\end{gathered}$ Not stated $0.77 \quad 0.406$

\begin{tabular}{|c|c|c|c|}
\hline $\mathrm{pH}$ & & 0.77 & 1.91 \\
\hline Drip loss & Not stated & 0.40 & 0.19 \\
\hline $\begin{array}{c}\text { Expressible } \\
\text { fluid }\end{array}$ & Not stated & $\begin{array}{l}0.52 \\
0.83\end{array}$ & $\begin{array}{c}0.86 \mathrm{~g} / 100 \mathrm{~g} \\
0.36\end{array}$ \\
\hline
\end{tabular}

PC1 could represent the measured quality traits well and generated classification results similar to or better than those based on the quality traits alone

\begin{tabular}{|c|c|c|c|c|c|c|c|}
\hline $\begin{array}{l}\text { Evaluate the } \\
\text { feasibility of NIR } \\
\text { spectroscopy to } \\
\text { predict Sodium } \\
\text { (Na) content in } \\
\text { commercial processed } \\
\text { meat sample }\end{array}$ & 850-1050 & $\begin{array}{l}\text { Fresh meat } \\
\text { Cured meat } \\
\text { Dry meat } \\
\text { boiled } \\
\text { sausages }\end{array}$ & $\begin{array}{l}\text { SNV + DT } \\
\text { SNV + DT } \\
\text { MSC } \\
\text { None }\end{array}$ & $\begin{array}{l}0.91 \\
0.92 \\
0.97 \\
0.40\end{array}$ & $\begin{array}{l}0.08 \mathrm{~g} / 100 \mathrm{~g} \\
0.12 \mathrm{~g} / 100 \mathrm{~g} \\
0.07 \mathrm{~g} / 100 \mathrm{~g} \\
0.09 \mathrm{~g} / 100 \mathrm{~g}\end{array}$ & [59] & $\begin{array}{l}\text { NIR is more adaptable for } \\
\text { predicting Na content in fresh, } \\
\text { cured, and dry meat than in } \\
\text { sausages. Similar studies on fresh } \\
\text { sausages can help understand this } \\
\text { important phenomenon, as Na in } \\
\text { meat products has gained attention } \\
\text { for health reasons }\end{array}$ \\
\hline Predict chicken color & $400-2498$ & $\begin{array}{l}\text { Color (intact } \\
\text { chicken) } \\
\text { Color } \\
\text { (minced } \\
\text { chicken) }\end{array}$ & $\begin{array}{l}\text { None } \\
\text { MSC } \\
\text { None } \\
\text { MSC }\end{array}$ & $\begin{array}{l}0.91 \\
0.88 \\
0.89 \\
0.87\end{array}$ & $\begin{array}{l}1.99 \\
2.30 \\
1.93 \\
2.09\end{array}$ & {$[60]$} & $\begin{array}{l}\text { Spectral preprocessing techniques } \\
\text { did not improve the robustness of } \\
\text { prediction methods when compared } \\
\text { to the raw spectra }\end{array}$ \\
\hline $\begin{array}{l}\text { Predict the physical } \\
\text { traits of yak meat } \\
\text { using NIRS }\end{array}$ & 1000-1800 & $\begin{array}{l}\text { Color } \\
\text { Saturation } \\
\text { index } \\
\text { Shear force }\end{array}$ & $\begin{array}{l}\text { OSC }+ \text { DT } \\
+1 \text { st der. } \\
\text { D1 + OSC } \\
\text { D1 + OSC }\end{array}$ & $\begin{array}{l}0.71 \\
0.85 \\
0.46\end{array}$ & $\begin{array}{c}1.90 \\
1.63 \\
27.43\end{array}$ & [179] & $\begin{array}{l}\text { NIR spectra predictive performance } \\
\text { was worst for shear force } \\
\text { performance although it was better } \\
\text { for saturation index }\end{array}$ \\
\hline $\begin{array}{l}\text { Predict protein, } \\
\text { moisture and lipid } \\
\text { levels in } \\
\text { Tilapia fillets }\end{array}$ & $1000-2500$ & $\begin{array}{l}\text { Moisture } \\
\text { Crude } \\
\text { protein } \\
\text { Lipid }\end{array}$ & $\begin{array}{c}\mathrm{SNV}+ \\
\mathrm{MSC}\end{array}$ & $\begin{array}{l}0.95 \\
0.30 \\
0.97\end{array}$ & $\begin{array}{c}0.87 \\
0.55 \mathrm{~g} / 100 \mathrm{~g} \\
0.70 \mathrm{~g} / 100 \mathrm{~g}\end{array}$ & {$[180]$} & $\begin{array}{l}\text { NIRS showed good prediction level } \\
\text { for moisture and lipid, but weaker } \\
\text { results for crude protein in } \\
\text { tilapia fillets }\end{array}$ \\
\hline
\end{tabular}

1st der.: first-order derivative; DT = detrend; MSC = multiplicative scatter correction; OSC = orthogonal signal correction; $\mathrm{R}_{\mathrm{V}}^{2}$ = coefficient of determination of cross-validation; $\mathrm{SG}=$ Savitzky-Golay smoothing; $\mathrm{SNV}=\mathrm{standard}$ normal variate. 
Table 5. Overview of molecular spectroscopic techniques for authentication and adulteration determination in cultivated mushroom.

\begin{tabular}{|c|c|c|c|c|c|c|}
\hline $\begin{array}{l}\text { Spectroscopic } \\
\text { Technique }\end{array}$ & $\begin{array}{l}\text { Investigated } \\
\text { Parameter }\end{array}$ & $\begin{array}{c}\text { Spectral } \\
\text { Region (nm) }\end{array}$ & $\begin{array}{l}\text { Pre-Processing } \\
\text { Method }\end{array}$ & Chemometrics & Results & Reference \\
\hline $\begin{array}{l}\text { Vis/NIR } \\
\text { spectroscopy }\end{array}$ & $\begin{array}{l}\text { classification } \\
\text { Agaricus } \\
\text { bisporus quality: } \\
\text { water content, } \\
\text { Brix\% }\end{array}$ & $400-1000$ & SNV & PCA, PLS & No data on classification & [67] \\
\hline $\begin{array}{l}\text { Fourier- } \\
\text { transform } \\
\text { near-infrared } \\
\text { spectroscopy } \\
\text { (FT-NIR) }\end{array}$ & $\begin{array}{l}\text { classification } \\
\text { Pleurotus } \\
\text { ostreatus } \\
\text { cultivar } \\
\text { candidates }\end{array}$ & $1111-2630$ & SG-2nd der. & $\begin{array}{c}\text { PCA, LDA, } \\
\text { HCA }\end{array}$ & $\begin{array}{l}\text { Probability } \\
\text { Free amino acid: } 100 \% \\
\text { Cysteine, methionine, } \\
\text { proline: }>90 \% \\
\text { TPC, FRAP > } 83 \%\end{array}$ & [68] \\
\hline $\begin{array}{l}\text { Near-infrared } \\
\text { spectroscopy } \\
\text { (NIR) }\end{array}$ & $\begin{array}{l}\text { adulteration } \\
\text { "porcini" } \\
\text { mushroom }\end{array}$ & $1111-2500$ & $\begin{array}{c}\text { SNV, SG-11 } \\
\text { points 2nd der. }\end{array}$ & $\begin{array}{c}\text { PCA, } \\
\text { PLS-DM, } \\
\text { UNEQ, } \\
\text { SIMCA }\end{array}$ & $\begin{array}{l}\text { PCA: Tylopilus spp. and } \\
\text { the BEAS samples are well } \\
\text { separated, but there is } \\
\text { more overlap with the } \\
\text { Boletus violaceofuscus } \\
\text { samples } \\
\text { sensitivity } \\
\text { UNEQ: } 100 \% \\
\text { SIMCA: } 81.8 \%\end{array}$ & [75] \\
\hline
\end{tabular}

\begin{tabular}{|c|c|c|c|c|c|c|}
\hline \multirow{5}{*}{$\begin{array}{l}\text { Fourier- } \\
\text { transform } \\
\text { mid-infrared } \\
\text { spectroscopy } \\
\text { (FTIR) }\end{array}$} & $\begin{array}{l}\text { classification } \\
\text { aging; } \\
\text { fresh vs. } \\
\text { refrigerated }\end{array}$ & $\begin{array}{c}2500-3230 \\
3700-5880 \\
5880-25,000\end{array}$ & SNV & $\begin{array}{l}\text { RF, PCA, } \\
\text { PLS-DA }\end{array}$ & $\begin{array}{l}\text { sensitivity: } 89.2 \% \\
\text { specificity: } 91.2 \%\end{array}$ & [69] \\
\hline & $\begin{array}{l}\text { classification } \\
\text { geographical } \\
\text { origin: } \\
\text { B.edulis vs. B. } \\
\text { tomentipes }\end{array}$ & $5555-25,000$ & MSC, 2nd der. & $\begin{array}{l}\text { PCA, HCA, } \\
\text { PLS-DA }\end{array}$ & Accuracy: $100 \%$ & [71] \\
\hline & $\begin{array}{l}\text { authentication } \\
\text { geographical } \\
\text { Boletus } \\
\text { tomentipes }\end{array}$ & $\begin{array}{c}2700-3570 \\
4170-4350 \\
4760-25,000\end{array}$ & $\begin{array}{l}\text { SNV, SG-2nd } \\
\text { der. }\end{array}$ & $\begin{array}{c}\text { PCA, SVM, } \\
\text { RF }\end{array}$ & Accuracy $>94 \%$ & [72] \\
\hline & $\begin{array}{l}\text { classification } \\
\text { Boletaceae }\end{array}$ & $2500-25,000$ & $\begin{array}{l}\text { SG-15 points, } \\
\text { 2nd der., }\end{array}$ & SVM & Accuracy > 98\% & [74] \\
\hline & $\begin{array}{l}\text { classification } \\
\text { geographical } \\
\text { origin Boletaceae }\end{array}$ & $2500-25,000$ & $\begin{array}{c}\text { SNV, SG-15 } \\
\text { points, 2nd der., }\end{array}$ & $\begin{array}{l}\text { PCA, SVM, } \\
\text { PLS-DA }\end{array}$ & Accuracy > 99\% & [73] \\
\hline $\begin{array}{l}\text { Diffuse } \\
\text { reflectance } \\
\text { Fourier- } \\
\text { transform } \\
\text { mid-infrared } \\
\text { spectroscopy } \\
\text { (DRIFT) }\end{array}$ & $\begin{array}{l}\text { classification } \\
\text { Pleurotus taxa }\end{array}$ & $\begin{array}{c}5555-5880 \\
7353-7782 \\
8890-9360 \\
10,530-15,380\end{array}$ & SG-95 points & HCA & Successful classification & [70] \\
\hline
\end{tabular}


Table 6. Overview of molecular spectroscopic techniques for authentication and adulteration determination in spices.

\begin{tabular}{|c|c|c|c|c|c|c|}
\hline $\begin{array}{l}\text { Spectroscopic } \\
\text { Technique }\end{array}$ & $\begin{array}{l}\text { Investigated } \\
\text { Parameter }\end{array}$ & $\begin{array}{c}\text { Spectral } \\
\text { Region (nm) }\end{array}$ & $\begin{array}{l}\text { Preprocessing } \\
\text { Method }\end{array}$ & Chemometrics & Results & Reference \\
\hline UV/Vis spectroscopy & $\begin{array}{l}\text { classification } \\
\text { geographical origin } \\
\text { turmeric }\end{array}$ & $200-800$ & SNV & PCA, HCA & $\begin{array}{l}\text { Unsuccessful } \\
\text { clustering }\end{array}$ & {$[78]$} \\
\hline \multirow{7}{*}{$\begin{array}{l}\text { Near-infrared } \\
\text { spectroscopy } \\
\text { (NIRS) }\end{array}$} & $\begin{array}{l}\text { classification } \\
\text { geographic origin } \\
\text { saffron }\end{array}$ & $1610-2530$ & 2nd der. & PCR & $\begin{array}{l}\text { Pattern } \\
\text { recognition for } \\
\text { Iranian samples } \\
100 \%\end{array}$ & {$[77]$} \\
\hline & $\begin{array}{l}\text { adulteration } \\
\text { chili }\end{array}$ & $1110-2500$ & SNV, MSC, SG & $\begin{array}{l}\text { PCA, PLS-DA, } \\
\text { PCR, PLS }\end{array}$ & LOD $0.25 \%$ & {$[181]$} \\
\hline & $\begin{array}{l}\text { adulteration } \\
\text { turmeric }\end{array}$ & $1350-1550$ & $\begin{array}{l}\text { SNV, MSC, 1st } \\
\text { der. 2nd der. }\end{array}$ & PCA, PCR, PLSR & $\begin{array}{l}\text { Prediction ability: } \\
\mathrm{Q}^{2}=0.993\end{array}$ & [87] \\
\hline & $\begin{array}{l}\text { adulteration } \\
\text { black pepper }\end{array}$ & $1100-2300$ & $\mathrm{BC}$ & PCA & $\begin{array}{l}\text { Discrimination: } \\
\text { pepper vs. } \\
\text { papaya: } 100 \%\end{array}$ & {$[86]$} \\
\hline & & 833-1100 & SNV, SG-der & PCA, OPLS-DA & $\begin{array}{l}\text { Prediction ability: } \\
\mathrm{Q}^{2}=0.98\end{array}$ & [88] \\
\hline & $\begin{array}{l}\text { classification } \\
\text { geographic origin } \\
\text { cinnamon } \\
\text { adulteration } \\
\text { cinnamon }\end{array}$ & $\begin{array}{c}944-1640 \\
1850-2500\end{array}$ & Not reported & $\begin{array}{c}\text { PCA, PLS, } \\
\text { PLS-DA, PNN, }\end{array}$ & $\begin{array}{l}\text { Discrimination: } \\
99.25 \% \\
\mathrm{R}^{2}: 0.97\end{array}$ & {$[83,84]$} \\
\hline & $\begin{array}{l}\text { adulteration } \\
\text { coriander seed }\end{array}$ & $\begin{array}{l}\text { A. } 740-1070 \\
\text { B. } 1350-2550 \\
\text { C. } 1100-1350 \\
1350-1650 \\
1550-1950 \\
1750-2150 \\
2000-2450\end{array}$ & $\begin{array}{l}\text { SNV, SG-35 } \\
\text { points, 1st der., } \\
\text { 2nd der. }\end{array}$ & PLS-DA, PLS-R & $\begin{array}{l}\text { Discrimination: } \\
100 \%\end{array}$ & {$[85]$} \\
\hline \multirow{3}{*}{$\begin{array}{l}\text { Fourier-transform } \\
\text { mid-infrared } \\
\text { spectroscopy (FTIR) }\end{array}$} & $\begin{array}{l}\text { classification } \\
\text { geographical origin } \\
\text { turmeric }\end{array}$ & $2500-25,000$ & SNV & PCA, HCA & $\begin{array}{l}\text { Unsuccessful } \\
\text { clustering }\end{array}$ & [89] \\
\hline & $\begin{array}{l}\text { adulteration } \\
\text { paprika }\end{array}$ & $2500-15,400$ & SNV & NAS, HLA & $\begin{array}{l}\mathrm{R}^{2}=0.97 \\
\mathrm{RMSEP}=0.05 \%\end{array}$ & {$[89,90]$} \\
\hline & $\begin{array}{l}\text { adulteration } \\
\text { turmeric }\end{array}$ & $\begin{array}{l}6262-10,030 \\
6060-14,280\end{array}$ & $\begin{array}{l}\text { SG-3 points } \\
\text { Not reported }\end{array}$ & $\begin{array}{c}\text { Single peak } \\
\text { intensity, ratio of } \\
\text { peak intensity, } \\
\text { and intensity at a } \\
\text { neutral band } \\
\text { PLSR }\end{array}$ & $\begin{array}{l}\mathrm{R}^{2}=0.95 \\
\mathrm{R}^{2}=0.97 \text { and } \mathrm{R}^{2} \\
=0.95\end{array}$ & $\begin{array}{l}{[96]} \\
{[84]}\end{array}$ \\
\hline \multirow{3}{*}{$\begin{array}{l}\text { Attenuated total } \\
\text { reflectance } \\
\text { Fourier-transform } \\
\text { infrared spectroscopy } \\
\text { (ATR-FTIR) }\end{array}$} & $\begin{array}{l}\text { adulteration } \\
\text { cinnamon }\end{array}$ & $2850-5560$ & $\begin{array}{l}\text { SNV, MSC, SG-4 } \\
\text { points 2nd der. }\end{array}$ & PLSR & $\mathrm{R}^{2}: 0.96$ & {$[84]$} \\
\hline & $\begin{array}{l}\text { adulteration } \\
\text { black pepper }\end{array}$ & $3570-5560$ & SNV, SG-der & PCA, OPLS-DA & $\begin{array}{l}\text { Prediction ability: } \\
\mathrm{Q}^{2}=0.97\end{array}$ & [88] \\
\hline & $\begin{array}{l}\text { adulteration } \\
\text { oregano }\end{array}$ & $5560-11,100$ & SNV, SG-2nd der. & PCA, OPLS-DA & $\begin{array}{l}\mathrm{Q}^{2}=0.96 \\
\mathrm{RMSECV}=9.7 \%\end{array}$ & {$[90,92]$} \\
\hline $\begin{array}{l}\text { Diffuse reflectance } \\
\text { Fourier-transform } \\
\text { mid-infrared } \\
\text { spectroscopy (DRIFT) }\end{array}$ & $\begin{array}{l}\text { adulteration } \\
\text { saffron }\end{array}$ & $2500-16,700$ & $\begin{array}{l}\text { BC, MC, MSC, } \\
\text { SNV, SG 1st der. }\end{array}$ & $\begin{array}{l}\text { PCA, PLS-DA, } \\
\text { PLS, siPLS }\end{array}$ & Discrimination: 99\% & {$[90,91]$} \\
\hline Raman spectroscopy (RS) & $\begin{array}{l}\text { adulteration } \\
\text { paprika }\end{array}$ & $5550-11,100$ & Not reported & PLSR & $\% C C=89$ & [93] \\
\hline $\begin{array}{l}\text { Raman hyperspectral } \\
\text { imaging system (R-HSI) }\end{array}$ & $\begin{array}{l}\text { adulteration } \\
\text { paprika }\end{array}$ & 785 & $\mathrm{BC}$ & QRM & $\mathrm{R}^{2}>0.98$ & {$[85,89]$} \\
\hline \multirow[b]{2}{*}{$\begin{array}{l}\text { Fourier-transform } \\
\text { raman spectroscopy } \\
\text { (FT-RS) }\end{array}$} & $\begin{array}{l}\text { adulteration } \\
\text { chili }\end{array}$ & $5560-12,500$ & SNV, MSC, SG & $\begin{array}{l}\text { PCA, PLS-DA, } \\
\text { PCR, PLS }\end{array}$ & LOD $0.88 \%$ & {$[181]$} \\
\hline & $\begin{array}{l}\text { adulteration } \\
\text { turmeric }\end{array}$ & $3570-11,760$ & SG-3 points, MSC & $\begin{array}{c}\text { Single peak } \\
\text { intensity, ratio of } \\
\text { peak intensity, } \\
\text { and intensity at a } \\
\text { neutral band }\end{array}$ & $\mathrm{R}^{2}=0.93$ & {$[96,98]$} \\
\hline $\begin{array}{l}\text { Sensor combining } \\
\text { Raman spectroscopy } \\
\text { (SERS) }\end{array}$ & $\begin{array}{l}\text { adulteration } \\
\text { paprika }\end{array}$ & $\begin{array}{c}8100-8260 \\
13,800-14,100\end{array}$ & $\mathrm{BC}$ & PCA, PLSR & $\mathrm{Q}^{2}=0.978$ & [85] \\
\hline
\end{tabular}


Table 6. Cont.

\begin{tabular}{|c|c|c|c|c|c|c|}
\hline $\begin{array}{l}\text { Spectroscopic } \\
\text { Technique }\end{array}$ & $\begin{array}{c}\text { Investigated } \\
\text { Parameter }\end{array}$ & $\begin{array}{c}\text { Spectral } \\
\text { Region (nm) }\end{array}$ & $\begin{array}{l}\text { Preprocessing } \\
\text { Method }\end{array}$ & Chemometrics & Results & Reference \\
\hline \multirow{4}{*}{$\begin{array}{l}\text { Nuclear magnetic } \\
\text { resonance }\left({ }^{1} \mathrm{H}-\mathrm{NMR}\right)\end{array}$} & $\begin{array}{l}\text { classification } \\
\text { geographical origin } \\
\text { saffron }\end{array}$ & $600 \mathrm{MHz}$ & $\mathrm{MC}$ & PCA & Not reported & {$[80]$} \\
\hline & $\begin{array}{l}\text { classification } \\
\text { geographical origin } \\
\text { turmeric }\end{array}$ & $\begin{array}{l}400 \mathrm{MHz} \\
500 \mathrm{MHz}\end{array}$ & $\begin{array}{l}\text { Not reported } \\
\mathrm{BC}\end{array}$ & $\begin{array}{l}\text { PCA, HCA } \\
\text { PLS-DA, } \\
\text { OPLS-DA }\end{array}$ & $\begin{array}{l}\text { Classification: } 100 \% \\
\mathrm{Q}^{2}: 0.706\end{array}$ & $\begin{array}{l}{[78]} \\
{[79]}\end{array}$ \\
\hline & $\begin{array}{l}\text { classification } \\
\text { geographical origin } \\
\text { cinnamon }\end{array}$ & $600 \mathrm{MHz}$ & $\mathrm{MC}$ & PCA, OPLS-DA & $\mathrm{Q}^{2}=0.65$ & [81] \\
\hline & $\begin{array}{l}\text { adulteration } \\
\text { saffron }\end{array}$ & $500 \mathrm{MHz}$ & Not reported & PCA, PLS-DA & sensitivity: $100 \%$ & [99] \\
\hline
\end{tabular}

$\mathrm{BC}=$ baseline correction; \% CC: percentage of correctly classified samples, HCA = hierarchal cluster analysis $\mathrm{HLA}=$ hybrid linear analysis, $\mathrm{MC}=$ mean centering, MSC = multiplicative scatter correction; NAS = a net analyte signal; OPLS-DA =orthogonal partial least square discriminant analysis; PLS-DA = partial least squares discriminate analysis; QRM = quadratic regression model; SG-2nd = Savitzky-Golay; siPLS = synergy interval PLS; SNV = standard normal variate; $S V M=$ support vector machine; UNEQ = modeling version of quadratic discriminant analysis.

Table 7. Overview of molecular spectroscopic techniques for authentication and adulteration determination in coffee bean, roasted coffee, and grounded coffee.

\begin{tabular}{|c|c|c|c|c|c|c|}
\hline $\begin{array}{l}\text { Spectroscopic } \\
\text { Technique }\end{array}$ & $\begin{array}{l}\text { Investigated } \\
\text { Parameter }\end{array}$ & $\begin{array}{c}\text { Spectral } \\
\text { Region (nm) }\end{array}$ & $\begin{array}{c}\text { Pre-Processing } \\
\text { Method }\end{array}$ & Chemometrics & Statistical Parameters & Reference \\
\hline \multirow{5}{*}{$\begin{array}{l}\text { Fourier-transform } \\
\text { near-infrared } \\
\text { spectroscopy } \\
\text { (FT-NIR) }\end{array}$} & $\begin{array}{l}\text { identification } \\
\text { geographical } \\
\text { origin }\end{array}$ & 1000-2500 & $\begin{array}{c}\text { SNV, MSC, } \\
\text { SG-1st der., } \\
\text { SG-2nd der., } \\
\text { SNV + SG-1st der., } \\
\text { SNV + SG-2nd der., } \\
\text { MSC + SG-1st der., } \\
\text { MSC + SG-2nd der. }\end{array}$ & PLS-DA & $\begin{array}{l}\text { Continent-based } \\
\text { classification }>98 \% \\
\text { City-based classification } \\
100 \%\end{array}$ & {$[110]$} \\
\hline & $\begin{array}{l}\text { identification } \\
\text { geographical } \\
\text { origin } \\
\text { roasting type }\end{array}$ & $800-2500$ & No preprocessing & PCA, LDA & $\begin{array}{l}\text { Roasting method } 100 \% \\
\text { Geographical origin: } \\
100 \%\end{array}$ & [111] \\
\hline & $\begin{array}{l}\text { identification } \\
\text { Arabica/Robusta } \\
\text { ratio }\end{array}$ & $\begin{array}{l}1580-1750 \\
1820-1890 \\
1970-2240\end{array}$ & $\begin{array}{l}\text { SNV, 1st der., BC, 2nd } \\
\text { der. }\end{array}$ & PLS & $\begin{array}{l}\text { RMSECV: } 4.58 \% \\
\text { RMSEP: } 4.34 \% \\
\text { R }^{2}: 0.97 \\
\text { Bias: }-4.10^{-3}\end{array}$ & {$[112]$} \\
\hline & $\begin{array}{l}\text { identification } \\
\text { coffee leaves }\end{array}$ & $800-2500$ & SG-17 points 2nd der. & PCA, SIMCA & Classification rate: $100 \%$ & {$[113]$} \\
\hline & $\begin{array}{l}\text { classification } \\
\text { geographical } \\
\text { origin }\end{array}$ & 1100-2498 & MSC & SVM, PCA & $\begin{array}{l}\text { SV: } 10-25 \\
\text { Accuracy: } 1.0000 \\
\text { SENS: } 1.0000 \\
\text { SPEC: } 1.0000\end{array}$ & {$[116]$} \\
\hline \multirow{2}{*}{$\begin{array}{l}\text { Near-infrared } \\
\text { spectroscopy (NIRS) }\end{array}$} & $\begin{array}{l}\text { authentication } \\
\text { geographic and } \\
\text { genotypic origin } \\
\text { Arabica }\end{array}$ & $1100-2498$ & $\mathrm{MSC}+\mathrm{SG}-2 \mathrm{nd}$ & PLS-DA & $\begin{array}{l}\text { Geographic origin } \\
\text { (Sample from Londrina } \\
\text {-south of Brazil): } \\
\text { RMSEP: } 0.1024 \\
\text { SENS: } 1.0000 \\
\text { SPEC: } 1.0000 \\
\text { Genotip origin (IA59 } \\
\text { cultivated variety) } \\
\text { RMSEP: } 0.1585 \\
\text { SENS: } 1.0000 \\
\text { SPEC: } 1.0000\end{array}$ & {$[106]$} \\
\hline & $\begin{array}{l}\text { classification } \\
\text { Robusta varieties }\end{array}$ & $1000-2500$ & $\begin{array}{l}\text { MSC, EMSC, SNV } \\
\text { SG-15 points 1st der. } \\
\text { OSC }\end{array}$ & $\begin{array}{c}\text { PCA } \\
\text { PLS-DA; } \\
\text { SIMCA, SOM, } \\
\text { SVM, }\end{array}$ & $\begin{array}{l}\text { MCC } \\
\text { SIMCA: } 0.922-1.000 \\
\text { PLS-DA: } 0.430-1.000 \text { (1st) } \\
\text { PLS-DA: } 0.841-1.000 \\
\text { (OSC) } \\
\text { SVM (4PCs): } 0.922-1.000 \\
\text { SOM: } 1.000\end{array}$ & [107] \\
\hline
\end{tabular}


Table 7. Cont.

\begin{tabular}{|c|c|c|c|c|c|c|}
\hline $\begin{array}{l}\text { Spectroscopic } \\
\text { Technique }\end{array}$ & $\begin{array}{c}\text { Investigated } \\
\text { Parameter }\end{array}$ & $\begin{array}{c}\text { Spectral } \\
\text { Region (nm) }\end{array}$ & $\begin{array}{l}\text { Pre-Processing } \\
\text { Method }\end{array}$ & Chemometrics & Statistical Parameters & Reference \\
\hline & $\begin{array}{l}\text { authentication } \\
\text { roasting } \\
\text { conditions, } \\
\text { geographical } \\
\text { origin } \\
\text { varietal origin }\end{array}$ & $1000-2500$ & SNV & $\begin{array}{l}\text { ASCA, } \\
\text { PLS-DA } \\
\text { SIMCA }\end{array}$ & $\begin{array}{l}\text { Classification: } 98 \% \\
\text { SENS > } 0.9000 \\
\text { SPEC > } 0.9000\end{array}$ & {$[114]$} \\
\hline & $\begin{array}{l}\text { authentication: } \\
\text { geographical } \\
\text { origin } \\
\text { farming system }\end{array}$ & $1400-1500$ & $\begin{array}{l}\text { SNV, Detrending, } \\
\text { SG.9 points, LDA, } \\
\text { LDA-SVM, } \\
\text { LDA-kNN }\end{array}$ & PLS-DA & $\begin{array}{l}\text { geographical origin. } 39 \% \\
\text { farming system: } 89 \%\end{array}$ & {$[108]$} \\
\hline & $\begin{array}{l}\text { authentication } \\
\text { specialty type }\end{array}$ & $900-1650$ & SG-11 points 2nd der. & $\begin{array}{l}\text { PCA, HCA, } \\
\text { SIMCA, ED }\end{array}$ & CCR: $87-100 \%$ & [109] \\
\hline & $\begin{array}{l}\text { adulteration } \\
\text { peels/sticks, corn, } \\
\text { Robusta coffee in } \\
\text { three roasting } \\
\text { levels }\end{array}$ & $908-1676$ & SG-7 points 1st der. & PCA, PLS & $\begin{array}{l}\text { adulterant with } \\
\text { peels/sticks } \\
\text { RMSEP: } 11.4 \% w / w \\
\mathrm{R}^{2}: 0.8589 \\
\text { adulterant with corn } \\
\text { RMSEP: } 4.0 \% w / w \\
\mathrm{R}^{2}: 0.9788 \\
\text { roasting level } \\
\text { RMSEP: } 2.8-6.6 \% w / w \\
\mathrm{R}^{2}: 0.9700-0.9925\end{array}$ & {$[115]$} \\
\hline & $\begin{array}{l}\text { adulteration } \\
\text { with barley }\end{array}$ & $\begin{array}{l}1660-1740 \\
2050-2090 \\
2130-2340\end{array}$ & No data pretreatment & PLS + GA & RMSEP: $0.8-1.4 \%, w / w$ & {$[121,122]$} \\
\hline \multirow{3}{*}{$\begin{array}{l}\text { Fourier-transform } \\
\text { mid-infrared } \\
\text { spectroscopy (FTIR) }\end{array}$} & $\begin{array}{l}\text { classification } \\
\text { geographical } \\
\text { origin }\end{array}$ & $5560-12,500$ & MSC & SVM, PCA & $\begin{array}{l}\text { SV: } 34-55 \\
\text { Accuracy: } 0.9504-0.9835 \\
\text { SENS: 08889-1.0000 } \\
\text { SPEC }=0.9412-1.0000\end{array}$ & {$[116]$} \\
\hline & $\begin{array}{l}\text { classification } \\
\text { geographical } \\
\text { origin } \\
\text { genotypic origin }\end{array}$ & $2670-13,300$ & SNV & $\begin{array}{l}\text { RBF } \\
\text { SIMCA } \\
\text { MLP }\end{array}$ & $\begin{array}{l}\text { geographically } 100 \% \\
\text { genotypically } 94.44 \%\end{array}$ & {$[118]$} \\
\hline & $\begin{array}{l}\text { identification } \\
\text { traditional vs. } \\
\text { genetically } \\
\text { modified } \\
\text { cultivars }\end{array}$ & $\begin{array}{l}2780-3130 \\
6250-9090\end{array}$ & No data pretreatment & PCA & Not reported & [119] \\
\hline $\begin{array}{l}\text { Diffuse reflectance } \\
\text { Fourier-transform } \\
\text { mid-infrared } \\
\text { spectroscopy (DRIFT) }\end{array}$ & $\begin{array}{l}\text { adulteration } \\
\text { with barley, corn, } \\
\text { coffee husks }\end{array}$ & $\begin{array}{c}3333-3570 \\
5560-14,300\end{array}$ & SNV, BC & PCA & $\begin{array}{l}\text { Recognition and } \\
\text { prediction } 100 \%\end{array}$ & {$[123]$} \\
\hline \multirow{5}{*}{$\begin{array}{l}\text { Attenuated total } \\
\text { reflectance } \\
\text { Fourier-transform } \\
\text { infrared spectroscopy } \\
\text { (ATR-FTIR) }\end{array}$} & $\begin{array}{l}\text { authentication } \\
\text { geographical } \\
\text { origin }\end{array}$ & $3230-3640$ & no data pre-treatment & PCA, SIMCA & Classification rate: $100 \%$ & {$[101]$} \\
\hline & $\begin{array}{l}\text { adulteration } \\
\text { Sibutramine }\end{array}$ & $3640-3770$ & SNV + 1st der. & $\begin{array}{l}\text { HCA, PCA, } \\
\text { k-NN }\end{array}$ & Accuracy: $100 \%$ & {$[125]$} \\
\hline & $\begin{array}{l}\text { adulteration } \\
\text { defective and non- } \\
\text { defective Arabica } \\
\text { coffee bean }\end{array}$ & $\begin{array}{l}3230-3310 \\
5560-5630 \\
6440-6750\end{array}$ & $\mathrm{BC}, \mathrm{SNV}$ & PCA, HCA & Accuracy: 100\% & {$[102]$} \\
\hline & $\begin{array}{l}\text { adulteration } \\
\text { roasted barley } \\
\text { roasted maize }\end{array}$ & $2500-14,300$ & SNV & $\begin{array}{l}\text { PLS-DA } \\
\text { HM, DF }\end{array}$ & $\begin{array}{l}\text { First-level models: } \\
\text { unadulter- } \\
\text { ated/adulterated } \\
\text { misclassification: } \\
\text { ATR: } 4.5 \% \text {; DR:3.3\% } \\
\text { Second-level models } \\
\text { Identity of each specific } \\
\text { adulterant } \\
\text { Misclassification: } 0 \%\end{array}$ & {$[90,124]$} \\
\hline & $\begin{array}{l}\text { adulteration } \\
\text { blends }\end{array}$ & $5260-12,500$ & 1st der., 2nd der. & PCR, PLS & $\mathrm{R}^{2}=0.999$ & {$[100]$} \\
\hline
\end{tabular}


Table 7. Cont.

\begin{tabular}{|c|c|c|c|c|c|c|}
\hline $\begin{array}{l}\text { Spectroscopic } \\
\text { Technique }\end{array}$ & $\begin{array}{l}\text { Investigated } \\
\text { Parameter }\end{array}$ & $\begin{array}{c}\text { Spectral } \\
\text { Region (nm) }\end{array}$ & $\begin{array}{l}\text { Pre-Processing } \\
\text { Method }\end{array}$ & Chemometrics & Statistical Parameters & Reference \\
\hline \multirow{3}{*}{$\begin{array}{l}\text { NIR hyperspectral } \\
\text { imaging system } \\
\text { (NIR-HSI) }\end{array}$} & $\begin{array}{l}\text { classification } \\
\text { Arabica/Robusta }\end{array}$ & $\begin{array}{l}1150 ; 1200 ; \\
1250 ; 1400\end{array}$ & Not reported & $\begin{array}{l}\text { PLS-DA; } \\
\text { sPLS-DA }\end{array}$ & $\begin{array}{l}\text { Average spectra } \\
\text { EFF }_{\mathrm{CV}}: 97.3-99.3 \\
\text { EFF }_{\mathrm{TEST}}: 94.0-98.3\end{array}$ & {$[126]$} \\
\hline & $\begin{array}{l}\text { classification } \\
\text { Arabica/Robusta }\end{array}$ & $900-1700$ & MA, EMD, MF, WT & SVM & Classification: $88.4-90.9 \%$ & [117] \\
\hline & $\begin{array}{l}\text { classification } \\
\text { Arabica/Robusta }\end{array}$ & $874-1734$ & Not reported & $\begin{array}{l}\text { PLS-DA, RF, } \\
\text { SVM, k-NN, } \\
\text { ELM }\end{array}$ & Classification: 97\% & {$[120]$} \\
\hline $\begin{array}{l}\text { Fourier-transform } \\
\text { Raman spectroscopy } \\
\text { (FT-RS) }\end{array}$ & $\begin{array}{l}\text { botanical origin: } \\
\text { Arabica/Robusta }\end{array}$ & $\begin{array}{l}5880-7140 \\
6380 ; 6770\end{array}$ & $\mathrm{BC}, \mathrm{SNV}$ & PCA & $\begin{array}{l}\text { PC1 }=93 \% ; P C 2=3 \% \\
\text { Accuracy: } 100 \%\end{array}$ & {$[127]$} \\
\hline \multirow{5}{*}{$\begin{array}{l}\text { Nuclear magnetic } \\
\text { resonance (NMR) }\end{array}$} & $\begin{array}{l}\text { origin } \\
\text { Arabica/Robusta }\end{array}$ & $\begin{array}{l}400 \mathrm{MHz} \\
7.85 \mathrm{ppm} \\
9.20 \mathrm{ppm}\end{array}$ & Not reported & $\begin{array}{c}\text { PCA, } \\
\text { PLS-DA }\end{array}$ & $\begin{array}{l}\text { SEN: } 95-95 \% \\
\text { SPEC: } 96-97 \%\end{array}$ & [132] \\
\hline & $\begin{array}{l}\text { geographical } \\
\text { origins } \\
\text { Arabica/Robusta } \\
\text { and blends }\end{array}$ & $500 \mathrm{MHz}$ & Not reported & OPLS-DA & Classification: $100 \%$ & {$[128,130]$} \\
\hline & $\begin{array}{l}\text { classified } \\
\text { according to } \\
\text { quality }\end{array}$ & 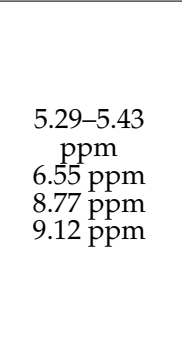 & $\begin{array}{l}\text { Signal alignment, area } \\
\text { normalization, auto } \\
\text { scaling of the data }\end{array}$ & PCA & $\begin{array}{l}\text { Lipids, organic and } \\
\text { caffeoylquinic acids: } \\
\text { unique characteristics in } \\
\text { order to discriminate } \\
\text { them from the other } \\
\text { samples } \\
\text { gourmet/superior } \\
\text { Quality samples had as } \\
\text { descriptors the malic, } \\
\text { citric and caffeoylquinic } \\
\text { acids }\end{array}$ & {$[136]$} \\
\hline & $\begin{array}{l}\text { authenticity } \\
\text { Arabica }\end{array}$ & $\begin{array}{l}60 \mathrm{MHz} \\
600 \mathrm{MHz} \\
3.16 \mathrm{ppm}\end{array}$ & Not reported & Not reported & Accuracy: 100\% & {$[135]$} \\
\hline & authenticity & $600.13 \mathrm{MHz}$ & $\begin{array}{l}\text { Mean centering, } \\
\text { smoothing, SNV }\end{array}$ & PCA, SIMCA & Classification: $100 \%$ & [134] \\
\hline
\end{tabular}

ASCA = ANOVA simultaneous component analysis; $\mathrm{BC}=$ baseline correction; $\mathrm{CCR}=$ correct classification rate $\mathrm{DF}=$ data fusion; $\mathrm{ED}=$ Euclidean distance $; \mathrm{EDF}=$ empirical mode decomposition; $\mathrm{EFF}_{\mathrm{CV}}=$ classification efficiency values of cross-validation; $\mathrm{EFF}_{\mathrm{TEST}}=$ classification efficiency values of test validation; $\mathrm{EMSC}=$ extended multiplicative scattering correction; $\mathrm{EX} / \mathrm{EM}=$ excitation-emission pairs; GA = genetic algorithm; HCA = hierarchical cluster analysis; $\mathrm{HM}$ = hierarchical models; $\mathrm{k}-\mathrm{NN}$ = k-nearest neighbors; LDA = linear discriminant analysis; $\mathrm{MA}=\mathrm{moving}$ average smoothing; $\mathrm{MCC}=$ Matthews correlation coefficient; MF = median filter; MSC = multiplicative scatter correction; NMC = number of misclassifications; NPLS-DA = superior order or N Partial least squares or multilinear PLS discriminant analysis; OPLS-DA = orthogonal projections to latent structures discriminant analysis OSC = orthogonal signal correction; PARAFAC = parallel factor analysis; RBF = radial basis function network; SENS = sensitivity; SG-1st der. = Savitzky-Golay first derivative; SG-2nd der. = Savitzky-Golay second derivative SIMCA = soft independent modeling of class analogies; SNV = standard normal variation; $\mathrm{SPEC}=$ specificity sPLS-DA = sparse PLS-DA; SV = support vectors; UPLS-DA = unfolded partial least squares with discriminant analysis; $\mathrm{WT}=$ wavelet transform.

Table 8. Overview of molecular spectroscopic techniques for authentication and adulteration determination in tea.

\begin{tabular}{|c|c|c|c|c|c|c|}
\hline $\begin{array}{l}\text { Spectroscopic } \\
\text { Technique }\end{array}$ & Investigated Parameter & $\begin{array}{c}\text { Spectral } \\
\text { Region (nm) }\end{array}$ & $\begin{array}{l}\text { Pre-Processing } \\
\text { Method }\end{array}$ & Chemometrics & Results & Reference \\
\hline \multirow{3}{*}{$\begin{array}{l}\mathrm{UV} / \mathrm{Vis} \\
\text { spectroscopy }\end{array}$} & $\begin{array}{l}\text { identification } \\
\text { green tea varieties }\end{array}$ & $200-800$ & - & PCA, RF, PLSR & $\begin{array}{l}\text { Successful } \\
\text { discrimination of } \\
3 \text { varieties from } 5\end{array}$ & {$[141]$} \\
\hline & $\begin{array}{l}\text { authentication } \\
\text { green tea varieties }\end{array}$ & $\begin{array}{l}200-400 \\
400-800\end{array}$ & & PCA, HCA & Not reported & {$[142]$} \\
\hline & $\begin{array}{l}\text { adulteration: } \\
\text { Matcha vs. green tea }\end{array}$ & $500-700$ & - & $\begin{array}{l}\text { PCA, LDA, } \\
\text { SIMCA, PLS }\end{array}$ & Accuracy: $100 \%$ & {$[150]$} \\
\hline
\end{tabular}


Table 8. Cont.

\begin{tabular}{|c|c|c|c|c|c|c|}
\hline $\begin{array}{l}\text { Spectroscopic } \\
\text { Technique }\end{array}$ & Investigated Parameter & $\begin{array}{c}\text { Spectral } \\
\text { Region (nm) }\end{array}$ & $\begin{array}{l}\text { Pre-Processing } \\
\text { Method }\end{array}$ & Chemometrics & Results & Reference \\
\hline $\begin{array}{l}\text { Fourier-transform } \\
\text { near-infrared } \\
\text { spectroscopy } \\
\text { (FT-NIRS) }\end{array}$ & $\begin{array}{l}\text { adulteration: } \\
\text { sugar and glucose syrup }\end{array}$ & $1450-2440$ & $\begin{array}{c}\text { SNV, MSC, } \\
\text { MIN /MAX, 1st der., } \\
\text { 2nd de., 1st + SLS, } \\
\text { 1st +SNV, 1st + } \\
\text { MSC }\end{array}$ & PLS & $\begin{array}{l}\text { Accuracy: } 96 \% \\
\text { (sugar) } 100 \% \\
\text { (glucose syrup) }\end{array}$ & {$[152]$} \\
\hline \multirow{3}{*}{$\begin{array}{l}\text { Near-infrared } \\
\text { spectroscopy } \\
\text { (NIRS) }\end{array}$} & $\begin{array}{l}\text { identification } \\
\text { green tea varieties }\end{array}$ & $1000-2500$ & $\begin{array}{l}\text { SNV, MSC, } \\
\text { SG-1st }\end{array}$ & PCA, RF, PLSR & $\begin{array}{l}\text { Successful } \\
\text { discrimination of } \\
\text { all } 5 \text { varieties }\end{array}$ & {$[141]$} \\
\hline & $\begin{array}{l}\text { identification } \\
\text { green, black, and } \\
\text { Oolong tea varieties }\end{array}$ & $9090-2500$ & $\begin{array}{l}\text { SNV, SG-1st, } \\
\text { SG-2nd }\end{array}$ & SVM, PCA & $\begin{array}{l}\text { Identification rate: } \\
\text { green tea: } 95 \% \\
\text { black tea: } 100 \% \\
\text { Oolong tea: } 90 \%\end{array}$ & {$[143,144]$} \\
\hline & $\begin{array}{l}\text { adulteration: } \\
\text { Darjeeling vs. } \\
\text { Ceylon tea }\end{array}$ & $1000-2000$ & $\begin{array}{l}\text { SNV, SG-15 points, } \\
\text { 1st, 2nd der. } \\
\text { SNV + 1st der. + } \\
\text { mean centering }\end{array}$ & PLS-DA, SIMCA & $\begin{array}{l}\text { Correct } \\
\text { classification: } \\
92.3-100 \%\end{array}$ & {$[151]$} \\
\hline \multirow{3}{*}{$\begin{array}{l}\text { Fourier-transform } \\
\text { mid-infrared } \\
\text { spectroscopy (FTIR) }\end{array}$} & $\begin{array}{l}\text { authentication } \\
\text { green, yellow, white, } \\
\text { black, and Oolong tea }\end{array}$ & $2500-25,000$ & SNV & $\begin{array}{c}\text { PCA, HCA, } \\
\text { PLS-DA, SIMCA }\end{array}$ & $\begin{array}{l}\text { Modeling power } \\
\text { nearly } 0.85\end{array}$ & {$[146]$} \\
\hline & $\begin{array}{l}\text { authentication } \\
\text { different tea varieties } \\
\text { geographical origin }\end{array}$ & $\begin{array}{c}2500-7520 \\
7520-25,000\end{array}$ & MSC & $\begin{array}{l}\text { PCA, LDA, } \\
\text { AIPCM }\end{array}$ & Accuracy $98.5 \%$ & {$[147]$} \\
\hline & $\begin{array}{l}\text { adulteration: } \\
\text { talcum }\end{array}$ & $9480-10,100$ & smoothing, SNV & $\begin{array}{l}\text { PCA, PLS, biPLS, } \\
\text { CARS, SPA }\end{array}$ & $\mathrm{R}^{2}: 0.963$ & {$[153]$} \\
\hline $\begin{array}{l}\text { Attenuated total } \\
\text { reflectance } \\
\text { Fourier-transform } \\
\text { infrared } \\
\text { spectroscopy } \\
\text { (ATR-FTIR) }\end{array}$ & $\begin{array}{l}\text { adulteration } \\
\text { sibutramine }\end{array}$ & $3640-3770$ & SNV + 1st der. & $\begin{array}{l}\text { HCA, PCA, } \\
\text { k-NN }\end{array}$ & Accuracy: 100\% & {$[125]$} \\
\hline \multirow{3}{*}{$\begin{array}{l}\text { NIR hyperspectral } \\
\text { imaging system } \\
\text { (NIR-HSI) }\end{array}$} & $\begin{array}{l}\text { classification } \\
\text { Oolong, green, yellow, } \\
\text { white, black, and Pu-erh }\end{array}$ & $950-1760$ & Not reported & $\begin{array}{l}\text { PCA, MDS, } \\
\text { t-SNE, ISOMAP, } \\
\text { ECOC, SVM, } \\
\text { SVM-ECOC }\end{array}$ & $\begin{array}{l}\text { Accuracy } 97.41 \pm \\
0.16 \%\end{array}$ & {$[148]$} \\
\hline & $\begin{array}{l}\text { classification } \\
\text { green tea }\end{array}$ & $380-1030$ & Not reported & $\begin{array}{l}\text { SVM, CT, LDC, } \\
\text { k-NN }\end{array}$ & Accuracy $>93 \%$ & {$[145]$} \\
\hline & $\begin{array}{l}\text { classification } \\
\text { fermentation degree }\end{array}$ & $\begin{array}{l}589,635 \\
670,783\end{array}$ & SNV & $\begin{array}{c}\text { PCA, LDA, } \\
\text { Lib-SVM, ELM }\end{array}$ & $\mathrm{CCR}>98 \%$ & {$[146]$} \\
\hline $\begin{array}{l}\text { Surface-enhanced } \\
\text { Raman } \\
\text { spectroscopy } \\
\text { (SERS) }\end{array}$ & $\begin{array}{l}\text { classification } \\
\text { processing (black, } \\
\text { green) and cultivation }\end{array}$ & $5000-25,000$ & $\begin{array}{l}\text { baseline correction } \\
\text { derivatization }\end{array}$ & PCA & $\begin{array}{l}\text { Identification } \\
\text { rate: } 100 \%\end{array}$ & {$[149]$} \\
\hline
\end{tabular}

AIPCM = adaptive improved possibilistic c-means; biPLS = backward interval partial least squares CARS = competitive adaptive reweighted sampling algorithm; CCR = correct classification rate $\mathrm{CT}=$ classification tree; ELM = extreme learning machine; ISOMAP = isometric mapping; $\mathrm{k}-\mathrm{NN}=\mathrm{k}-\mathrm{nearest}$ neighbor; $\quad \mathrm{LDC}=$ linear discriminant classification; Lib-SVM = library support vector machine MDS = multidimensional scaling; MIN/MAX = minimum/maximum normalization; MSC = multiplicative scatter correction; RF = random forest; SG-1st, Savitzky-Golay first derivative; SG-2nd Savitzky-Golay second derivative; SLS = straight line subtraction; SNV = standard normal variation; SVM = support vector machine; $\mathrm{SPA}=$ successive projections algorithm; $\mathrm{t}-\mathrm{SNE}=$ nonlinear $\mathrm{t}$-distributed stochastic neighbor embedding.

\section{Conclusions}

Of the molecular spectroscopic techniques presented, NIRS, IR, and NMR stand out in particular for the identification of geographical origin, compositional analysis, authentication, and the detection of adulteration. UV/Vis and RS techniques have been sparely applied in these areas, but their potential is not negligible. Clearly, from this review, the different spectroscopic techniques have proven to be capable in the monitoring of geographical origin, compositional qualities, conditions of production, and conditions of 
storage for meat, fish, mushroom, spices, coffee, and tea. As these products are highly sorted and prone to certain forms of adulteration, which can result in severe health consequences, molecular spectroscopic tools could be an efficient and promising tool to guarantee that meat and fish products are safe before reaching the consumer.

Perhaps, the critical need for preprocessing and chemometric analysis may be among the dominant challenges when non-experts use these methods. However, many programs have simplified the application of these preprocessing methods and chemometric techniques such that, even with little expertise, the instruments can be successfully used for food quality monitoring. As outlined in this review, baseline correction, standard normal variate, multiplicative scatter correction, Savitzky-Golay smoothing, and derivation are the most commonly used data preprocessing methods for the evaluation of spectral data. Quantitative and classification chemometric evaluation methods have been used to classify and predict different quality criteria in meat, fish, coffee, tea, mushroom, and spices. Lastly, the emergence of handheld versions of these spectroscopic techniques further highlights their potential and advantages, as the portable versions present the unique advantage of rapid and on-site analysis for preliminary and meaningful information extraction, in addition to all the other existing advantages of the techniques.

Author Contributions: Conceptualization, M.F., J.-L.Z.Z., and Z.K.; methodology, M.F., E.B., J.-L.Z.Z., and Z.K.; investigation, M.F., E.B., J.-L.Z.Z., G.B., and Z.K.; resources, M.F., E.B., J.-L.Z.Z., G.B., and Z.K., writing—original draft preparation, M.F., E.B., J.-L.Z.Z., G.B., and Z.K.; writing-review and editing, M.F., E.B., J.-L.Z.Z., G.B., and Z.K.; visualization, E.B.; supervision, M.F., E.B., J.-L.Z.Z., G.B., and Z.K.; project administration, M.F. All authors have read and agreed to the published version of the manuscript.

Funding: This research received no external funding.

Institutional Review Board Statement: Not applicable.

Informed Consent Statement: Not applicable.

Acknowledgments: We are grateful for the support of Doctoral School of Food Science of the Hungarian University of Agricultural and Life Sciences.

Conflicts of Interest: The authors declare no conflict of interest.

$\begin{array}{ll}\text { Abbreviations } \\ \text { \% CC } & \text { Percentage of correctly classified samples; } \\ \text { 1st der } & \text { First derivative; } \\ \text { AIPCM } & \text { Adaptive improved possibility c-means; } \\ \text { ANN } & \text { Artificial neural network; } \\ \text { ANOVA } & \text { Analysis of variance; } \\ \text { ASCA } & \text { ANOVA simultaneous component analysis; } \\ \text { ATR-FTIR } & \text { Attenuated total reflection Fourier-transform infrared; } \\ \text { BC } & \text { Baseline correction; } \\ \text { biPLS } & \text { Backward interval partial least squares; } \\ \text { BP-NN } & \text { Backpropagation neural network; } \\ \text { CARS } & \text { Competitive adaptive reweighted sampling algorithm; } \\ \text { CASSI } & \text { Coded aperture snapshot spectral imaging; } \\ \text { CCDs } & \text { Charge-coupled devices; } \\ \text { CCR } & \text { Correct classification rate; } \\ \text { CIE } & \text { Commission on Illumination; } \\ \text { CODEX } & \text { Codex Alimentarius; } \\ \text { CT } & \text { Classification tree; } \\ \text { CTDs } & \text { Sensitive charge transfer devices; } \\ \text { DA } & \text { Discriminant analysis; } \\ \text { DAD } & \text { Diode-array detector; }\end{array}$




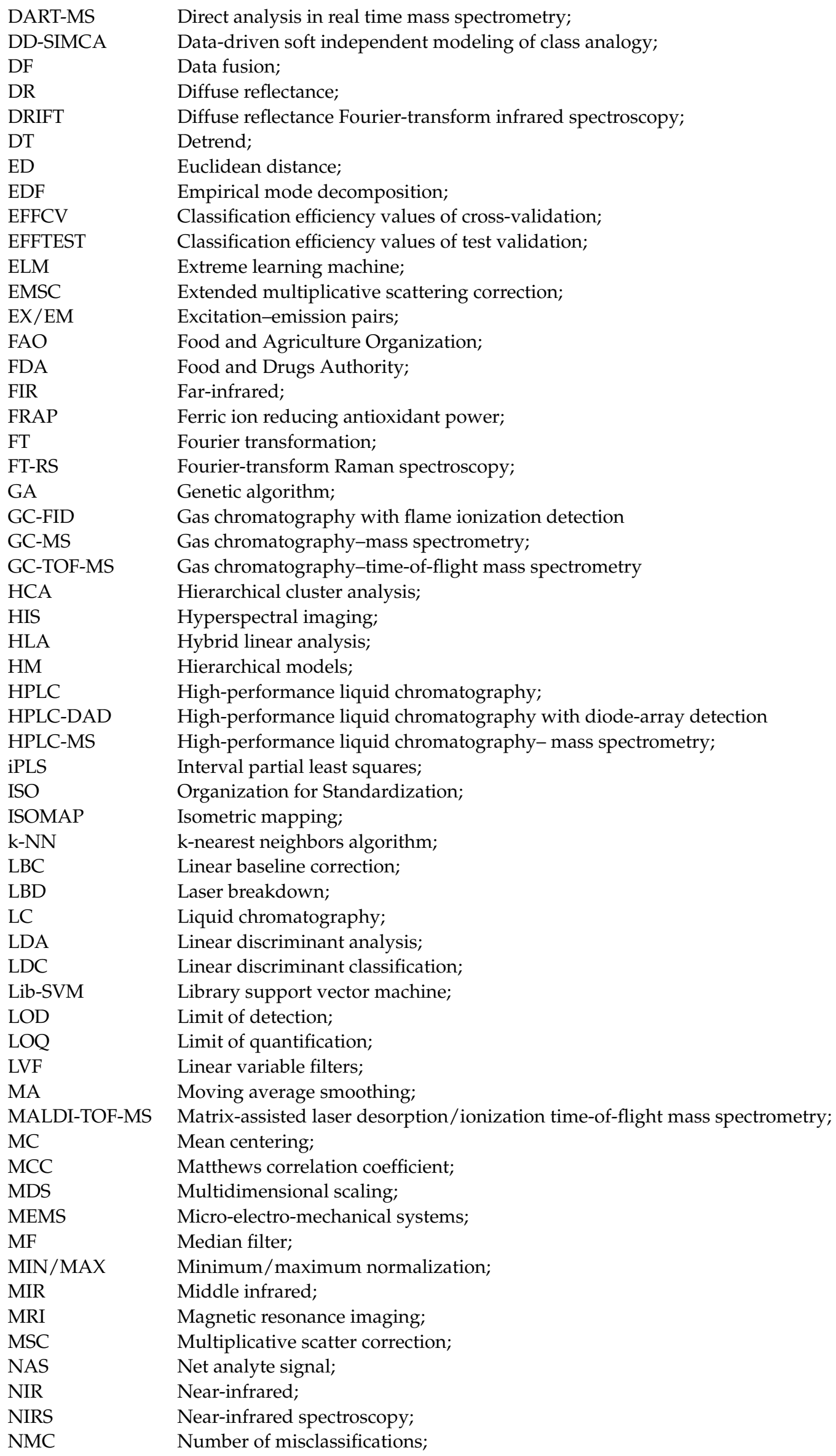




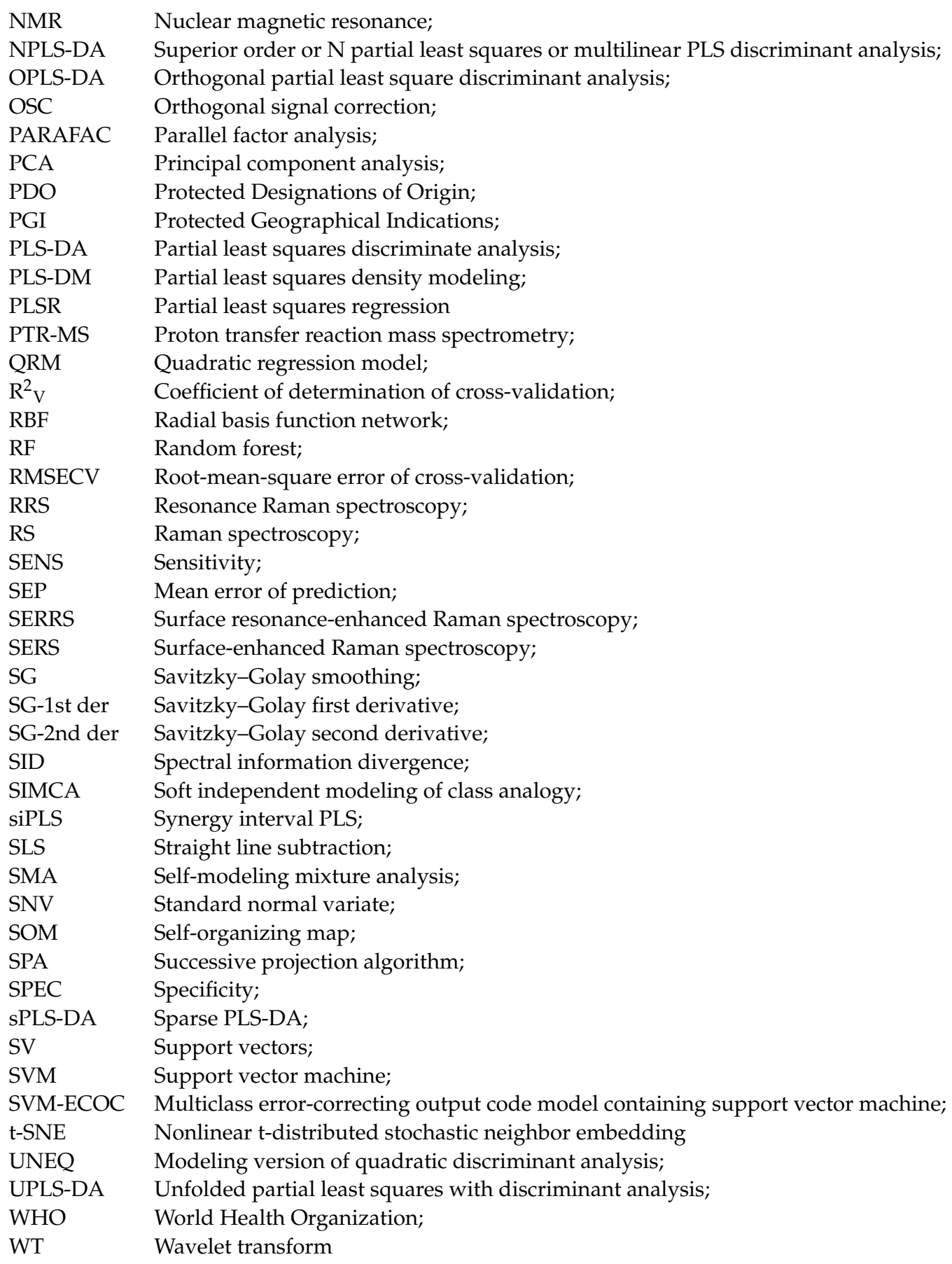

\section{References}

1. FAO. Rome Declaration on World Food Security and World Food Summit Plan of Action; FAO: Rome, Italy, $1996 ;$ p. 43.

2. Danezis, G.P.; Tsagkaris, A.S.; Camin, F.; Brusic, V.; Georgiou, C.A. Food Authentication: Techniques, Trends \& Emerging Approaches. Trends Anal. Chem. 2016, 85, 123-132. [CrossRef]

3. Rajendran, V.; Chang, H.; Liu, R.S. Recent Progress on Broadband Near-Infrared Phosphors-Converted Light Emitting Diodes for Future Miniature Spectrometers. Opt. Mater. X 2019, 1, 100011. [CrossRef]

4. Ozier, I. Molecular Spectroscopy. Phys. Today 1985, 38, 15. [CrossRef]

5. ISO 20473:2007; Optics and Photonics-Spectral Bands. ISO/IEC Directives International Standard: Geneve, Switzerland, 2007.

6. Ju, H. Grand Challenges in Analytical Chemistry: Towards More Bright Eyes for Scientific Research, Social Events and Human Health. Front. Chem. 2013, 1, 1-6. [CrossRef]

7. Brown, C.W. Ultraviolet, Visible, and near-Infrared Spectrophotometers. Appl. Spectrosc. Rev. 2000, 35, 151-173. [CrossRef]

8. Jones, R.R.; Hooper, D.C.; Zhang, L.; Wolverson, D.; Valev, V.K. Raman Techniques: Fundamentals and Frontiers. Nanoscale Res. Lett. 2019, 14, 1-34. [CrossRef] 
9. Brereton, R.G. (Ed.) New Analytical Approaches for Verifying the Origin of Food A Volume in Woodhead Publishing Series in Food Science, Technology and Nutrition; Woodhead Publishing Limited: Sawston, UK, 2013; ISBN 978-0-85709-274-8.

10. Jacobsen, N.E. Interpretation of Proton (1H) NMR Spectra. NMR Spectrosc. Explain. 2007, 39-73. [CrossRef]

11. Tian, Y.; He, Q.; Chen, X.; Wang, S. Nuclear Magnetic Resonance Spectroscopy for Food Quality Evaluation. Eval. Technol. Food Qual. 2019, 2019, 193-217. [CrossRef]

12. Burns, D.A.; Ciurczak, E.W. Handbook of Near-Infrared Analysis; Burns, D.A., Ciurczak, E.W., Eds.; Taylor \& Francis Inc.: Boca Raton, FL, USA, 2007; ISBN 978-0-8493-7393-0.

13. Caporaso, N.; Whitworth, M.B.; Fisk, I.D. Near-Infrared Spectroscopy and Hyperspectral Imaging for Non-Destructive Quality Assessment of Cereal Grains. Appl. Spectrosc. Rev. 2018, 53, 667-687. [CrossRef]

14. Kagaya, Y.; Miyamoto, S. A Systematic Review of Near-Infrared Spectroscopy in Flap Monitoring: Current Basic and Clinical Evidence and Prospects. J. Plast. Reconstr. Aesthet. Surg. 2017, 71, 246-257. [CrossRef]

15. Aenugu, H.P.R.; Sathis Kumar, D.; Srisudharson; Parthiban, N.; Ghosh, S.S.; Banji, D. Near Infra Red Spectroscopy- An Overview. Int. J. ChemTech. Res. 2011, 3, 825-836. [CrossRef]

16. Okazaki, Y. Near-Infrared Spectroscopy-Its Versatility in Analytical. Anal Chem 2012, 28, 545-562. [CrossRef]

17. Ciurczak, E. Principles of NIR Spectroscopy. In Handbook of Near-Infrared Analysis; Burns, D.A., Ciurczak, E.W., Eds.; CRC Press: Boca Raton, FL, USA, 2008; pp. 8-9. ISBN 0-8493-7393-X.

18. Bumbrah, G.S.; Sharma, R.M. Raman Spectroscopy—Basic Principle, Instrumentation and Selected Applications for the Characterization of Drugs of Abuse. Egypt. J. Forensic Sci. 2016, 6, 209-215. [CrossRef]

19. Osborne, B.G. Near-Infrared Spectroscopy in Food Analysis. In Encyclopedia of Analytical Chemistry; 2000; pp. 1-14; ISBN 978-0-470-02731-8. Available online: https://www.hackteria.org/wiki/images/0/03/NIR_food_analysis.pdf (accessed on 20 December 2021).

20. Brodie, C.H.; Devasagayam, J.; Collier, C.M. A Hyperspectral Imaging Instrumentation Architecture Based on Accessible Optical Disc Technology and Frequency-Domain Analyses. IEEE Trans. Instrum. Meas. 2019, 68, 2531-2538. [CrossRef]

21. Agelet, L.E.; Hurburgh, C.R. A Tutorial on near Infrared Spectroscopy and Its Calibration. Crit. Rev. Anal. Chem. 2010, 40, 246-260 [CrossRef]

22. Savitzky, A.; Golay, M.J.E. Smoothing and Differentiation of Data by Simplified Least Squares Procedures. Anal. Chem. 1964, 36, 1627-1639. [CrossRef]

23. Liland, K.H.; Almøy, T.; Mevik, B.-H. Optimal Choice of Baseline Correction for Multivariate Calibration of Spectra. Appl. Spectrosc. 2010, 64, 1007-1016. [CrossRef]

24. van den Berg, R.A.; Hoefsloot, H.C.J.; Westerhuis, J.A.; Smilde, A.K.; van der Werf, M.J. Centering, Scaling, and Transformations: Improving the Biological Information Content of Metabolomics Data. BMC Genom. 2006, 7, 1-15. [CrossRef]

25. Barnes, R.J.; Dhanoa, M.S.; Lister, S.J. Standard Normal Variate Transformation and De-Trending of Near-Infrared Diffuse Reflectance Spectra. Appl. Spectrosc. 1989, 43, 772-777. [CrossRef]

26. Rodriguez, J.D.; Westenberger, B.J.; Buhse, L.F.; Kauffman, J.F. Standardization of Raman Spectra for Transfer of Spectral Libraries across Different Instruments. Analyst 2011, 136, 4232-4240. [CrossRef]

27. Dobson, P.D.; Doig, A.J.; Blanch, E.W. A Simple Approach to Normalization for Spectroscopic Data Mining. Appl. Spectrosc. 2005, 59, 542-544. [CrossRef]

28. Windig, W.; J, S.; Bro, R. Loopy MSC: A Simple Way to Improve Multiplicative Scatter Correction. Appl. Spectrosc. 2008, 62, 1153-1159. [CrossRef]

29. Naes, T.; Issakson, T.; Fearn, T.; Davies, T. Scatter Correction of Spectroscopic Data. In A User-Friendly Guide to Multivariate Calibration and Classification; Naes, T., Issakson, T., Fearn, T., Davies, T., Eds.; NIR Publication: Chichester, UK, 2002 ; pp. 105-127. ISBN 978-1-906715-25-0.

30. Yakubu, H.G.; Kovacs, Z.; Toth, T.; Bazar, G. The Recent Advances of Near-Infrared Spectroscopy in Dairy Production-a Review. Crit. Rev. Food Sci. Nutr. 2020, 1-22. [CrossRef]

31. Benes, E.; Bajusz, D.; Gere, A.; Fodor, M.; Rácz, A. Comprehensive Chemometric Classification of Snack Products Based on Their near Infrared Spectra. LWT 2020, 133, 110130. [CrossRef]

32. Rácz, A.; Fodor, M.; Héberger, K.; Online, V.A.; Fodor, M.; Rácz, A.; Fodor, M.; Héberger, K. Development and Comparison of Regression Models for the Determination of Quality Parameters in Margarine Spread Samples Using NIR Spectroscopy. Anal. Methods 2018, 10, 3089-3099. [CrossRef]

33. Soladoye, O.P.; Prieto, N.; Lopez-campos, O.; Aalhus, J.L.; Uttaro, B.; Roberts, J.C.; Larsen, I. Potential of near Infrared (NIR) Spectroscopy and Dual Energy X-Ray Absorptiometry (DXA) in Predicting Pork Belly Softness. Meat Sci. 2018, 142, 1-4. [CrossRef]

34. Hassoun, A.; Sahar, A.; Lakhal, L.; Aït-Kaddour, A. Fluorescence Spectroscopy as a Rapid and Non-Destructive Method for Monitoring Quality and Authenticity of Fish and Meat Products: Impact of Different Preservation Conditions. LWT 2019, 103, 279-292. [CrossRef]

35. Rahman, A.; Kondo, N.; Ogawa, Y.; Suzuki, T.; Kanamori, K. Determination of K Value for Fish Flesh with Ultraviolet-Visible Spectroscopy and Interval Partial Least Squares (IPLS) Regression Method. Biosyst. Eng. 2016, 141, 12-18. [CrossRef]

36. Andueza, D.; Listrat, A.; Durand, D.; Normand, J.; Mourot, B.P.; Gruffat, D. Prediction of Beef Meat Fatty Acid Composition by Visible-near-Infrared Spectroscopy Was Improved by Preliminary Freeze-Drying. Meat Sci. 2019, 158, 107910. [CrossRef] 
37. Alamprese, C.; Casale, M.; Sinelli, N.; Lanteri, S.; Casiraghi, E. Detection of Minced Beef Adulteration with Turkey Meat by UV-Vis, NIR and MIR Spectroscopy. LWT 2013, 53, 225-232. [CrossRef]

38. Ma, J.; Sun, D.W.; Pu, H.; Wei, Q.; Wang, X. Protein Content Evaluation of Processed Pork Meats Based on a Novel Single Shot (Snapshot) Hyperspectral Imaging Sensor. J. Food Eng. 2019, 240, 207-213. [CrossRef]

39. Ma, J.; Sun, D.W. Prediction of Monounsaturated and Polyunsaturated Fatty Acids of Various Processed Pork Meats Using Improved Hyperspectral Imaging Technique. Food Chem. 2020, 321, 126695. [CrossRef] [PubMed]

40. Zhang, Y.; Huang, Y.; Zhai, F.; Du, R.; Liu, Y.; Lai, K. Analyses of Enrofloxacin, Furazolidone and Malachite Green in Fish Products with Surface-Enhanced Raman Spectroscopy. Food Chem. 2012, 135, 845-850. [CrossRef] [PubMed]

41. Prieto, N.; Roehe, R.; Lavín, P.; Batten, G.; Andrés, S. Application of near Infrared Reflectance Spectroscopy to Predict Meat and Meat Products Quality: A Review. Meat Sci. 2009, 83, 175-186. [CrossRef] [PubMed]

42. Hajirezaee, S.; Abed-Elmdoust, A.; Alekhina, N.; Chupradit, S.; Mustafa, Y.F. Metabolite Profiling of the Post-Ovulatory Oocytes of the Common Carp, Cyprinus Carpio: A 1H NMR-Based Metabolomics Approach. Comp. Biochem. Physiol. Part Genom. Proteom. 2021, 40, 100917. [CrossRef] [PubMed]

43. Rahimi, R.; Hajirezaee, S.; Rahimi Pordanjani, H. A 1HNMR-Based Molecular Study of Anesthesia in Fish. Aquaculture 2020, 520, 734995. [CrossRef]

44. Ceylan, C.; Tanrikul, T.; Özgener, H. Biophysical Evaluation of Physiological Effects of Gilthead Sea Bream (Sparus Aurata) Farming Using FTIR Spectroscopy. Food Chem. 2014, 145, 1055-1060. [CrossRef]

45. Gao, F.; Ben-Amotz, D.; Yang, Z.; Han, L.; Liu, X. Complementarity of FT-IR and Raman Spectroscopies for the Species Discrimination of Meat and Bone Meals Related to Lipid Molecular Profiles. Food Chem. 2021, 345, 128754. [CrossRef]

46. Robert, C.; Jessep, W.; Sutton, J.J.; Hicks, T.M.; Loeffen, M.; Farouk, M.; Ward, J.F.; Bain, W.E.; Craigie, C.R.; Fraser-Miller, S.J.; et al. Evaluating Low- Mid- and High-Level Fusion Strategies for Combining Raman and Infrared Spectroscopy for Quality Assessment of Red Meat. Food Chem. 2021, 361, 130154. [CrossRef]

47. Mabood, F.; Boqué, R.; Alkindi, A.Y.; Al-Harrasi, A.; Al Amri, I.S.; Boukra, S.; Jabeen, F.; Hussain, J.; Abbas, G.; Naureen, Z.; et al. Fast Detection and Quantification of Pork Meat in Other Meats by Reflectance FT-NIR Spectroscopy and Multivariate Analysis. Meat Sci. 2020, 163, 108084. [CrossRef]

48. Prieto, N.; Juárez, M.; Larsen, I.L.; López-campos, Ó.; Zijlstra, R.T.; Aalhus, J.L. Rapid Discrimination of Enhanced Quality Pork by Visible and near Infrared Spectroscopy. Meat Sci. 2015, 110, 76-84. [CrossRef]

49. Yang, Y.; Zhuang, H.; Yoon, S.C.; Wang, W.; Jiang, H.; Jia, B. Rapid Classification of Intact Chicken Breast Fillets by Predicting Principal Component Score of Quality Traits with Visible/near-Infrared Spectroscopy. Food Chem. 2018, 244, 184-189. [CrossRef]

50. Zamora-Rojas, E.; Garrido-Varo, A.; De Pedro-Sanz, E.; Guerrero-ginel, J.E.; Pérez-marín, D.; Pedro-sanz, E.D.; Guerrero-ginel, J.E.; Pérez-marín, D. Prediction of Fatty Acids Content in Pig Adipose Tissue by near Infrared Spectroscopy: At-Line versus in-Situ Analysis. Meat Sci. 2013, 95, 503-511. [CrossRef]

51. Bázár, G.; Szabó, A.; Romvári, R. NIR Based Quality Control of Frying Fat Samples by Means of Polar Qualification System. Food Control 2010, 21, 992-997. [CrossRef]

52. Bilge, G.; Murat, H.; Sezer, B.; Efe, K.; Hakki, I. Identification of Meat Species by Using Laser-Induced Breakdown Spectroscopy. Meat Sci. 2016, 119, 118-122. [CrossRef]

53. Balage, J.M.; da Luz e Silva, S.; Gomide, C.A.; de Bonin, M.N.; Figueira, A.C. Predicting Pork Quality Using Vis/NIR Spectroscopy. Meat Sci. 2015, 108, 37-43. [CrossRef]

54. Bázár, G.; Princz, Z.; Jekkel, G.; Locsmándi, L.; Andrássy-Baka, G.; Kövér, G.; Szendrő, Z.; Romvári, R. NIRS Prediction for Protein and Intramuscular Fat Content of Rabbit Hind Leg Meat. In Proceedings of the 9th World Rabbit Congress Meat Quality and Safetyth World Rabbit Congress Meat Quality and Safety, Verona, Italy, 10-13 June 2008; pp. 1301-1305.

55. Su, H.; Sha, K.; Zhang, L.; Zhang, Q.; Xu, Y.; Zhang, R.; Li, H.; Sun, B. Development of near Infrared Re Fl Ectance Spectroscopy to Predict Chemical Composition with a Wide Range of Variability in Beef. Meat Sci. 2014, 98, 110-114. [CrossRef]

56. Alamprese, C.; Manuel, J.; Casiraghi, E.; Balling, S. Identification and Quantification of Turkey Meat Adulteration in Fresh, Frozen-Thawed and Cooked Minced Beef by FT-NIR Spectroscopy and Chemometrics. Meat Sci. 2016, 121, 175-181. [CrossRef]

57. Rady, A.; Adedeji, A. Assessing Different Processed Meats for Adulterants Using Visible-near-Infrared Spectroscopy. Meat Sci. 2018, 136, 59-67. [CrossRef]

58. Riovanto, R.; De Marchi, M.; Cassandro, M.; Penasa, M. Use of near Infrared Transmittance Spectroscopy to Predict Fatty Acid Composition of Chicken Meat. Food Chem. 2012, 134, 2459-2464. [CrossRef]

59. Marchi, M.D.; Manuelian, C.L.; Manfrin, D.; Meneghesso, M.; Cassandro, M.; Penasa, M.; De Marchi, M.; Manuelian, C.L.; Ton, S.; Manfrin, D.; et al. Prediction of Sodium Content in Commercial Processed Meat Products Using near Infrared Spectroscopy. Meat Sci. 2017, 125, 61-65. [CrossRef] [PubMed]

60. Barbin, D.F.; Kaminishikawahara, C.M.; Soares, A.L.; Mizubuti, I.Y.; Grespan, M.; Shimokomaki, M.; Hirooka, E.Y. Prediction of Chicken Quality Attributes by near Infrared Spectroscopy. Food Chem. 2015, 168, 554-560. [CrossRef] [PubMed]

61. Prieto, N.; López-campos, Ó.; Aalhus, J.L.; Dugan, M.E.R.; Juárez, M.; Uttaro, B. Use of near Infrared Spectroscopy for Estimating Meat Chemical Composition, Quality Traits and Fatty Acid Content from Cattle Fed Sun Fl Ower or Fl Axseed. Meat Sci. 2014, 98, 279-288. [CrossRef] [PubMed]

62. Prieto, N.; Andre, S.; Lav1, P. Ability of near Infrared Reflectance Spectroscopy ( NIRS ) to Estimate Physical Parameters of Adult Steers ( Oxen ) and Young Cattle Meat Samples's. Meat Sci. 2008, 79, 692-699. [CrossRef] 
63. Osborne, B.G.; Fearn, T.; Hindle, P.H. Practical Nir Spectroscopy With Applications in Food and Beverage Analysis; Addison-Wesley Longman Ltd.: Boston, MA, USA, 1993; ISBN 978-0-582-09946-3.

64. Geladi, P.; Kowalski, B.R.R. Partial Least Square Regression: A Tutorial. Anal. Chim. Acta 1986, 185, 1-17. [CrossRef]

65. Boschetti, L.; Ottavian, M.; Facco, P.; Barolo, M.; Serva, L.; Balzan, S.; Novelli, E. A Correlative Study on Data from Pork Carcass and Processed Meat (Bauernspeck) for Automatic Estimation of Chemical Parameters by Means of near-Infrared Spectroscopy. Meat Sci. 2013, 95, 621-628. [CrossRef]

66. Kalač, P. A Review of Chemical Composition and Nutritional Value of Wild-Growing and Cultivated Mushrooms. J. Sci. Food Agric. 2013, 93, 209-218. [CrossRef]

67. Giovenzana, V.; Tugnolo, A.; Casson, A.; Guidetti, R.; Beghi, R. Application of Visible-near Infrared Spectroscopy to Evaluate the Quality of Button Mushrooms. J. Infrared Spectrosc. 2019, 27, 38-45. [CrossRef]

68. Fodor, M.; Mikola, E.E.; Geösel, A.; Stefanovits-Bányai, É.; Mednyánszky, Z. Application of Near-Infrared Spectroscopy to Investigate Some Endogenic Properties of Pleurotus Ostreatus Cultivars. Sensors 2020, 20, 6632. [CrossRef]

69. O'Gorman, A.; Downey, G.; Gowen, A.A.; Barry-Ryan, C.; M. Frias, J. Use of Fourier Transform Infrared Spectroscopy and Chemometric Data Analysis To Evaluate Damage and Age in Mushrooms (Agaricus Bisporus) Grown in Ireland. J. Agric. Food Chem. 2010, 58, 7770-7776. [CrossRef]

70. Zervakis, G.I.; Bekiaris, G.; Tarantilis, P.A.; Pappas, C.S. Rapid Strain Classification and Taxa Delimitation within the Edible Mushroom Genus Pleurotus through the Use of Diffuse Reflectance Infrared Fourier Transform (DRIFT) Spectroscopy. Fungal Biol. 2012, 116, 715-728. [CrossRef]

71. Qi, L.-M.; Zhang, J.; Liu, H.-G.; Li, T.; Wang, Y.-Z. Fourier Transform Mid-Infrared Spectroscopy and Chemometrics to Identify and Discriminate Boletus Edulis and Boletus Tomentipes Mushrooms. Int. J. Food Prop. 2017, 20, S56-S68. [CrossRef]

72. Li, Y.; Wang, Y. Synergistic Strategy for the Geographical Traceability of Wild Boletus Tomentipes by Means of Data Fusion Analysis. Microchem. J. 2018, 140, 38-46. [CrossRef]

73. Yao, S.; Li, T.; Li, J.Q.; Liu, H.G.; Wang, Y.Z. Geographic Identification of Boletus Mushrooms by Data Fusion of FT-IR and UV Spectroscopies Combined with Multivariate Statistical Analysis. Spectrochim. Acta Part Mol. Biomol. Spectrosc. 2018, 198, 257-263. [CrossRef]

74. Yao, S.; Li, J.; Li, T.; Liu, H.; Wang, Y. Discrimination of Boletaceae Mushrooms Based on Data Fusion of FT-IR and ICP-AES Combined with SVM. Int. J. Food Prop. 2018, 21, 255-266. [CrossRef]

75. Casale, M.; Bagnasco, L.; Zotti, M.; Di Piazza, S.; Sitta, N.; Oliveri, P. A NIR Spectroscopy-Based Efficient Approach to Detect Fraudulent Additions within Mixtures of Dried Porcini Mushrooms. Talanta 2016, 160, 729-734. [CrossRef]

76. Oliveira, M.M.; Cruz-Tirado, J.P.; Barbin, D.F. Nontargeted Analytical Methods as a Powerful Tool for the Authentication of Spices and Herbs: A Review. Compr. Rev. Food Sci. Food Saf. 2019, 18, 670-689. [CrossRef]

77. Zalacain, A.; Ordoudi, S.A.; Díaz-Plaza, E.M.; Carmona, M.; Blázquez, I.; Tsimidou, M.Z.; Alonso, G.L. Near-Infrared Spectroscopy in Saffron Quality Control: Determination of Chemical Composition and Geographical Origin. J. Agric. Food Chem. 2005, 53, 9337-9341. [CrossRef]

78. Gad, H.A.; Bouzabata, A. Application of Chemometrics in Quality Control of Turmeric (Curcuma Longa) Based on Ultra-Violet, Fourier Transform-Infrared and 1H NMR Spectroscopy. Food Chem. 2017, 237, 857-864. [CrossRef]

79. Windarsih, A.; Rohman, A.; Swasono, R.T. Authentication of turmeric using proton-nuclear magnetic resonance spectroscopy and multivariate analysis. Int. J. Appl. Pharm. 2018, 10, 174-180. [CrossRef]

80. Sobolev, A.P.; Carradori, S.; Capitani, D.; Vista, S.; Trella, A.; Marini, F.; Mannina, L. Saffron Samples of Different Origin: An NMR Study of Microwave-Assisted Extracts. Foods 2014, 3, 403-419. [CrossRef] [PubMed]

81. Farag, M.A.; Labib, R.M.; Noleto, C.; Porzel, A.; Wessjohann, L.A. NMR Approach for the Authentication of 10 Cinnamon Spice Accessions Analyzed via Chemometric Tools. LWT 2018, 90, 491-498. [CrossRef]

82. Ellis, D.I.; Brewster, V.L.; Dunn, W.B.; Allwood, J.W.; Golovanov, A.P.; Goodacre, R. Fingerprinting Food: Current Technologies for the Detection of Food Adulteration and Contamination. Chem. Soc. Rev. 2012, 41, 5706-5727. [CrossRef] [PubMed]

83. Cantarelli, M.; Moldes, C.A.; Marchevsky, E.J.; Azcarate, S.M.; Camiña, J.M. Low-Cost Analytic Method for the Identification of Cinnamon Adulteration. Microchem. J. 2020, 159, 105513. [CrossRef]

84. Yasmin, J.; Ahmed, M.R.; Lohumi, S.; Wakholi, C.; Lee, H.; Mo, C.; Cho, B.-K. Rapid Authentication Measurement of Cinnamon Powder Using FT-NIR and FT-IR Spectroscopic Techniques. Qual. Assur. Saf. Crops Foods 2019, 11, 257-267. [CrossRef]

85. McVey, C.; Gordon, U.; Haughey, S.A.; Elliott, C.T. Assessment of the Analytical Performance of Three Near-Infrared Spectroscopy Instruments (Benchtop, Handheld and Portable) through the Investigation of Coriander Seed Authenticity. Foods 2021, 10, 956. [CrossRef]

86. Vadivel, V.; Ravichandran, N.; Rajalakshmi, P.; Brindha, P.; Gopal, A.; Kumaravelu, C. Microscopic, Phytochemical, HPTLC, GC-MS and NIRS Methods to Differentiate Herbal Adulterants: Pepper and Papaya Seeds. J. Herb. Med. 2018, 11, 36-45. [CrossRef]

87. Kar, S.; Tudu, B.; Bag, A.K.; Bandyopadhyay, R. Application of Near-Infrared Spectroscopy for the Detection of Metanil Yellow in Turmeric Powder. Food Anal. Methods 2018, 11, 1291-1302. [CrossRef]

88. Wilde, A.S.; Haughey, S.A.; Galvin-King, P.; Elliott, C.T. The Feasibility of Applying NIR and FT-IR Fingerprinting to Detect Adulteration in Black Pepper. Food Control 2019, 100, 1-7. [CrossRef] 
89. Lohumi, S.; Joshi, R.; Kandpal, L.M.; Lee, H.; Kim, M.S.; Cho, H.; Mo, C.; Seo, Y.-W.; Rahman, A.; Cho, B.-K. Quantitative Analysis of Sudan Dye Adulteration in Paprika Powder Using FTIR Spectroscopy. Food Addit. Contam. Part A 2017, 34, 678-686. [CrossRef]

90. Valand, R.; Tanna, S.; Lawson, G.; Bengtström, L. A Review of Fourier Transform Infrared (FTIR) Spectroscopy Used in Food Adulteration and Authenticity Investigations. Food Addit. Contam. Part A 2020, 37, 19-38. [CrossRef]

91. Petrakis, E.A.; Polissiou, M.G. Assessing Saffron (Crocus Sativus L.) Adulteration with Plant-Derived Adulterants by Diffuse Reflectance Infrared Fourier Transform Spectroscopy Coupled with Chemometrics. Talanta 2017, 162, 558-566. [CrossRef]

92. Black, C.; Haughey, S.A.; Chevallier, O.P.; Galvin-King, P.; Elliott, C.T. A Comprehensive Strategy to Detect the Fraudulent Adulteration of Herbs: The Oregano Approach. Food Chem. 2016, 210, 551-557. [CrossRef]

93. Monago-Maraña, O.; Eskildsen, C.E.; Afseth, N.K.; Galeano-Díaz, T.; Muñoz de la Peña, A.; Wold, J.P. Non-Destructive Raman Spectroscopy as a Tool for Measuring ASTA Color Values and Sudan I Content in Paprika Powder. Food Chem. 2019, 274, 187-193. [CrossRef]

94. Gao, F.; Hu, Y.; Chen, D.; Li-Chan, E.C.Y.; Grant, E.; Lu, X. Determination of Sudan I in Paprika Powder by Molecularly Imprinted Polymers-Thin Layer Chromatography-Surface Enhanced Raman Spectroscopic Biosensor. Talanta 2015, 143, 344-352. [CrossRef]

95. Lohumi, S.; Lee, H.; Kim, M.S.; Qin, J.; Kandpal, L.M.; Bae, H.; Rahman, A.; Cho, B.-K. Calibration and Testing of a Raman Hyperspectral Imaging System to Reveal Powdered Food Adulteration. PLoS ONE 2018, 13, e0195253. [CrossRef]

96. Dhakal, S.; Chao, K.; Schmidt, W.; Qin, J.; Kim, M.; Chan, D. Evaluation of Turmeric Powder Adulterated with Metanil Yellow Using FT-Raman and FT-IR Spectroscopy. Foods 2016, 5, 36. [CrossRef]

97. Dhakal, S.; Chao, K.; Schmidt, W.; Qin, J.; Kim, M.; Huang, Q. Detection of Azo Dyes in Curry Powder Using a 1064-Nm Dispersive Point-Scan Raman System. Appl. Sci. 2018, 8, 564. [CrossRef]

98. Chao, K.; Dhakal, S.; Schmidt, W.F.; Qin, J.; Kim, M.; Peng, Y.; Huang, Q. Raman and IR Spectroscopic Modality for Authentication of Turmeric Powder. Food Chem. 2020, 320, 126567. [CrossRef]

99. Dowlatabadi, R.; Farshidfar, F.; Zare, Z.; Pirali, M.; Rabiei, M.; Khoshayand, M.R.; Vogel, H.J. Detection of Adulteration in Iranian Saffron Samples by 1H NMR Spectroscopy and Multivariate Data Analysis Techniques. Metabolomics 2017, 13, 19. [CrossRef]

100. Wang, J.; Jun, S.; Bittenbender, H.C.; Gautz, L.; Li, Q.X. Fourier Transform Infrared Spectroscopy for Kona Coffee Authentication. J. Food Sci. 2009, 74, C385-C391. [CrossRef]

101. Wang, N.; Fu, Y.; Lim, L.-T. Feasibility Study on Chemometric Discrimination of Roasted Arabica Coffees by Solvent Extraction and Fourier Transform Infrared Spectroscopy. J. Agric. Food Chem. 2011, 59, 3220-3226. [CrossRef] [PubMed]

102. Craig, A.P.; Franca, A.S.; Oliveira, L.S. Evaluation of the Potential of FTIR and Chemometrics for Separation between Defective and Non-Defective Coffees-ScienceDirect. Food Chem. 2021, 132, 1368-1374. [CrossRef] [PubMed]

103. Suchánek, M.; Filipová, H.; Volka, K.; Davies, I.M.; Suchánek; Filipová, H.; Volka, K.; Davies, I.; Delgadillo, I.; Davies, A.N. Qualitative Analysis of Green Coffee by Infrared Spectrometry. Fresenius J. Anal. Chem. 1996, 354, 327-332. [CrossRef]

104. Galanakis, C.M.; Charis, M. Innovative Food Analysis; Charis, M., Galanakis, E., Eds.; Elsevier: Amsterdam, The Netherlands, 2021; ISBN 978-0-12-819493-5.

105. Mendez, J.; Mendoza, L.; Cruz-Tirado, J.P.; Quevedo, R.; Siche, R. Trends in Application of NIR and Hyperspectral Imaging for Food Authentication. Sci. Agropecu. 2019, 10, 143-161. [CrossRef]

106. Marquetti, I.; Link, J.V.; Lemes, A.L.G.; Scholz, M.B.; dos Valderrama, P.S.; Bona, E. Partial Least Square with Discriminant Analysis and near Infrared Spectroscopy for Evaluation of Geographic and Genotypic Origin of Arabica Coffee. Comput. Electron. Agric. 2016, 121, 313-319. [CrossRef]

107. Luna, A.S.; da Silva, A.P.; Alves, E.A.; Rocha, R.B.; Lima, I.C.A.; de Gois, J.S.; da Silva, A.P.; Alves, E.A.; Rocha, R.B.; Lima, I.C.A.; et al. Evaluation of Chemometric Methodologies for the Classification of Coffea Canephora Cultivars via FT-NIR Spectroscopy and Direct Sample Analysis. Anal. Methods 2017, 9, 4255-4260. [CrossRef]

108. Monteiro, P.I.; Santos, J.S.; Alvarenga Brizola, V.R.; Pasini Deolindo, C.T.; Koot, A.; Boerrigter-Eenling, R.; van Ruth, S.; Georgouli, K.; Koidis, A.; Granato, D. Comparison between Proton Transfer Reaction Mass Spectrometry and near Infrared Spectroscopy for the Authentication of Brazilian Coffee: A Preliminary Chemometric Study. Food Control 2018, 91, 276-283. [CrossRef]

109. Manuel, M.N.B.; da Silva, A.C.; Lopes, G.S.; Ribeiro, L.P.D. One-Class Classification of Special Agroforestry Brazilian Coffee Using NIR Spectrometry and Chemometric Tools. Food Chem. 2022, 366, 130480. [CrossRef]

110. Giraudo, A.; Grassi, S.; Savorani, F.; Gavoci, G.; Casiraghi, E.; Geobaldo, F. Determination of the Geographical Origin of Green Coffee Beans Using NIR Spectroscopy and Multivariate Data Analysis. Food Control 2019, 99, 137-145. [CrossRef]

111. Jesztl, B.; Benes, E.; Fodor, M. FT-NIR Origin Identification of Coffee Samples. J. Food Investig. 2019, 65, $2372-2376$.

112. Bertone, E.; Venturello, A.; Giraudo, A.; Pellegrino, G.; Geobaldo, F. Simultaneous Determination by NIR Spectroscopy of the Roasting Degree and Arabica/Robusta Ratio in Roasted and Ground Coffee. Food Control 2016, 59, 683-689. [CrossRef]

113. Mees, C.; Souard, F.; Delporte, C.; Deconinck, E.; Stoffelen, P.; Stévigny, C.; Kauffmann, J.-M.; De Braekeleer, K. Identification of Coffee Leaves Using FT-NIR Spectroscopy and SIMCA. Talanta 2018, 177, 4-11. [CrossRef]

114. De Luca, S.; De Filippis, M.; Bucci, R.; Magrì, A.D.; Magrì, A.L.; Marini, F. Characterization of the Effects of Different Roasting Conditions on Coffee Samples of Different Geographical Origins by HPLC-DAD, NIR and Chemometrics. Microchem. J. 2016, 129, 348-361. [CrossRef]

115. Correia, R.M.; Tosato, F.; Domingos, E.; Rodrigues, R.R.T.T.; Aquino, L.F.M.; Filgueiras, P.R.; Lacerda, V.; Romão, W. Portable near Infrared Spectroscopy Applied to Quality Control of Brazilian Coffee. Talanta 2018, 176, 59-68. [CrossRef] 
116. Bona, E.; Marquetti, I.; Link, J.V.; Makimori, G.Y.F.; da Costa Arca, V.; Guimarães Lemes, A.L.; Ferreira, J.M.G.; dos Santos Scholz, M.B.; Valderrama, P.; Poppi, R.J. Support Vector Machines in Tandem with Infrared Spectroscopy for Geographical Classification of Green Arabica Coffee. LWT 2017, 76, 330-336. [CrossRef]

117. Zhang, C.; Liu, F.; He, Y. Identification of Coffee Bean Varieties Using Hyperspectral Imaging: Influence of Preprocessing Methods and Pixel-Wise Spectra Analysis. Sci. Rep. 2018, 8, 2166. [CrossRef]

118. Link, J.V.; Lemes, A.L.G.; Marquetti, I.; dos Santos Scholz, M.B.; Bona, E. Geographical and Genotypic Classification of Arabica Coffee Using Fourier Transform Infrared Spectroscopy and Radial-Basis Function Networks. Chemom. Intell. Lab. Syst. 2014, 135, 150-156. [CrossRef]

119. Moreira, I.; Scarminio, I.S. Chemometric Discrimination of Genetically Modified Coffea Arabica Cultivars Using Spectroscopic and Chromatographic Fingerprints. Talanta 2013, 107, 416-422. [CrossRef]

120. Bao, Y.-D.; Chen, N.; He, Y.; Liu, F.; Zhang, C.; Kong, W.-W. Rapid Identification of Coffee Bean Variety by near Infrared Hyperspectral Imaging Technology. Optics Precis. Eng. 2015, 23, 349-355. [CrossRef]

121. Barbin, D.F.; Felicio, A.L.; De, S.M.; Sun, D.-W.; Nixdorf, S.L.; Hirooka, E.Y. Application of Infrared Spectral Techniques on Quality and Compositional Attributes of Coffee: An Overview. Food Res. Int. 2014, 61, 23-32. [CrossRef]

122. Ebrahimi-Najafabadi, H.; Leardi, R.; Oliveri, P.; Chiara Casolino, M.; Jalali-Heravi, M.; Lanteri, S. Detection of Addition of Barley to Coffee Using near Infrared Spectroscopy and Chemometric Techniques. Talanta 2012, 99, 175-179. [CrossRef] [PubMed]

123. Reis, N.; Franca, A.S.; Oliveira, L.S. Discrimination between Roasted Coffee, Roasted Corn and Coffee Husks by Diffuse Reflectance Infrared Fourier Transform Spectroscopy. LWT 2013, 50, 715-722. [CrossRef]

124. Reis, N.; Botelho, B.G.; Franca, A.S.; Oliveira, L.S. Simultaneous Detection of Multiple Adulterants in Ground Roasted Coffee by ATR-FTIR Spectroscopy and Data Fusion. Food Anal. Methods 2017, 10, 2700-2709. [CrossRef]

125. Cebi, N.; Yilmaz, M.T.; Sagdic, O. A Rapid ATR-FTIR Spectroscopic Method for Detection of Sibutramine Adulteration in Tea and Coffee Based on Hierarchical Cluster and Principal Component Analyses. Food Chem. 2017, 229, 517-526. [CrossRef]

126. Calvini, R.; Amigo, J.M.; Ulrici, A. Transferring Results from NIR-Hyperspectral to NIR-Multispectral Imaging Systems: A Filter-Based Simulation Applied to the Classification of Arabica and Robusta Green Coffee. Anal. Chim. Acta 2017, 967, 33-41. [CrossRef]

127. Rubayiza, A.B.; Meurens, M. Chemical Discrimination of Arabica and Robusta Coffees by Fourier Transform Raman Spectroscopy. J. Agric. Food Chem. 2005, 53, 4654-4659. [CrossRef]

128. Consonni, R.; Cagliani, L.R.; Cogliati, C. NMR Based Geographical Characterization of Roasted Coffee. Talanta 2012, 88, 420-426. [CrossRef]

129. Cagliani, L.R.; Scano, P.; Consonni, R. NMR-Based Metabolomics: Quality and Authenticity of Plant-Based Foods. In Modern Magnetic Resonance; Webb, G.A., Ed.; Springer International Publishing: Cham, Switzerland, 2017; pp. 1-20. ISBN 978-3-31928275-6.

130. Cagliani, L.R.; Pellegrino, G.; Giugno, G.; Consonni, R. Quantification of Coffea Arabica and Coffea Canephora Var. Robusta in Roasted and Ground Coffee Blends. Talanta 2013, 106, 169-173. [CrossRef]

131. Wei, F.; Furihata, K.; Miyakawa, T.; Tanokura, M. A Pilot Study of NMR-Based Sensory Prediction of Roasted Coffee Bean Extracts. Food Chem. 2014, 152, 363-369. [CrossRef]

132. Arana, V.A.; Medina, J.; Alarcon, R.; Moreno, E.; Heintz, L.; Schäfer, H.; Wist, J. Coffee's Country of Origin Determined by NMR: The Colombian Case. Food Chem. 2015, 175, 500-506. [CrossRef]

133. Kwon, D.-J.; Jeong, H.-J.; Moon, H.; Kim, H.-N.; Cho, J.-H.; Lee, J.-E.; Hong, K.S.; Hong, Y.-S. Assessment of Green Coffee Bean Metabolites Dependent on Coffee Quality Using a 1H NMR-Based Metabolomics Approach. Food Res. Int. 2015, 67, 175-182. [CrossRef]

134. de Moura Ribeiro, M.V.; Boralle, N.; Redigolo Pezza, H.; Pezza, L.; Toci, A.T. Authenticity of Roasted Coffee Using 1 H NMR Spectroscopy. J. Food Compos. Anal. 2017, 57, 24-30. [CrossRef]

135. Milani, M.I.; Rossini, E.L.; Catelani, T.A.; Pezza, L.; Toci, A.T.; Pezza, H.R. Authentication of Roasted and Ground Coffee Samples Containing Multiple Adulterants Using NMR and a Chemometric Approach. Food Control 2020, 112, 107104. [CrossRef]

136. dos Santos, H.D.; Alvarenga, Y.A.; Boffo, E.F. 1H NMR Metabolic Fingerprinting of Chapada Diamantina/Bahia (Brazil) Coffees as a Tool to Assessing Their Qualities. Microchem. J. 2020, 152, 104293. [CrossRef]

137. Lee, S.G.; Vance, T.M.; Nam, T.G.; Kim, D.O.; Koo, S.I.; Chun, O.K. Evaluation of PH Differential and HPLC Methods Expressed as Cyanidin-3-Glucoside Equivalent for Measuring the Total Anthocyanin Contents of Berries. J. Food Meas. Charact. 2016, 10, 562-568. [CrossRef]

138. Lv, H.P.; Zhang, Y.J.; Lin, Z.; Liang, Y. rong Processing and Chemical Constituents of Pu-Erh Tea: A Review. Food Res. Int. 2013, 53, 608-618. [CrossRef]

139. Ruan, J.; Haerdter, R.; Gerendás, J. Impact of Nitrogen Supply on Carbon/Nitrogen Allocation: A Case Study on Amino Acids and Catechins in Green Tea [Camellia Sinensis (L.) O. Kuntze] Plants. Plant Biol. 2010, 12, 724-734. [CrossRef]

140. Ozturk, B.; Seyhan, F.; Ozdemir, I.S.; Karadeniz, B.; Bahar, B.; Ertas, E.; Ilgaz, S. Change of Enzyme Activity and Quality during the Processing of Turkish Green Tea. LWT 2016, 65, 318-324. [CrossRef]

141. Wang, X.; Huang, J.; Fan, W.; Lu, H. Identification of Green Tea Varieties and Fast Quantification of Total Polyphenols by Near-Infrared Spectroscopy and Ultraviolet-Visible Spectroscopy with Chemometric Algorithms. Anal. Methods 2015, 7, 787-792. [CrossRef] 
142. Aboulwafa, M.M.; Youssef, F.S.; Gad, H.A.; Sarker, S.D.; Nahar, L.; Al-Azizi, M.M.; Ashour, M.L. Authentication and Discrimination of Green Tea Samples Using UV-Visible, FTIR and HPLC Techniques Coupled with Chemometrics Analysis. J. Pharm. Biomed. Anal. 2018, 164, 653-658. [CrossRef]

143. Chen, Q.; Zhao, J.; Fang, C.H.; Wang, D. Feasibility Study on Identification of Green, Black and Oolong Teas Using near-Infrared Reflectance Spectroscopy Based on Support Vector Machine (SVM). Spectrochim. Acta. A. Mol. Biomol. Spectrosc. 2007, 66, 568-574. [CrossRef]

144. Zhao, J.; Chen, Q.; Huang, X.; Fang, C.H. Qualitative Identification of Tea Categories by near Infrared Spectroscopy and Support Vector Machine. J. Pharm. Biomed. Anal. 2006, 41, 1198-1204. [CrossRef]

145. Zhou, R.; Li, X.; He, Y. Grading of Green Tea and Quantitative Determination of Beta-Carotene and Lutein Based on Hyperspectral Imaging. In Proceedings of the 2017 ASABE Annual International Meeting, Spokane, WA, USA, 16-19 July 2017.

146. Ning, J.; Sun, J.; Li, S.; Sheng, M.; Zhang, Z. Classification of Five Chinese Tea Categories with Different Fermentation Degrees Using Visible and Near-Infrared Hyperspectral Imaging. Int. J. Food Prop. 2017, 20, 1515-1522. [CrossRef]

147. Zhou, H.; Fu, H.; Wu, X.; Wu, B.; Dai, C. Discrimination of Tea Varieties Based on FTIR Spectroscopy and an Adaptive Improved Possibilistic C-Means Clustering. J. Food Process. Preserv. 2020, 44, e14795. [CrossRef]

148. Mishra, P.; Nordon, A.; Tschannerl, J.; Lian, G.; Redfern, S.; Marshall, S. Near-Infrared Hyperspectral Imaging for Non-Destructive Classification of Commercial Tea Products. J. Food Eng. 2018, 238, 70-77. [CrossRef]

149. Buyukgoz, G.G.; Soforoglu, M.; Basaran Akgul, N.; Boyaci, I.H. Spectroscopic Fingerprint of Tea Varieties by Surface Enhanced Raman Spectroscopy. J. Food Sci. Technol. 2016, 53, 1709-1716. [CrossRef] [PubMed]

150. Yu, X.-L.; He, Y. Fast Nondestructive Identification of Steamed Green Tea Powder Adulterations in Matcha by Visible Spectroscopy Combined with Chemometrics. Spectrosc. Lett. 2018, 51, 112-117. [CrossRef]

151. Firmani, P.; De Luca, S.; Bucci, R.; Marini, F.; Biancolillo, A. Near Infrared (NIR) Spectroscopy-Based Classification for the Authentication of Darjeeling Black Tea. Food Control 2019, 100, 292-299. [CrossRef]

152. Luqing, L.; Lingdong, W.; Jingming, N.; Zhengzhu, Z. Detection and Quantification of Sugar and Glucose Syrup in Roasted Green Tea Using near Infrared Spectroscopy. J. Infrared Spectrosc. 2015, 23, 317-325. [CrossRef]

153. Li, X.; Zhang, Y.; He, Y. Rapid Detection of Talcum Powder in Tea Using FT-IR Spectroscopy Coupled with Chemometrics. Sci. Rep. 2016, 6, 30313. [CrossRef]

154. Rateni, G.; Dario, P.; Cavallo, F. Smartphone-Based Food Diagnostic Technologies: A Review. Sensors 2017, 17, 1453. [CrossRef]

155. Coronel-Reyes, J.; Ramirez-Morales, I.; Fernandez-Blanco, E.; Rivero, D.; Pazos, A. Determination of Egg Storage Time at Room Temperature Using a Low-Cost NIR Spectrometer and Machine Learning Techniques. Comput. Electron. Agric. 2018, 145, 1-10. [CrossRef]

156. Wijaya, D.R.; Sarno, R.; Zulaika, E.; Sabila, S.I. Development of Mobile Electronic Nose for Beef Quality Monitoring Procedia Comput. Sci. 2017, 124, 728-735. [CrossRef]

157. Bázár, G.; Kovacs, Z.; Hoffmann, I. Detection of Beef Aging Combined with the Differentiation of Tenderloin and Sirloin Using a Handheld NIR Scanner. In Proceedings of the OCM 2017: 3rd International Conference on Optical Characterization of Materials, Karlsruhe, Germany, 22-23 March 2017; pp. 25-32.

158. Piao, S.; Okura, T.; Irie, M. On-Site Evaluation of Wagyu Beef Carcasses Based on the Monounsaturated, Oleic, and Saturated Fatty Acid Composition Using a Handheld Fiber-Optic near-Infrared Spectrometer. Meat Sci. 2018, 137, 258-264. [CrossRef]

159. Beć, K.B.; Grabska, J.; Siesler, H.W.; Huck, C.W. Handheld Near-Infrared Spectrometers: Where Are We Heading? NIR News 2020, 31, 28-35. [CrossRef]

160. Pilot, R. SERS Detection of Food Contaminants by Means of Portable Raman Instruments. J. Raman Spectrosc. 2018, 49, 954-981. [CrossRef]

161. Bakeev, K.A. Process Analytical Technology: Spectroscopic Tools and Implementation Strategies for the Chemical and Pharmaceutical Industries; Bakeev, K.A., Ed.; Wiley Online Library: Hoboken, NJ, USA, 2010; ISBN 978-0-470-72207-7.

162. Chester, T.L.; Winefordner, J.D. Throughput Advantage and Disadvantage in Analytical Ultraviolet-Visible Spectrometry by Considerations of Signal and Noise Spectral Bandpasses. Anal. Chem. 1977, 49, 119-123. [CrossRef]

163. Tom, J. UV-Vis Spectroscopy: Principle, Strengths and Limitations and Application. Technol. Netw. Anal. Sep. 2021, 1-20.

164. Ozaki, Y.; Genkawa, T.; Futami, Y. Near-Infrared Spectroscopy. In Encyclopedia of Spectroscopy and Spectrometry; Lindon, J.C., Tranter, G.E., Koppenaal, D.W.B.T.-E., Eds.; Academic Press: Oxford, UK, 2017; pp. 40-49. ISBN 978-0-12-803224-4.

165. Villena Gonzales, W.; Mobashsher, A.T.; Abbosh, A. The Progress of Glucose Monitoring-A Review of Invasive to Minimally and Non-Invasive Techniques, Devices and Sensors. Sensors 2019, 19, 800. [CrossRef]

166. Capuano, E.; van Ruth, S.M. Infrared Spectroscopy: Applications. In Encyclopedia of Food and Health; Caballero, B., Finglas, P.M., Toldrá, F.B.T.-E., Eds.; Academic Press: Oxford, UK, 2016; pp. 424-431. ISBN 978-0-12-384953-3.

167. Liu, Y.; Pu, H.; Sun, D.-W. Hyperspectral Imaging Technique for Evaluating Food Quality and Safety during Various Processes: A Review of Recent Applications. Trends Food Sci. Technol. 2017, 69, 25-35. [CrossRef]

168. Riolo, D.; Piazza, A.; Cottini, C.; Serafini, M.; Lutero, E.; Cuoghi, E.; Gasparini, L.; Botturi, D.; Marino, I.G.; Aliatis, I.; et al. Raman Spectroscopy as a PAT for Pharmaceutical Blending: Advantages and Disadvantages. J. Pharm. Biomed. Anal. 2018, 149, 329-334. [CrossRef]

169. Thygesen, L.G.; Løkke, M.M.; Micklander, E.; Engelsen, S.B. Vibrational Microspectroscopy of Food. Raman vs. FT-IR. Trends Food Sci. Technol. 2003, 14, 50-57. [CrossRef] 
170. Silva Elipe, M.V. Advantages and Disadvantages of Nuclear Magnetic Resonance Spectroscopy as a Hyphenated Technique. Anal. Chim. Acta 2003, 497, 1-25. [CrossRef]

171. Yao, X.; Cai, F.; Zhu, P.; Fang, H.; Li, J.; He, S. Non-Invasive and Rapid PH Monitoring for Meat Quality Assessment Using a Low-Cost Portable Hyperspectral Scanner. Meat Sci. 2019, 152, 73-80. [CrossRef]

172. Yuan, H.; Liu, M.; Huang, S.; Zhao, J.; Tao, J. Classification and Detection of Testosterone Propionate and Nandrolone Residues in Duck Meat Using Surface-Enhanced Raman Spectroscopy Coupled with Multivariate Analysis. Poult. Sci. 2021, 100, $296-301$. [CrossRef]

173. Andersen, P.V.; Wold, J.P.; Gjerlaug-Enger, E.; Veiseth-Kent, E. Predicting Post-Mortem Meat Quality in Porcine Longissimus Lumborum Using Raman, near Infrared and Fluorescence Spectroscopy. Meat Sci. 2018, 145, 94-100. [CrossRef]

174. Sezer, B.; Bjelak, A.; Murat Velioglu, H.; Hakkı Boyaci, I. Identification of Meat Species in Processed Meat Products by Using Protein Based Laser Induced Breakdown Spectroscopy Assay. Food Chem. 2022, 372, 131245. [CrossRef]

175. Ma, G.; Chen, H.; Zhang, Q.; Ma, J.; Yu, Q.; Han, L.; Chen, C.; Song, R. Protective Characterization of Low Dose Sodium Nitrite on Yak Meat Myoglobin in a Hydroxy Radical Oxidation Environment: Fourier Transform Infrared Spectroscopy and Laser Micro-Raman Spectroscopy. LWT 2019, 116, 108556. [CrossRef]

176. Laub-ekgreen, M.H.; Martinez-lopez, B.; Jessen, F.; Skov, T. Non-Destructive Measurement of Salt Using NIR Spectroscopy in the Herring Marinating Process. LWT 2018, 97, 610-616. [CrossRef]

177. Krepper, G.; Romeo, F.; Fernandes, D.D.d.S.; Diniz, P.H.G.D.; de Araújo, M.C.U.; Di Nezio, M.S.; Pistonesi, M.F.; Centurión, M.E. Determination of Fat Content in Chicken Hamburgers Using NIR Spectroscopy and the Successive Projections Algorithm for Interval Selection in PLS Regression (ISPA-PLS). Spectrochim. Acta Part Mol. Biomol. Spectrosc. 2018, 189, 300-306. [CrossRef] [PubMed]

178. Ripoll, G.; Lobón, S.; Joy, M. Use of Visible and near Infrared Re Fl Ectance Spectra to Predict Lipid Peroxidation of Light Lamb Meat and Discriminate Dam 's Feeding Systems. Meat Sci. 2018, 143, 24-29. [CrossRef] [PubMed]

179. Zhang, L.; Sun, B.; Xie, P.; Li, H.; Su, H.; Sha, K.; Huang, C.; Lei, Y.; Liu, X.; Wang, H. Using near Infrared Spectroscopy to Predict the Physical Traits of Bos Grunniens Meat. LWT 2015, 64, 602-608. [CrossRef]

180. Liu, Y.; Ma, D.H.; Wang, X.C.; Liu, L.P.; Fan, Y.X.; Cao, J. xuan Prediction of Chemical Composition and Geographical Origin Traceability of Chinese Export Tilapia Fillets Products by near Infrared Reflectance Spectroscopy. LWT 2015, 60, 1214-1218. [CrossRef]

181. Haughey, S.A.; Galvin-King, P.; Ho, Y.-C.; Bell, S.E.J.; Elliott, C.T. The Feasibility of Using near Infrared and Raman Spectroscopic Techniques to Detect Fraudulent Adulteration of Chili Powders with Sudan Dye. Food Control 2015, 48, 75-83. [CrossRef] 